\title{
ESTUDO DE UMA METODOLOGIA PARA ESTIMAR A QUANTIDADE DE CARBONO EM AMOSTRAS DE SOLO UTILIZANDO ESPECTROSCOPIA DE EMISSÃO ÓPTICA COM PLASMA INDUZIDO POR LASER (LIBS)
}

Robson Marcel da Silva

Dissertação apresentada ao Instituto de Química de São Carlos, da Universidade de São Paulo para obtenção do título de Mestre em Ciências (Química Analítica).

Orientadora: $\mathrm{Dr}^{\mathrm{a}}$. Débora Marcondes Bastos Pereira Milori 


\section{Salmo 23}

O SENHOR é meu pastor, nada me faltará Deitar-me faz em verdes pastos, guia-me mansamente a águas tranquilas

Refrigera minha alma; guia-me pelas veredas da justiça, por amor de seu nome.

Ainda que eu andasse pelo vale da sombra da morte, não temerei mal algum, porque Tu estás comigo; a tua vara e o teu cajado me consolam Preparas uma mesa perante mim na presença dos meus inimigos, unges a minha cabeça com óleo, o meu cálice transborda.

Certamente que a bondade e a misericórdia me seguirão todos os dias da minha vida, e habitarei na casa do SENHOR por longos dias. 


\section{DEDICO}

Aos meus queridos e amados pais, Luiz e Romilda, pelo imenso amor, dedicação, carinho, incentivo, exemplo de honestidade e caráter. 


\section{AGRADECIMENTOS}

Ao Senhor Deus Altíssimo, em nome do Senhor Jesus Cristo, pela minha vida, saúde e força para superar todas as etapas ao longo de toda a minha vida.

Aos meus queridos e amados irmãos Elaine, Luciane e Jeferson, meus cunhados Simone e João e ao meu sobrinho Lucas por todo amor, incentivo e dedicação.

A Dra. Débora Marcondes Bastos Pereira Milori pela orientação, incentivo e amizade.

Aos amigos Ednaldo José Ferreira e Patrícia Brunelli por toda ajuda no tratamento estatístico dos dados obtidos.

Às amigas Edilene e Fabíola pela valiosa ajuda ao longo da realização deste projeto.

Aos meus grandes amigos que conheci em São Carlos: Cadu, Kelly, Cléber, Renato e Maristela por toda amizade, paciência, ótima convivência ao longo desses anos.

Aos amigos da Embrapa Instrumentação Agropecuária: Fernanda, Úrsula, Adriana, Larissa, André, Ana Flávia, Gabriel, Patrícia, Patrini, Jean pela amizade e ótima convivência ao longo desses anos.

Á Márcia por todo carinho, amizade e incentivo.

Aos meus grandes amigos Barbosa, Luis Fernando, Elisa e Igor pela amizade, incentivo e ótimos momentos compartilhados.

Á todos os funcionários da Embrapa Instrumentação Agropecuária pela ajuda prestada sempre que solicitada.

À Embrapa Instrumentação Agropecuária pela infra-estrutura concedida.

Ao Instituto de Química de São Carlos.

Ao Conselho Nacional de Desenvolvimento Científico e Tecnológico (CNPq) pela bolsa concedida.

A todos que direta ou indiretamente participaram da realização deste trabalho ou conviveram comigo ao longo desses anos.

Muito obrigado a todos! 


\section{SUMÁRIO}

LISTA DE FIGURAS ...................................................................................... i

LISTA DE TABELAS ......................................................................................... iii

RESUMO ................................................................................................... iv

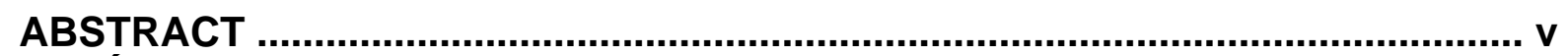

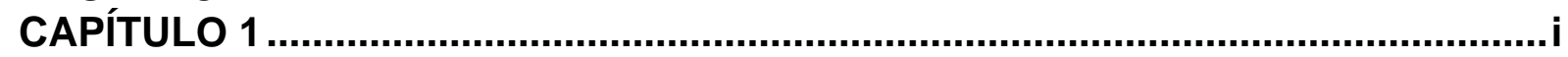

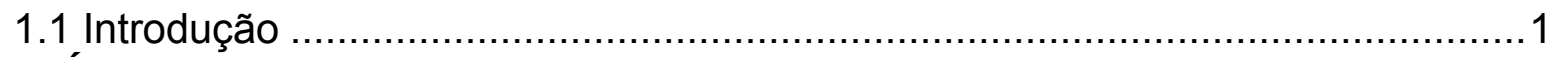

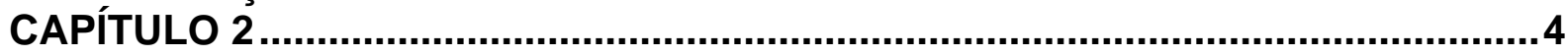

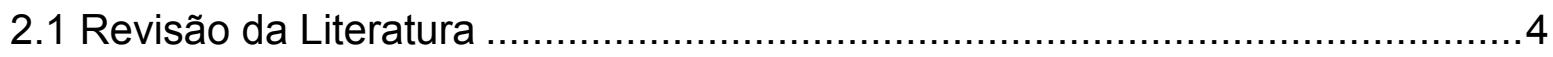

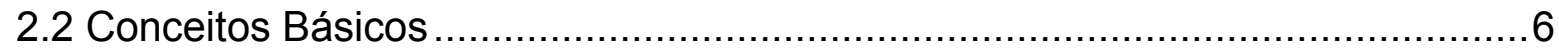

2.2.1 Espectroscopia de emissão óptica assistida por lasers: contexto histórico ..6

2.2.2 Espectroscopia de emissão óptica com plasma induzido por laser - LIBS ..7

CAPÍTULO 3

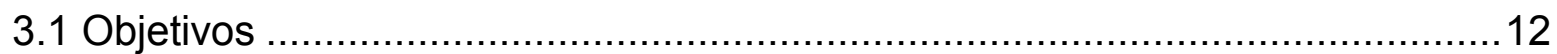

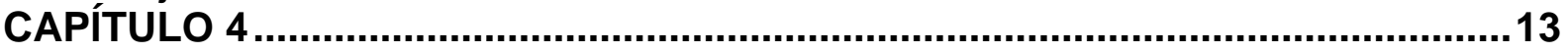

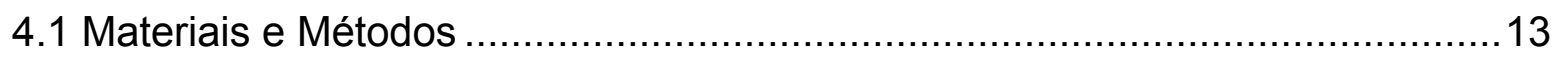

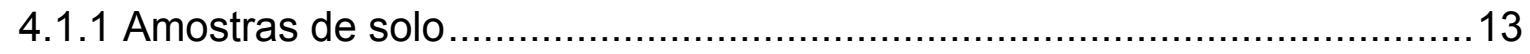

4.1.2 Moinho Criogênico.................................................................... 15

4.1.3 Analisador de Carbono Orgânico Total .............................................. 16

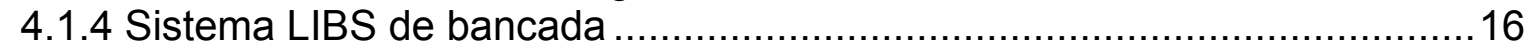

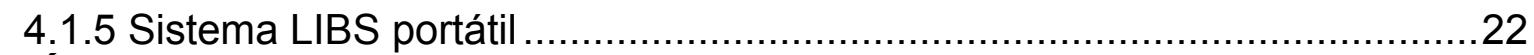

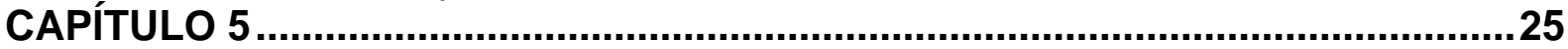

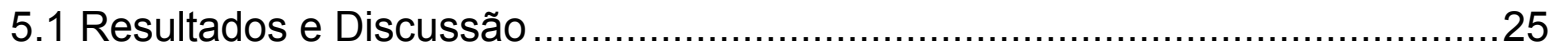

5.1.1 Determinação do Carbono Orgânico Total ...............................................25

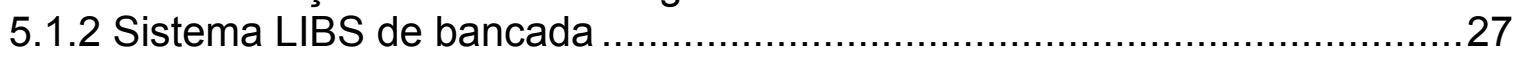

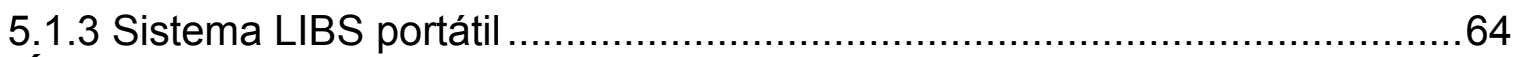

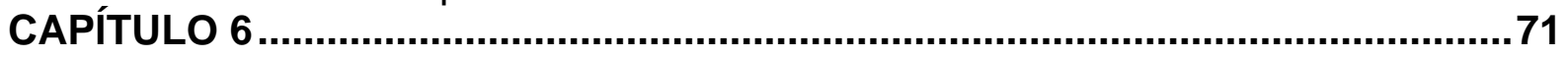

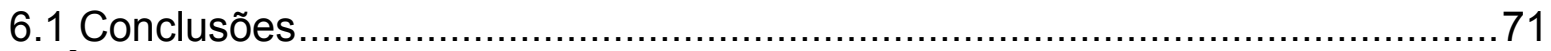

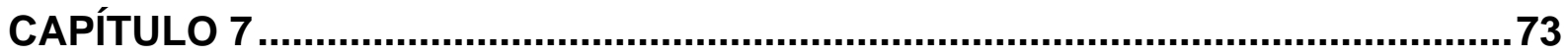

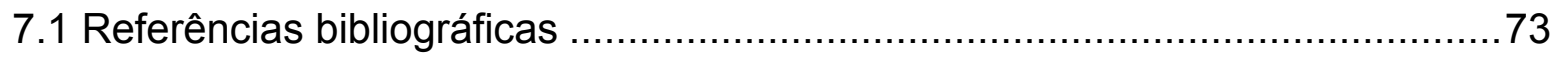




\section{LISTA DE FIGURAS}

Figura 1: Esquema de um sistema LIBS (figura adaptada de

http://www.appliedphotonics.co.uk).

Figura 2: Pastilha de solo em comparação com uma moeda................................15

Figura 3: Sistema LIBS de bancada modelo LIBS2500plus: (1) fonte de energia; (2)

laser; (3) câmara de ablação; (4) conjunto de espectrômetros. ……......................17

Figura 4: Construção do gráfico de caixas. .....................................................20

Figura 5: Sistema LIBS portátil modelo PORTA-LIBS-2000 (retirada de

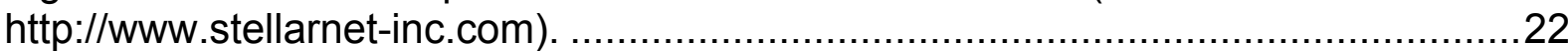

5.1.2.1.1 Energia do laser $50 \mathrm{~mJ}$ e acúmulo de 10 tiros ..................................27

Figura 6: Espectro obtido para o tratamento SI na profundidade $0-10 \mathrm{~cm}$ utilizando energia do laser em $50 \mathrm{~mJ}$ e acúmulo de 10 tiros..............................................28

Figura 7: (a) Exemplo da variação na intensidade do sinal de fundo tiro a tiro para amostra na profundidade $0-10 \mathrm{~cm}$ do tratamento SI obtido com energia do laser em $50 \mathrm{~mJ}$ e acúmulo de 10 tiros; (b) Visualização da variação na intensidade do sinal no pico de carbono em 193,03 nm.................................................................29

Figura 8: Correção do perfil ascendente do sinal de fundo - comparação entre o espectro sem correção e o mesmo corrigido utilizando o programa SAS.

Figura 9: Espectro ilustrando os picos de emissão de carbono e alumínio utilizados para normalização.

Figura 10: Gráfico de caixas para detecção de medidas discrepantes do tratamento

SI realizado com energia do laser em $50 \mathrm{~mJ}$ e acúmulo de 10 tiros. ......................32

Figura 11: Regressão linear obtida com os tratamentos E0, E33, E66 e E100

utilizando energia do laser em $50 \mathrm{~mJ}$ e acúmulo de 10 tiros

Figura 12: Validação da análise de regressão linear simples dos dados obtidos com

LIBS para amostras dos tratamentos SI e W100 utilizando energia do laser em 50 $\mathrm{mJ}$ e acúmulo de 10 tiros.

Figura 13: Crescimento exponencial obtido com os tratamentos E0, E33, E66 e E100

utilizando energia do laser em $50 \mathrm{~mJ}$ e acúmulo de 10 tiros.

Figura 14: Validação do modelo de crescimento exponencial dos dados obtidos com

LIBS para amostras dos tratamentos SI e W100 utilizando energia do laser em 50

$\mathrm{mJ}$ e acúmulo de 10 tiros.

5.1.2.1.2 Energia do laser $50 \mathrm{~mJ}$ e acúmulo de 2 tiros ....................................39

Figura 15: Regressão linear obtida com os tratamentos E0, E33, E66 e E100

utilizando energia do laser em $50 \mathrm{~mJ}$ e acúmulo de 2 tiros.

Figura 16: Validação da análise de regressão linear simples dos dados obtidos com

LIBS para amostras dos tratamentos SI e W100 utilizando energia do laser em 50 mJ e acúmulo de 2 tiros.

Figura 17: Crescimento exponencial obtido com os tratamentos E0, E33, E66 e E100 utilizando energia do laser em $50 \mathrm{~mJ}$ e acúmulo de 2 tiros.

Figura 18: Validação do modelo de crescimento exponencial dos dados obtidos com LIBS para amostras dos tratamentos SI e W100 utilizando energia do laser em 50 mJ e acúmulo de 2 tiros.

Figura 19: Regressão linear obtida com os tratamentos E0, E33, E66 e E100 utilizando energia do laser em $25 \mathrm{~mJ}$ e acúmulo de 10 tiros.

Figura 20: Validação da análise de regressão linear simples dos dados obtidos com LIBS para amostras dos tratamentos SI e W100 utilizando energia do laser em 25 mJ e acúmulo de 10 tiros. 
Figura 21: Crescimento exponencial obtido com os tratamentos E0, E33, E66 e E100 utilizando energia do laser em $25 \mathrm{~mJ}$ e acúmulo de 10 tiros.

Figura 22: Validação do modelo de crescimento exponencial dos dados obtidos com LIBS para amostras dos tratamentos SI e W100 utilizando energia do laser em 25 mJ e acúmulo de 10 tiros.

5.1.2.1.4 Energia do laser $25 \mathrm{~mJ}$ e acúmulo de 2 tiros .....................................50

Figura 23: Regressão linear obtida com os tratamentos E0, E33, E66 e E100

utilizando energia do laser em $25 \mathrm{~mJ}$ e acúmulo de 2 tiros.

Figura 24: Validação da análise de regressão linear simples dos dados obtidos com LIBS para amostras dos tratamentos SI e W100, utilizando energia do laser em 25 mJ e acúmulo de 2 tiros.

Figura 25: Crescimento exponencial obtido com os tratamentos E0, E33, E66 e E100 utilizando energia do laser em $25 \mathrm{~mJ}$ e acúmulo de 2 tiros..................................52 Figura 26: Validação do modelo de crescimento exponencial dos dados obtidos com LIBS para amostras dos tratamentos SI e W100 utilizando energia do laser em 25 mJ e acúmulo de 2 tiros.

5.1.2.1.5 Comparação entre as metodologias

Figura 27: Regressão linear obtida com os tratamentos E0, E33, E66 e E100 não moídos utilizando energia do laser em $50 \mathrm{~mJ}$ e acúmulo de 10 tiros.

Figura 28: Validação da análise de regressão linear simples dos dados obtidos com LIBS para amostras dos tratamentos SI e W100 não moídos utilizando energia do laser em $50 \mathrm{~mJ}$ e acúmulo de 10 tiros.

Figura 29: Crescimento exponencial obtido com os tratamentos E0, E33, E66 e E100

não moídos, utilizando energia do laser em $50 \mathrm{~mJ}$ e acúmulo de 10 tiros.

Figura 30: Validação do modelo de crescimento exponencial dos dados obtidos com LIBS para amostras não moídas dos tratamentos SI e W100, utilizando energia do laser em $50 \mathrm{~mJ}$ e acúmulo de 10 tiros.

Figura 31: Espectro de emissão médio da amostra na profundidade $0-10 \mathrm{~cm}$ do tratamento SI obtido utilizando o sistema LIBS portátil.

Figura 32: Espectro de emissão da amostra 0-10 cm do tratamento SI ilustrando o sinal de emissão do carbono.

Figura 33: Programa computacional desenvolvido por Gornushkin para correção do sinal de fundo de espectros LIBS.

Figura 34: Comparação entre espectro sem correção do sinal de fundo e o mesmo corrigido pelo programa desenvolvido por Gornushkin.

Figura 35: Regressão linear para amostras do tratamento SI obtida utilizando o sistema LIBS portátil. 


\section{LISTA DE TABELAS}

Tabela 1: Porcentagens de carbono orgânico no solo obtidas pela técnica TOC. ....26 Tabela 2: Concentrações de carbono estimadas pelo sistema LIBS utilizando o modelo de regressão linear simples e crescimento exponencial, utilizando energia do laser em $50 \mathrm{~mJ}$ e acúmulo de 10 tiros.............................................................. 38

Tabela 3: Erros de predição utilizando os modelos de regressão linear simples e crescimento exponencial, utilizando energia do laser em $50 \mathrm{~mJ}$ e acúmulo de 10 tiros.

Tabela 4: Concentrações de carbono estimadas pelo sistema LIBS utilizando o modelo de regressão linear simples e crescimento exponencial, utilizando energia do laser em $50 \mathrm{~mJ}$ e acúmulo de 2 tiros.

Tabela 5: Erros de predição utilizando os modelos de regressão linear simples e crescimento exponencial, utilizando energia do laser em $50 \mathrm{~mJ}$ e acúmulo de 2 tiros.

Tabela 6: Concentrações de carbono estimadas pelo sistema LIBS utilizando o modelo de regressão linear simples e crescimento exponencial, utilizando energia do laser em $25 \mathrm{~mJ}$ e acúmulo de 10 tiros.

Tabela 7: Erros de predição utilizando os modelos de regressão linear simples e crescimento exponencial utilizando energia do laser em $25 \mathrm{~mJ}$ e acúmulo de 10 tiros.

Tabela 8: Concentrações de carbono estimadas pelo sistema LIBS utilizando o modelo de regressão linear simples e crescimento exponencial utilizando energia do laser em 25 mJ e acúmulo de 2 tiros. 54

Tabela 9: Erros de predição utilizando os modelos de regressão linear simples e crescimento exponencial utilizando energia do laser em $25 \mathrm{~mJ}$ e acúmulo de 2 tiros.

Tabela 10: Comparação entre os valores de concentração estimados pelo LIBS utilizando o modelo de regressão linear simples.

Tabela 11: Erros médios absolutos obtidos pelas 4 metodologias utilizando o modelo

de regressão linear simples

Tabela 12: Erros médios absolutos obtidos com os modelos de regressão linear

simples e crescimento exponencial.

Tabela 13: Concentrações de carbono estimadas pelo sistema LIBS utilizando o modelo de regressão linear simples e crescimento exponencial, utilizando energia do laser em $50 \mathrm{~mJ}$ e acúmulo de 10 tiros.

Tabela 14: Erros de predição utilizando os modelos de regressão linear simples e crescimento exponencial utilizando as amostras não moídas e energia do laser em $50 \mathrm{~mJ}$ e acúmulo de 10 tiros.

Tabela 15: Comparação entre os valores preditos utilizando o modelo de regressão linear simples para as amostras moídas e não moídas.

Tabela 16: Comparação entre os valores preditos utilizando o modelo crescimento exponencial para as amostras moídas e não moídas. 


\section{RESUMO}

Os solos representam um importante componente no ciclo biogeoquímico do carbono, armazenado cerca de quatro vezes mais carbono que a biomassa vegetal e quase três vezes mais que a atmosfera. Além disso, a quantidade de carbono está diretamente ligada a capacidade de retenção de água, fertilidade entre outras propriedades. Assim, a quantificação de carbono do solo em condições de campo é um tema importante para estudos do ciclo de carbono relacionado às mudanças climáticas globais. Atualmente, espectroscopia de emissão óptica com plasma induzido por laser (LIBS) pode ser usada para análise elementar qualitativa sem tratamento prévio das amostras e os resultados são obtidos rapidamente. Novas tecnologias ópticas tornaram possível sistema LIBS portáteis e, agora, a grande expectativa é o desenvolvimento de métodos que possibilitam medições quantitativas com sistemas LIBS. LIBS é uma técnica espectroanalítica que emprega a microamostragem por ablação com laser e subseqüente excitação dos átomos presentes no microplasma induzido durante a ablação. Sendo assim, o presente projeto de pesquisa visou desenvolver uma metodologia para quantificar carbono em amostras intactas de solo e avaliar o desempenho de sistemas LIBS portáteis para análises em campo. Trinta e seis amostras de solo da região do Cerrado brasileiro (Argissolo Vermelho Distrófico Latossólico) foram utilizadas. Para avaliar o efeito de heterogeneidade, trabalhou-se com as amostras moídas criogenicamente e não moídas. Com o intuito de estudar uma melhor forma para estimar a quantidade de carbono no solo, quatro metodologias diferentes foram empregadas utilizando o sistema LIBS de bancada e apenas uma metodologia para o sistema LIBS portátil. Para ambos os sistemas LIBS foi necessário inicialmente fazer correções no sinal de fundo dos espectros obtidos. A linha de emissão do carbono em 193,03 nm foi utilizada, pois esta não apresenta interferência da linha de emissão do elemento ferro. A técnica de análise térmica (combustão seca) conhecida como TOC (Total Organic Carbon) foi utilizada como referência para calibrar os sistemas. Utilizando o sistema LIBS de bancada, foram criados modelos com base em regressão linear simples e crescimento exponencial para estimar a quantidade de carbono nas amostras. Para o sistema LIBS portátil foram utilizados modelos com base em regressão linear simples e regressão linear múltipla. A melhor metodologia empregada para o sistema LIBS de bancada foi utilizando a energia máxima do laser $(50 \mathrm{~mJ})$ e o maior acúmulo de tiros (10 tiros) e o modelo de regressão linear simples apresentou um melhor ajuste. Não houve diferença entre os dados obtidos com as amostras moídas e não moídas. Para o sistema LIBS portátil a análise de regressão linear múltipla apresentou um melhor resultado, selecionando a melhor variável para o modelo. Sendo assim, conclui-se que sistemas LIBS são ferramentas úteis para se realizar estimativas quantitativas, podendo ser usados para a construção de inventários de carbono no solo, que são importantes para áreas ambientais com o foco em seqüestro de carbono, mudanças climáticas globais, avaliação do manejo de solos e o efeito da aplicação de águas residuárias em solos. 


\section{ABSTRACT}

Soils are an important component in the biogeochemical cycle of carbon, storing about four times more carbon that biomass plants and nearly three times more than the atmosphere. Moreover, the carbon content is directly related on the capacity of water retention, fertility, among others properties. Thus, soil carbon quantification in field conditions is an important challenge related to carbon cycle and global climate changes. Nowadays, Laser Induced Breakdown Spectroscopy (LIBS) has beeb applied to qualitative elemental analyses without previous treatment of samples and the results are obtained quickly. New optical technologies made possible portable LIBS systems and now, the great expectation is the development of methods that make possible quantitative analysis with LIBS. LIBS is a technique that employs a sampling by laser ablation and subsequent excitation of atoms present in induced microplasma during the ablation. The goal of this research was the development of methodology to estimate carbon in soil samples and evaluate the performance of portable LIBS systems for analysis in the field. Thirty six soil samples of Brazilian Cerrado region (Argisoil) were used. To evaluate the effect of heterogeneity, it was used samples that were grounding in a cryogenic ground and samples if not grounded. In order to study a better way to estimate the carbon content in the soil, four different methodologies were employed using the bench LIBS system and only one methodology for the portable LIBS system. For both LIBS systems was needed to do corrections in the background of obtained spectra. The carbon line at $193.03 \mathrm{~nm}$ was used because it does not present an interference of iron. The technique of thermal analysis known as TOC (Total Organic Carbon) was used as reference to calibrate the systems. Using the bench LIBS system have been adjusted models based on simple linear regression and exponential growth to estimate the carbon content in the samples. For portable LIBS system were used models based on simple linear regression and multiple linear regression. The best methodology used to the bench LIBS system was using the maximum of laser energy $(50 \mathrm{~mJ})$ and the largest shots count (10 shots count) and simple linear regression model showed a better fit. There was no difference between the data obtained from the grounded and not grounded samples. For the portable LIBS system multiple linear regression showed a better result because was select the best variable. Thus, it appears that LIBS systems are useful tools to perform quantitative estimates and could be used to build inventories of carbon in the soil that are important to environmental areas with the focus on carbon sequestration, global climate change, assessment the management of soils and the effect of wastewater into the soil. 


\section{CAPÍTULO 1}

\subsection{Introdução}

Os solos representam um importante componente no ciclo biogeoquímico do carbono, armazenando cerca de quatro vezes mais carbono que a biomassa vegetal e quase três vezes mais que a atmosfera [1]. A principal decorrência é que os solos podem atuar como fonte ou dreno de carbono para a atmosfera, dependendo das condições naturais e, sobretudo, do tipo de manejo adotado.

A exploração agrícola geralmente promove um aumento na taxa de oxidação da matéria orgânica do solo (MOS), favorecendo as emissões de $\mathrm{CO}_{2}$. Em solos de clima temperado, metade do conteúdo inicial de carbono do solo é perdida em um intervalo de 50 a 100 anos de cultivo, sendo que em ambientes tropicais as perdas podem ser ainda maiores [2]. Por outro lado, existem evidências de que práticas conservacionistas, como determinadas técnicas de plantio direto, pastagens bem manejadas, florestas plantadas e sistemas agroflorestais, podem reduzir drasticamente estas perdas, mantendo-se os níveis de matéria orgânica dos solos ou até mesmo aumentando-os [3].

A forma mais usual de realizar análise elementar em amostras sólidas, como quantificar carbono em solos, tem sido a conversão da amostra sólida em uma solução por meio de procedimentos de decomposição por via seca ou via úmida para compostos orgânicos, dissolução ácida para sólidos inorgânicos ou por fusão para matrizes inorgânicas refratárias [4]. No entanto, esses métodos de tratamento de amostra consomem muito tempo podendo variar de 5 minutos a 48 horas ou mais, dependendo da complexidade da matriz, consumo de reagentes e 
necessidade de equipamentos tais como microondas, chapa de aquecimento, mufla. Além disso, há um maior risco aos erros sistemáticos como contaminações ou perdas, desde a etapa de amostragem, com prejuízo para a exatidão e a precisão dos resultados analíticos.

Nesse contexto, qualquer possibilidade para se analisar diretamente as amostras sólidas sem qualquer ou com o mínimo de tratamento prévio pode ser vista como uma alternativa interessante. De um modo geral, a análise direta de sólidos apresenta vantagens importantes quando comparada aos procedimentos convencionais: (1) simplifica a etapa de pré-tratamento da amostra diminuindo-se o tempo gasto nessa etapa, possibilitando o aumento da freqüência analítica, (2) minimiza os riscos de contaminação devido ao uso de quantidades reduzidas de reagentes, pouca manipulação, (3) minimização das perdas do analito de interesse, (4) pode reduzir a periculosidade quando aliada ao fato de não se utilizar reagentes tóxicos ou corrosivos e, conseqüentemente, menor geração de resíduos, (5) maior poder e detecção em termos absolutos, uma vez que as amostras não são diluídas, e (6) possibilidade de se analisar pequena quantidade de amostra [5].

A possibilidade de analisar amostras diretamente na forma sólida já é uma realidade, embora técnicas instrumentais como a espectrometria de absorção atômica com atomização eletrotérmica (ETAAS), espectrometria de emissão atômica com plasma acoplado indutivamente (ICP-OES) e espectrometria de massa com plasma acoplado indutivamente (ICP-MS) sejam comumente utilizadas para analisar amostras na forma de solução. Para a análise direta de sólidos empregando-se ICPs, utilizam-se os sistemas de ablação com laser (LA-ICP-OES ou LA-ICP-MS), vaporização eletrotérmica (ETV-ICP-OES ou ETV- ICP-MS) [5,6]; para a análise 
direta por espectrometria de absorção atômica em forno de grafite é empregado um amostrador de sólidos (SS-ETAAS) [5,6].

O conhecimento acerca da análise direta por espectrometria atômica ainda é pequeno, principalmente para as técnicas que utilizam a amostragem por laser. Nos últimos 15 anos o emprego de laser para a amostragem e para a análise direta tem despertado grande interesse da comunidade cientifica mundial, particularmente devido ao grande avanço da indústria de componentes ópticos e eletrônicos no desenvolvimento e na miniaturização de lasers.

No início, o laser foi considerado uma tecnologia exótica e longe de alcançar a maioria dos cientistas. Mas atualmente a instrumentação assistida por lasers tem se tornado parte integrante de muitos laboratórios modernos. Os avanços da indústria eletroeletrônica permitiram a compactação de equipamentos, maior potência e menor custo, fazendo com que os lasers se tornassem uma ferramenta atrativa e útil para as técnicas ópticas de análise [7]. Diante deste contexto, a análise direta de amostras in situ tornou-se um desafio para a química analítica. 


\section{CAPÍTULO 2}

\subsection{Revisão da Literatura}

A técnica LIBS (Laser Induced Breakdown Spectroscopy), quando comparada a técnicas espectroanalíticas bem estabelecidas, como a espectroscopia de absorção atômica em chama (FAAS) e ICP-OES, é muito versátil e apresenta as seguintes características: (1) permite análises rápidas (0,5 min) e diretas in situ; (2) massas amostradas entre 0,1 e $100 \mu \mathrm{g}$ (tipicamente $1 \mu \mathrm{g}$ ); (3) pode dispensar totalmente ou simplificar o preparo da amostra; (4) possibilidade de análise direta de materiais de difícil dissolução [8].

Assim sendo, a técnica LIBS tem sido explorada para várias aplicações e caracterização de diversos materiais.

Uma característica atraente da técnica LIBS é a possibilidade de fazer medidas a distância utilizando-se sondas e/ou telescópios já que a distância entre focal entre o laser incidente e amostra pode variar grandemente, possibilitando maior segurança ao analista em ambientes de alta periculosidade e em locais geralmente impeditivos para outras técnicas analíticas [9-17]. Pode ser utilizada para identificação de explosivos, assim como compostos químicos e biológicos perigosos, usados pelas forças armadas dos Estados Unidos [18-20].

Torna-se importante ressaltar a possibilidade de análises individuais de partículas com massas menores que $1 \mu \mathrm{g}$, e análises de elementos que não podem ser determinados por outras técnicas com equipamentos portáteis, como a espectrometria de fluorescência de raios $X(X R F)$ [21].

Uma grande aplicação da técnica LIBS está direcionada para a análise de ligas metálicas [22-28] e caracterização de materiais geológicos [22, 29-32]. 
Uma aplicação bastante interessante da técnica LIBS é caracterização de materiais com imenso valor tais como obras de arte, objetos arqueológicos, jóias [22, 33-37]. A técnica também pode ser utilizada para avaliar compostos orgânicos tais como ácidos orgânicos, hidrocarbonetos, plásticos, petróleo, produtos farmacêuticos e até mesmo podendo ser usada para analisar tecido animal e vegetal [38-45].

Muitos estudos têm sido realizados objetivando a utilização da técnica LIBS em missões espaciais [46-50]. Para isso, os estudos foram realizados simulando as condições de temperatura, pressão e atmosfera em que as sondas serão submetidas ao realizarem medidas em solos e rochas.

Amostras de diferentes tipos de solos também foram analisadas utilizando a técnica LIBS [51-64]. Nesses estudos foram analisados vários elementos metálicos, não metálicos, macro e micro nutrientes, poluentes, podendo estimar a quantidade dos mesmos em amostras caracteristicamente heterogêneas como as de solo.

LIBS não é aplicável apenas em amostras sólidas. Pode ser utilizando também em amostras gasosas [65-68] e líquidas [69-72] obtendo-se também ótimos resultados em termos qualitativos e quantitativos.

Mesmo com todas essas aplicações, a técnica LIBS ainda é pouco conhecida e raramente utilizada. O principal motivo apontado nas revisões mais recentes $[\mathbf{2 2}, \mathbf{7 3 -}$ 76] é a ausência de métodos bem estabelecidos, ou mesmo em desenvolvimento, em comparação ao que já se observa com ICP-OES (bem estabelecida a partir de 1977) e ICP-MS (a partir de 1990). 


\subsection{Conceitos Básicos}

\subsubsection{Espectroscopia de emissão óptica assistida por lasers: contexto histórico}

Na década de 1960, Charles Townes e colaboradores desenvolvem o primeiro laser de rubi motivando a aplicação do mesmo em metodologias analíticas [8].

Em 1962, Brech utilizou o laser de rubi produzindo vapores de materiais metálicos e não metálicos que foram, então, excitados por uma fonte de energia formando um microplasma objetivando detectar seu espectro de emissão [77]. Considera-se esse o nascimento da técnica Laser Induced Breakdown Spectroscopy (LIBS) [22]

Dois anos depois, em 1964, Runge [78] construiu curvas de calibração utilizando linhas atômicas e/ou iônicas de crômio e níquel as quais foram detectadas diretamente no plasma formado na superfície de amostras de aço. Para isso, Runge utilizou o laser para a ablação (microasmostragem) e excitação atômica transformando o LIBS em uma técnica espectrométrica para análise direta de amostras [8].

Alguns anos mais tarde, na década de 1970, houve um desinteresse pela técnica LIBS devido ao alto custo da instrumentação e baixo desempenho em comparação com as técnicas ETAAS e ICP-OES [8,22].

Com o desenvolvimento de lasers de alta potência, mais rápidos e com custo muito menores, o interesse pela técnica LIBS foi renovado em meados da década de 1980. O desenvolvimento de detectores ICCD (intensified charge-coupled device) que possibilitam melhor resolução temporal nas medidas espectroscópicas e, conseqüentemente, melhor discriminação entre o espectro de emissão dos analitos 
e dos espectros de fundo da emissão do plasma, também contribuiu para o renascimento da técnica. A partir desse período, a capacidade do LIBS para análise multielementar de forma rápida e direta em qualquer tipo de amostra, assim como o seu renovado caráter de portabilidade, possibilitou o desenvolvimento de análises in situ ou com amostragens a distância do operador [8]. O novo desempenho tecnológico, aliado à possibilidade da técnica LIBS ser acoplada em um único equipamento com outras técnicas analíticas como Raman, despertou novamente o interesse mundial dos cientistas nos âmbitos acadêmicos, industriais e das forças armadas $[8,79]$.

\subsubsection{Espectroscopia de emissão óptica com plasma induzido por}

\section{laser - LIBS}

LIBS é uma técnica espectroanalítica que emprega a microamostragem por ablação com laser e subseqüente excitação dos átomos presentes no microplasma induzido durante a ablação. O acrônimo LIBS pode ser considerado como uma forma reduzida do acrônimo LIB OES, Laser Induced Breakdown Optical Emission Spectroscopy. O termo "breakdown" refere-se a um fenômeno coletivo relacionado à ruptura dielétrica das ligações moleculares do material, que ocorre anteriormente à formação do plasma e envolve propriedades da amostra, tais como elasticidade e compressibilidade. As propriedades da amostra também determinam os mecanismos de deposição e dissipação de energia em que ocorre o processo de ablação, formação do plasma, excitação, emissão atômica e/ou molecular [8].

Um esquema típico de um aparelho LIBS constituído por uma fonte de energia, um laser, lentes para focalizar, unidade de detecção (espectrômetro) e um computador para controle e processamento dos dados pode ser visto na Figura 1. 
A lente convergente focaliza o pulso do laser sobre a amostra, o material que a compõe é então dissociado em seus constituintes atômicos e iônicos [80]. Esse fenômeno, o chamado breakdown, é devido ao intenso gradiente de campo elétrico do laser que acompanha a focalização.

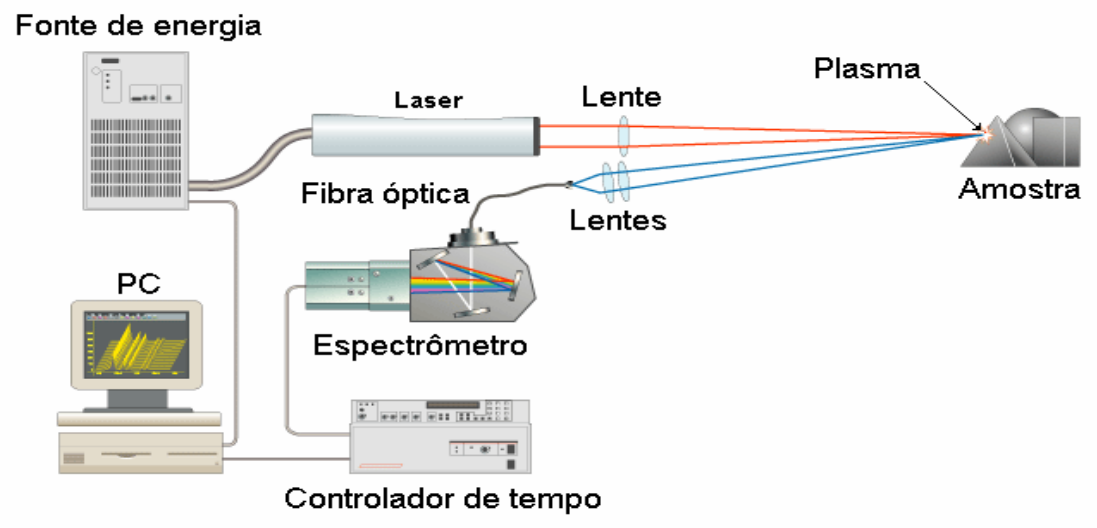

Figura 1: Esquema de um sistema LIBS (figura adaptada de http://www.appliedphotonics.co.uk).

O processo de início do plasma pode ser chamado de ignição, e é comumente aceito que este processo ocorre por emissão termo-iônica (Q-switched) ou ionização multifotônica (mode-locked), dependendo da intensidade do laser, ou dependendo da energia do fóton (Infravermelho, termo-iônica e ultravioleta, ionização multifotônica). Esse processo é seguido por uma avalanche eletrônica devido a colisões entre os elétrons livres e elétrons ligados aos átomos. Apesar de esses processos estarem estabelecidos desde 1960, atualmente existe uma controvérsia quanto ao processo de ionização multifotônica, discutindo-se também a possibilidade de ocorrência de ionização por impacto Zener. Posteriormente à avalanche, o plasma sofre um aquecimento promovido pela absorção do laser pelos componentes do plasma e se expande de forma adiabática. O plasma formado é denominado quasi-neutro devido à anulação da carga eletrônica total em função da distribuição local entre cargas elétricas dentro do plasma, blindando-o de 
interferências externas e criando uma nuvem denominada pluma. O fenômeno de blindagem ocorre devido ao equilíbrio de cargas elétricas do plasma, o qual proporciona uma força restauradora atuante entre íons e elétrons, de maneira que ao ser submetido à ação de campos eletromagnéticos, o sistema apresente comportamento coletivo de voltar ao estado de equilíbrio, dando origem às oscilações harmônicas denominadas plasmons. A blindagem do plasma dá origem a um fenômeno interessante no tocante à penetração de ondas eletromagnéticas. Para feixes laser com pulsos longos ( $\tau>10$ ps) não há transmissão de ondas eletromagnéticas através do plasma, pois as mesmas sofrem uma amortecimento e a sua penetração não acompanha a velocidade de expansão do plasma. No entanto, para pulsos ultracurtos ( $\tau<10$ ps) o feixe é transmitido, pois não há blindagem do plasma. Nesse sentido, a observação da dinâmica espacial da expansão do plasma é interessante, principalmente, comparando-se plasmas obtidos em regimes temporais de nanosegundo, onde ocorre ionização térmica e fenômenos de blindagem, com plasmas obtidos em regime de femtosegundos onde ocorre ionização multifotônica e transmissão [8].

A técnica LIBS utiliza um laser pulsado de alta irradiância, da ordem de $\mathrm{GW} \mathrm{cm}^{-2}$, que é focalizado sobre a superfície de uma amostra. Isso faz com que seja formado um plasma com temperatura variando de 10000 a 20000 K. Átomos, íons e fragmentos de moléculas, que foram excitados no plasma, durante a relaxação emitem um espectro característico do material da amostra que foi volatilizado. Então, o espectro de emissão obtido é analisado na região UV-VIS, em geral.

Atualmente LIBS tem se mostrado uma técnica conveniente para ser aplicada em análises de campo devido a sua característica de portabilidade, podendo realizar em 
um curto período analises direta e in situ de um grande número de amostras em tempo real no próprio local de amostragem.

O limite de detecção da técnica LIBS ainda é relativamente alto se comparado com os que são obtidos com as técnicas ICP-OES [81]. Outra característica da técnica LIBS é a sua baixa precisão. A falta de homogeneidade do material é a principal responsável pela imprecisão e inexatidão, que tende a ser ainda pior com a diminuição da massa amostrada, como aquela praticada em LIBS (m<20 $\mu \mathrm{g}$ ). Isso ocorre, pois se a amostra é subdividida em porções cada vez menores, ela tende a se tornar cada vez mais não homogênea, pois a probabilidade estatística de encontrar a mesma concentração média é baixa [82].

Pode-se dizer que a maioria dos sólidos, com raras exceções, como algumas ligas metálicas e vidros, é uma mistura heterogênea, sendo as rochas, os solos e os sedimentos [5] os materiais que apresentam composições mais heterogêneas.

Em se tratando de análises diretas em amostras in natura, conhecer e avaliar sistematicamente a influência da homogeneidade da amostra sobre os resultados é importante. A boa homogeneidade é pré-requisito para análise direta de amostras sólidas [83]. Esse parâmetro é fortemente influenciado por fatores como o tipo de material, densidade, massa de amostra utilizada e a concentração do elemento de interesse. Trabalhos têm relatado que a microheterogeneidade encontrada em pequenas massas de amostras é conseqüência da presença de partículas grandes chamadas "nuggets", nas quais podem estar contidas concentrações de elementos traços muito maiores do que aquelas encontradas em toda a amostra [84]. Uma maneira de contornar esse tipo de problema é reduzindo o tamanho das partículas das amostras utilizando procedimentos de moagem mais apropriados. 
Apesar de dificuldades como baixa precisão (coeficientes de variação das medidas entre 10 e 40\%) e limites de detecção inadequados para determinação de elementos que ocorrem em baixas concentrações, a técnica LIBS tem sido empregada com certa facilidade em análises qualitativas, mas requer esforço considerável em análises quantitativas. Para que o sucesso das determinações quantitativas seja alcançado é necessário que algumas informações analíticas, como a homogeneidade, o tamanho de partícula e a umidade da amostra e a sua influência sobre a precisão exatidão dos resultados, sejam esclarecidas. Conhecendo-se a influência desses fatores sobre o resultado analítico, poder-se-ão desenvolver métodos analíticos para tornar possível a aplicação da LIBS em análise de campo na determinação elementar em amostras de solos. 


\section{CAPÍTULO 3}

\subsection{Objetivos}

O presente trabalho de pesquisa pretende desenvolver uma metodologia para se estimar a quantidade de carbono em amostras de solos minimamente preparadas através da Espectroscopia de Emissão Óptica com Plasma Induzido por Laser (LIBS) e avaliar o desempenho de sistemas LIBS portáteis visando possível aplicação no campo. 


\section{CAPÍTULO 4}

\subsection{Materiais e Métodos}

\subsubsection{Amostras de solo}

As amostras foram coletadas em uma fazenda experimental no município de Lins, no Estado de São Paulo, com longitude $49^{\circ} 50^{\prime} \mathrm{W}$, latitude $22^{\circ} 21^{\prime} \mathrm{S}$ e altitude média de $440 \mathrm{~m}$. A região de coleta era situada ao lado da estação de tratamento de esgoto operada pela Sabesp, na Unidade de Negócios do Baixo Tietê e Grande no município de Lins.

O clima do local foi classificado como Cwa, caracterizado como mesotérmico de inverno seco. A temperatura média tem sido de $22^{\circ} \mathrm{C}$ no mês mais quente e de $18^{\circ} \mathrm{C}$ no mais frio e a precipitação anual tem variado de 1100 a $1300 \mathrm{~mm}$.

O solo da área experimental é um Argissolo Vermelho Distrófico Latossólico, de textura, média argilosa, cultivado com capim-Bermuda Tifton 85. O plantio do capim foi realizado em janeiro de 2002, quatro meses após a aplicação de 2,0 ton ha-1 de calcário dolomítico não sendo realizada qualquer fertilização, bem como correção da acidez do solo até o início dos experimentos em janeiro de 2003.

Todas as parcelas dos seis tipos de amostras utilizadas receberam anualmente as mesmas quantidades de fertilizante mineral potássico (na forma de cloreto de potássio) e fosfatado (na forma de superfosfato simples). Somente as doses na forma de nitrato de amônio variaram de 0 a $520 \mathrm{~kg} \mathrm{ha}^{-1} \mathrm{ano}^{-1}$, conforme o tratamento. Todos os fertilizantes minerais foram distribuídos manualmente, imediatamente após os cortes do capim.

As amostras de solo foram classificadas da seguinte forma: 
(1) E0 - irrigação com efluente de esgoto tratado e $0 \%\left(0 \mathrm{~kg} \mathrm{ha}^{-1} \mathrm{ano}^{-1}\right)$ da dose recomendada da fertilização nitrogenada mineral (FNM) para o capim Tifton - 85;

(2) E33 - irrigação com efluente de esgoto tratado e $33 \%\left(171,6 \mathrm{~kg} \mathrm{ha}^{-1} \mathrm{ano}^{-1}\right) \mathrm{da}$ FNM;

(3) E66 - irrigação com efluente de esgoto tratado e $66 \%\left(343,2 \mathrm{~kg} \mathrm{ha}^{-1} \mathrm{ano}^{-1}\right) \mathrm{da}$ FNM;

(4) E100 - irrigação com efluente de esgoto tratado e $100 \%\left(520 \mathrm{~kg} \mathrm{ha}^{-1} \mathrm{ano}^{-1}\right) \mathrm{da}$ FNM;

(5) SI - sem irrigação e sem FNM; (6) W100 - irrigação com água de consumo e $100 \%\left(520 \mathrm{~kg} \mathrm{ha}^{-1} \mathrm{ano}^{-1}\right)$ da FNM.

O experimento foi desenvolvido desta forma com o objetivo de avaliar o efeito da utilização de efluente de esgoto tratado como água de irrigação e seu impacto na agricultura. As amostras foram coletadas na primeira quinzena de maio de 2006 . O solo foi coletado por meio de trado holandês desde a superfície até, em geral, 100 $\mathrm{cm}$ de profundidade. Foram coletadas, nas parcelas experimentais, amostras de solo das camadas superficiais $(0-10$ e $10-20 \mathrm{~cm})$ e subsuperficiais $(20-40,40-60,60-80$ e 80-100 cm). Coletando-se dessa forma foi possível obter um gradiente no teor de carbono das amostras. Ao final, foi obtido 6 conjuntos com 6 amostras de solo cada, totalizando 36 amostras.

Depois de coletadas, as amostras de solos passaram por uma limpeza manual cuidadosa para retirada de raízes, restos de folhas. A seguir as amostras foram secas à temperatura ambiente, trituradas e passadas em peneira de malha de 212 $\mu \mathrm{m}$ para a obtenção da fração da chamada terra fina seca ao ar. 
Para avaliar o efeito de heterogeneidade, as amostras foram divididas em duas partes iguais: a primeira parte manteve-se apenas peneirada e a segunda parte foi moída criogenicamente.

Posteriormente foram feitas pastilhas com massa de aproximadamente $0,5 \mathrm{~g}$ de todas as amostras de solo, moídas e não moídas, utilizando-se uma prensa hidráulica aplicando uma carga de 14 ton. Na Figura 2 pode-se observar uma pastilha de solo em comparação com uma moeda de 50 centavos notando-se o tamanho diminuto e, conseqüentemente, a baixa quantidade de amostra requisitada.

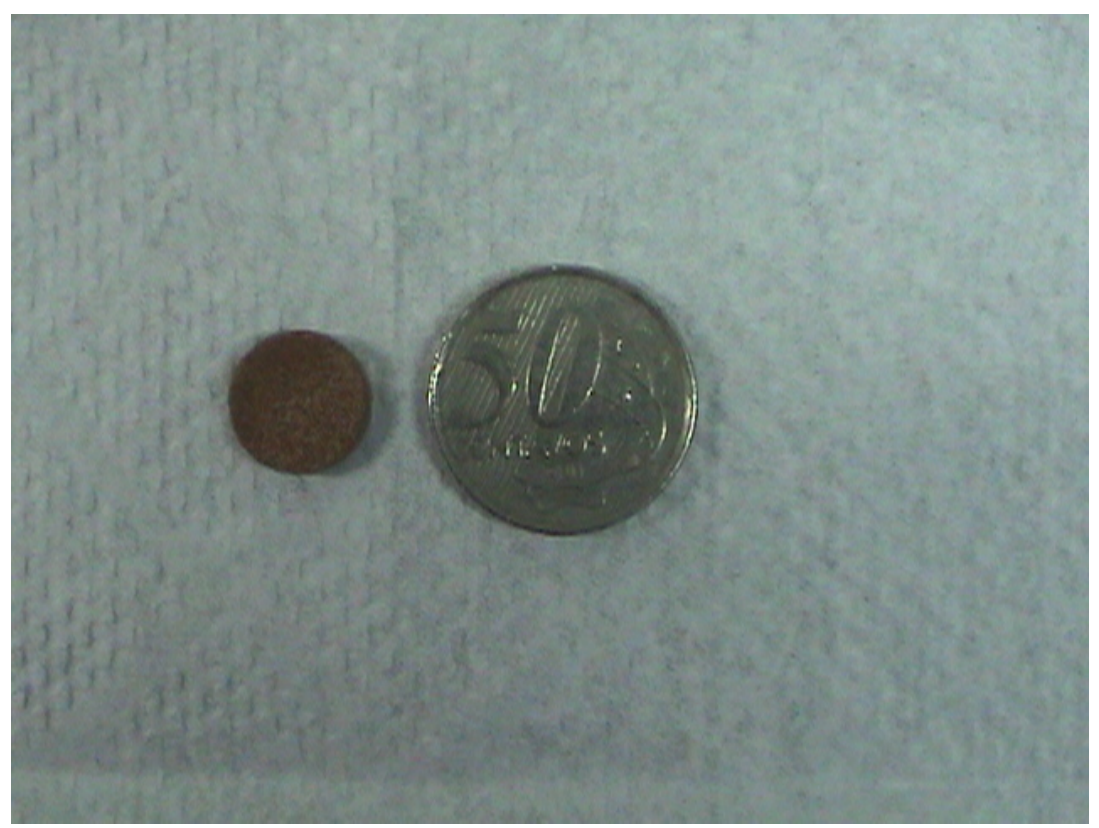

Figura 2: Pastilha de solo em comparação com uma moeda.

\subsubsection{Moinho Criogênico}

Para minimizar a heterogeneidade das amostras foi utilizado um moinho criogênico da SpexCertiprep, modelo 6750, que trabalha a temperatura do nitrogênio líquido $\left(-196^{\circ} \mathrm{C}\right)$ pertencente a Embrapa Pecuária Sudeste, localizada no município de São Carlos, SP. 
A programação utilizada foi: 2 fases de moagem de 2 min. cada, utilizando 2 passos de congelamento de 2 min. cada, um antes da primeira moagem e o outro entre a primeira e segunda fase de moagem.

\subsubsection{Analisador de Carbono Orgânico Total}

Para se estimar a porcentagem de carbono total nas amostras de solo foi utilizado o método de combustão seca (dry combustion) conhecido pelo acrônimo em inglês TOC (Total Organic Carbon). Para isso foi utilizado o equipamento Total Organic Carbon Analyser, modelo TOC-V CPH, marca Shimadzu, acoplado ao módulo para amostragem de sólidos, modelo SSM-5000 A, pertencente ao Laboratório de Química Ambiental do Instituto de Química de São Carlos da Universidade de São Paulo, localizado no município de São Carlos, SP.

Para essa análise foram utilizadas alíquotas de solo de $100 \mathrm{mg}$ cada de todas as amostras dos 6 tratamentos utilizados. Essas alíquotas foram oxidadas a $900{ }^{\circ} \mathrm{C}$ utilizando um fluxo de $0,3 \mathrm{~L} \mathrm{min.-1}$ de oxigênio. A quantidade de carbono foi estimada utilizando radiação infravermelha não dispersiva. Cada medida foi realizada em triplicata para se obter uma estimativa da reprodutibilidade das determinações.

\subsubsection{Sistema LIBS de bancada}

Os espectros de emissão das amostras foram obtidos utilizando um sistema LIBS de bancada da Ocean Optics, modelo LIBS2500plus pertencente a Embrapa Instrumentação Agropecuária, localizada no município de São Carlos, SP. O sistema é equipado com um laser de Nd:YAG de $50 \mathrm{~mJ}$ com duração de pulso de $20 \mathrm{~ns}$, diâmetro do feixe do laser (laser spot) em torno de $0,5 \mathrm{~mm}$, taxa de repetição de até $500 \mathrm{~Hz}$; detector CCD (charge-coupled device) de 14336 pixels; faixa 
espectrométrica de 190-980 nm e resolução óptica de 0,1 nm, com tempo de atraso (delay time) de $2 \mu$ s entre o pulso do laser e a aquisição do espectro. Na Figura 3 pode ser visto o sistema LIBS utilizado.

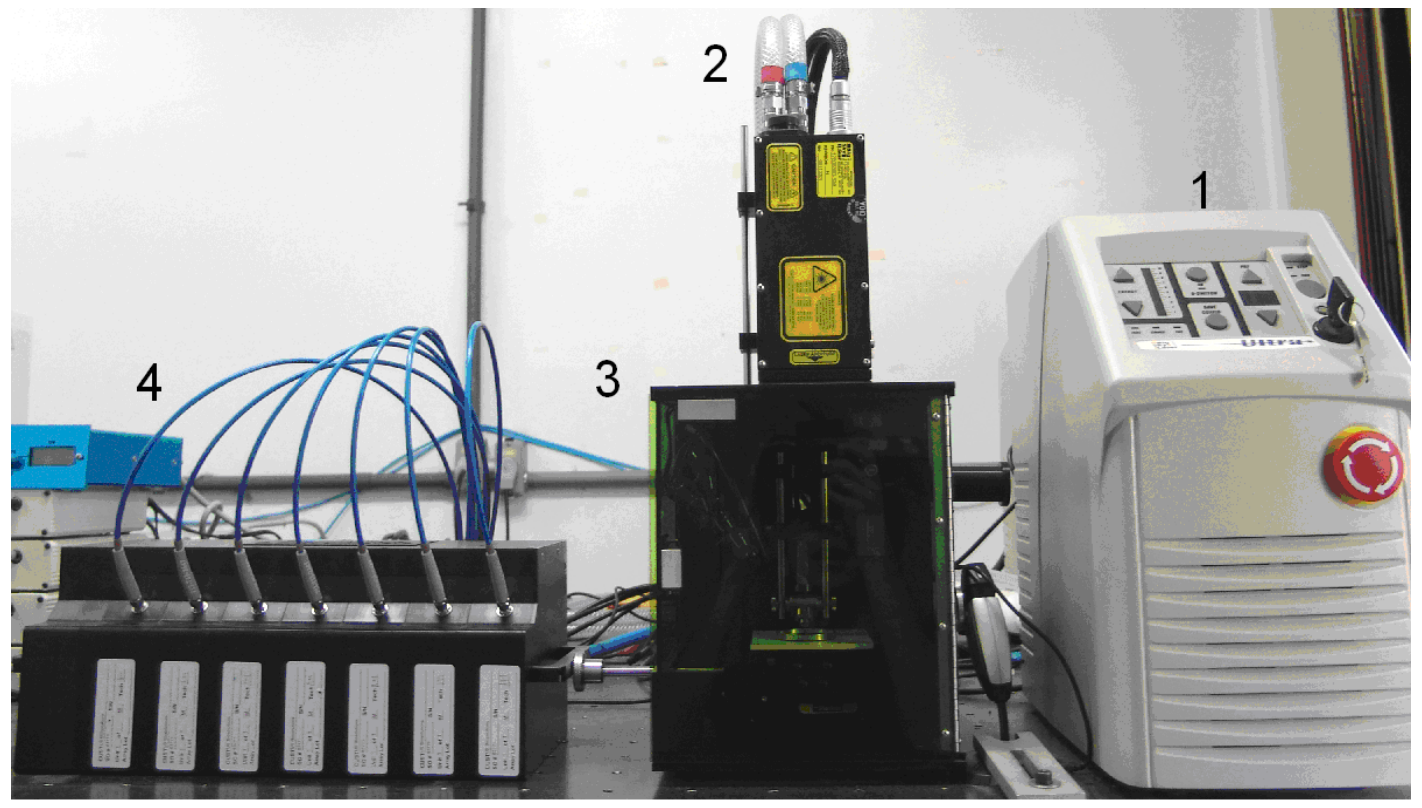

Figura 3: Sistema LIBS de bancada modelo LIBS2500plus: (1) fonte de energia; (2) laser; (3) câmara de ablação; (4) conjunto de espectrômetros.

O sistema é composto por: (1) fonte de energia que alimenta o laser e controla a energia do mesmo; (2) laser de Nd:YAG; (3) câmara de ablação; (4) conjunto de 7 espectrômetros.

O carbono apresenta duas linhas intensas de emissão com as quais se pode trabalhar em LIBS: 193,03 e 247,80 nm [51, 52]. A linha de carbono em $247,80 \mathrm{~nm}$ sofre uma forte interferência do elemento ferro [52], por isso nesse trabalho adotouse apenas a linha de carbono em 193,03 nm.

Os espectros foram adquiridos utilizando 4 metodologias diferentes para que fosse possível estimar uma melhor forma para realização de medidas de carbono em amostras de solo: 
(1) 60 medidas sendo que cada uma correspondia ao acúmulo de 10 tiros utilizando o laser com energia de $50 \mathrm{~mJ}$;

(2) 60 medidas sendo que cada uma correspondia ao acúmulo de 2 tiros utilizando o laser com energia de $50 \mathrm{~mJ}$;

(3) 60 medidas sendo que cada uma correspondia ao acúmulo de 10 tiros utilizando o laser com energia de $25 \mathrm{~mJ}$;

(4) 60 medidas sendo que cada uma correspondia ao acúmulo de 2 tiros utilizando o laser com energia de $25 \mathrm{~mJ}$.

Cada uma dessas 60 medidas foi feita em áreas diferentes da pastilha. Esse número elevado de medidas foi feito para se obter uma melhor relação sinal/ruído e o melhor desempenho possível nas medidas já que trata-se de um tipo de amostra muito heterogênea. Trabalhou-se com o espectro médio dessas 60 medidas em todas as quatro metodologias utilizadas. Todas as medidas foram feitas ao ar e pressão ambiente.

Os espectros obtidos no sistema LIBS de bancada apresentavam variação na intensidade (offset) e um perfil ascendente para o sinal de fundo. Trabalhou-se apenas com o espectro na faixa espectral de 191,49 a 230,04 nm. Para corrigir o problema do perfil ascendente do sinal de fundo, foi selecionada uma pequena região considerada como ruído, ou seja, não apresentava linhas de emissão de nenhum elemento. A região escolhida foi de 191,49 a 191,99 nm, pois esta apresentava certa linearidade, ou seja, sem uma inclinação ascendente do sinal de fundo. Calculou-se a média dos valores de intensidade nesta região escolhida e subtraiu-a do espectro levando o sinal de fundo do espectro para a região próxima à zero. A correção foi feita para as 60 replicatas de cada uma das amostras correspondentes as 6 profundidades em todos os tratamentos considerados. Em 
seguida, calculou-se o espectro médio considerando os 60 espectros corrigidos previamente.

O espectro médio, cujo sinal de fundo começa sempre próximo à zero, ainda apresentava uma inclinação linear do sinal de fundo. Para a correção dessa inclinação se ajustou uma reta na forma $y=a x+b$ que representava $a$ inclinação do espectro. A inclinação obtida, correspondente a cada espectro médio, foi subtraída permitindo a correção do sinal de fundo.

Para a correção desses dois problemas do sinal de fundo foi desenvolvido um programa computacional utilizando o programa computacional estatístico chamado Statistical Analysis System (SAS).

Observou-se nos espectros obtidos uma linha de emissão em 193,53 nm que através da base de dados do National Institute of Standards and Technology (NIST) foi atribuída ao alumínio atômico ( $\mathrm{Al}$ I) [85]. Por esta base de dados também foi observado que há outra linha de emissão de Al I em 193,16 nm com uma intensidade muito próxima à linha em 193,53 nm. Devido à proximidade com a linha de emissão de carbono em 193,03 nm e a baixa resolução do equipamento $(0,1 \mathrm{~nm})$ essa linha de Al I em 193,16 nm não era resolvida e, portanto, interferia no sinal da linha de carbono. Para minimizar esse efeito, o espectro foi divido pela intensidade do sinal de Al I em 193,53 nm.

Finalizadas as correções, iniciaram-se as análises estatísticas. Toda análise estatística deve ter início em uma análise exploratória dos dados, pois há a necessidade de resumir e entender o conjunto de dados em análise.

Primeiramente, para a verificação de possíveis erros de detecção, foi calculada a média e o desvio padrão para cada comprimento de onda de todos os espectros. Essas medidas são afetadas por valores extremos assim resolveu-se trabalhar com 
a mediana como medida de centralidade, os extremos (menor e maior valor do conjunto de dados) e os quartis. Cada quartil faz o mesmo que a mediana para as duas metades marcadas pela mediana, ou seja, a mediana é um valor que deixa metade dos dados abaixo e metade acima dele. O primeiro quartil $\left(Q_{1}\right)$ é um valor que deixa um quarto dos valores abaixo e três quartos acima dele. O terceiro quartil $\left(Q_{3}\right)$ é um valor que deixa três quartos dos dados abaixo e um quarto acima dele. $O$ segundo quartil é a mediana (md) [86]. Para isto foi utilizado o gráfico de caixas (box-plot), que representava os dados através de um retângulo construído com os quartis e identificava os valores extremos [87]. A Figura 4 mostra um esquema para a construção do gráfico de caixas onde os valores discrepantes são aqueles que apresentam valores acima de $Q_{3}+1,5 d$ ou $Q_{1}-1,5 d$, onde $d$ é a diferença entre quartil.

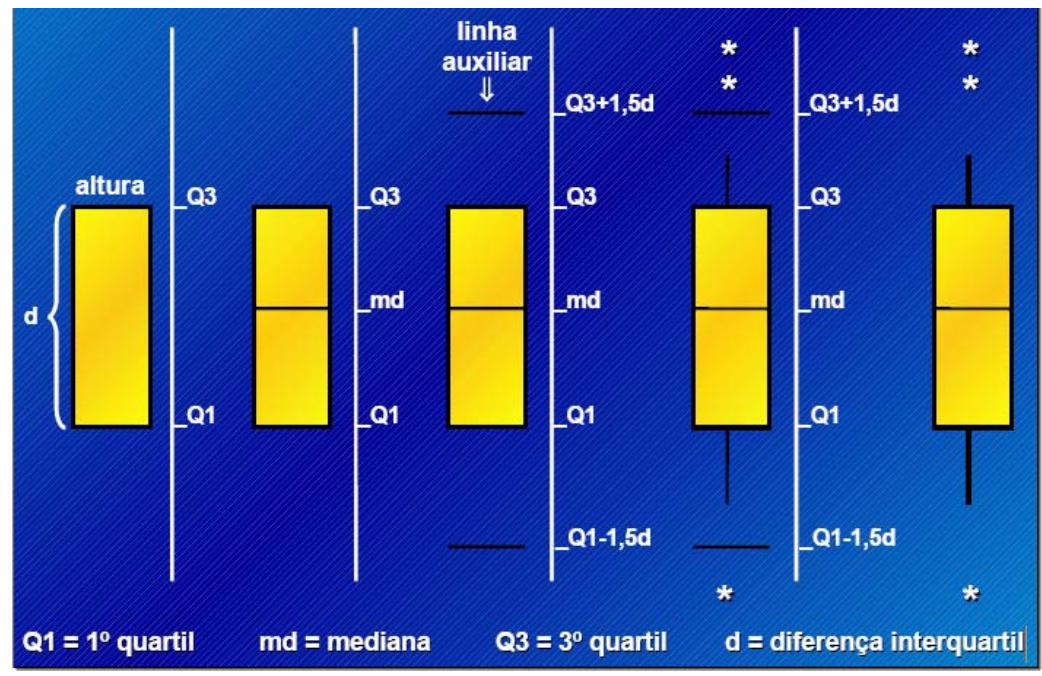

Figura 4: Construção do gráfico de caixas.

A análise de regressão linear simples foi utilizada para criar um modelo que pudesse estimar a concentração de carbono nas amostras a partir das intensidades de sinal medidas no sistema LIBS. Análise de regressão é uma metodologia estatística que utiliza a relação entre duas ou mais variáveis de forma que uma variável pode ser predita a partir da outra. Para isso foi utilizada a suposição de que a intensidade do sinal referente ao pico de carbono em 193,03 nm e a concentração 
de carbono medida pelo TOC apresentava relação. Assim sendo, a intensidade do sinal em 193,03 nm foi a variável independente e a concentração medida pelo TOC foi a variável dependente.

Os modelos criados foram do tipo $\mathrm{Y}=\mathrm{A}+\mathrm{BX}$, onde $\mathrm{Y}$ é o valor da intensidade do sinal de carbono medido em 193,03 nm; A é o valor da ordenada $Y$ da reta para o qual a abscissa $\mathrm{X}$ é nula (o intercepto); B é o coeficiente angular da reta; $\mathrm{X}$ é a concentração de carbono estimada.

Modelos baseados em crescimento exponencial também foram criados para que fosse possível estimar a concentração de carbono nas amostras a partir das intensidades de sinal medidas no sistema LIBS. Para isso, foi utilizada a mesma suposição empregada para a análise de regressão simples. Os modelos criados foram do tipo $Y=Y_{0}+A_{1} e^{(X / 1) 1)}$, onde $Y$ é o valor da intensidade do sinal de carbono medido em 193,03 nm; $Y_{0}, A_{1}, t_{1}$ são parâmetros gerados pelo modelo; $X$ é a concentração de carbono estimada.

Foram utilizadas as amostras dos tratamentos E0, E33, E66, E100 para criar os modelos de regressão linear e crescimento exponencial. O coeficiente de correlação de Pearson (R) foi utilizado para medir a correlação entre as variáveis para ambos os modelos.

As amostras dos tratamentos $\mathrm{SI}$ e W100 foram utilizadas para validar os modelos. As variáveis utilizadas nas validações dos modelos foram porcentagem de carbono estimada pelo LIBS e porcentagem de carbono estimada pelo TOC. Também foi utilizado o coeficiente de correlação de Pearson para medir a correlação entre as variáveis. 


\subsubsection{Sistema LIBS portátil}

Espectros de emissão de amostras de solo também foram adquiridos utilizando um espectrômetro LIBS portátil da StellarNet, modelo PORTA-LIBS-2000, equipado com um laser de Nd:YAG de 25 mJ com duração de pulso de 4 ns, diâmetro do feixe do laser (laser spot) em torno de 0,5 mm, taxa de repetição de $1 \mathrm{~Hz}$; detector CCD de 2048 pixels; faixa espectrométrica de 190-1000 nm e resolução óptica de 0,2 nm, com tempo de atraso de $2 \mu$ s entre o pulso do laser e a aquisição do espectro, pertencente a Embrapa Instrumentação Agropecuária, localizada no município de São Carlos, SP . Na Figura 5 pode ser observado o equipamento LIBS utilizado.

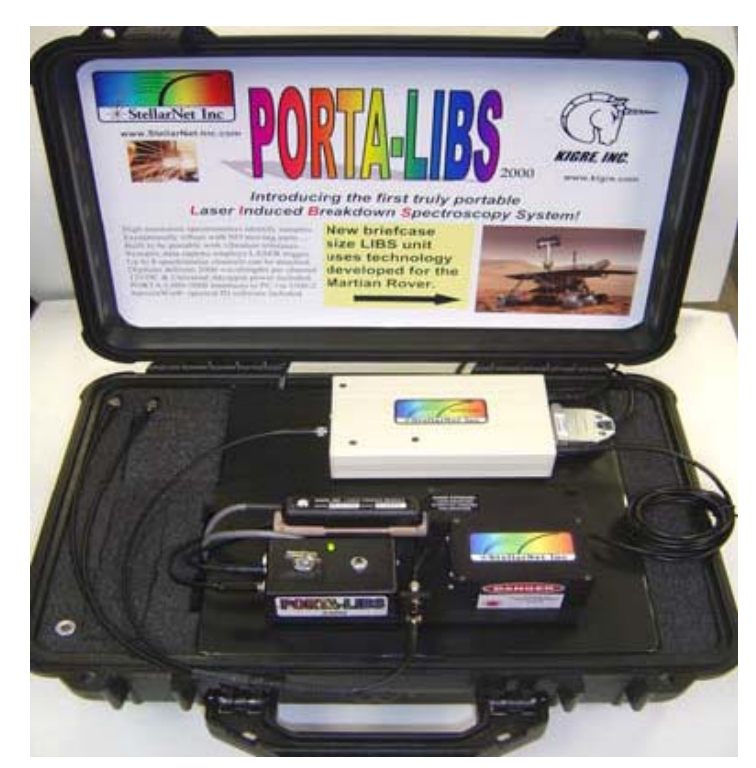

Figura 5: Sistema LIBS portátil modelo PORTA-LIBS-2000 (retirada de http://www.stellarnetinc.com).

O tamanho reduzido deste sistema pode ser observado por esta figura, pois os componentes constituintes do sistema tais como laser, câmara de ablação e espectrômetro podem ser dispostos em uma valise, assegurando a portabilidade do mesmo. 
Foram adquiridos 60 espectros de cada amostra, sendo que cada medida consistiu em 1 tiro do laser em áreas diferentes da pastilha. As medidas foram feitas ao ar a pressão ambiente. Trabalhou-se com o espectro médio dessas 60 medidas.

Diferentemente do que foi realizado para o LIBS de bancada, apenas as amostras do tratamento SI foram utilizadas, pois o sistema LIBS apresentou problemas técnicos que impediram a realização das medias em todas as amostras de todos os tratamentos.

Devido o processo de formação do plasma não ocorrer exatamente da mesma forma em amostras muito heterogêneas, inicialmente também foi necessário corrigir o sinal de fundo do espectro médio obtido. Apenas variações na intensidade do sinal de fundo (offset) precisaram ser corrigidas aqui. Para isso foi utilizado um programa computacional desenvolvido por Gornushkin e colaboradores [88] que foi gentilmente cedido pelos autores. Este programa foi utilizado aqui pois corrigia de modo rápido e eficaz esse problema de sinal de fundo apresentado. Basicamente, o algoritmo utilizado neste programa computacional divide o espectro em n partes prédeterminadas pelo usuário ou determinadas automaticamente pelo programa. Selecionadas as $\mathrm{n}$ partes, o algoritmo determina todos os pontos mínimos em cada uma das mesmas e em seguida escreve um polinômio de, no máximo, grau igual a 10. Em seguida esse polinômio é subtraído do espectro corrigindo o sinal de fundo.

Assim, como foi feito para o sistema LIBS de bancada, uma análise de regressão linear simples foi realizada para criar um modelo que pudesse estimar a concentração de carbono nas amostras a partir da intensidade do sinal medido no sistema portátil. Para isto foram utilizadas as intensidades do sinal do pico de carbono em 193,03 nm e as concentrações medidas pelo TOC. 
Na tentativa de se obter um melhor resultado, foi realizada também a análise de regressão linear múltipla. Foram utilizadas as intensidades de sinal nos comprimentos de onda 192,83; 192,92; 193,03; 193,11 e 193,20 nm como variáveis independentes e a concentração de carbono medida pelo TOC como variável dependente para podermos avaliar qual intensidade nesses comprimentos de onda apresentava melhor correlação. As intensidades de sinal nestes 5 comprimentos de onda referem-se à todo do o pico de emissão do carbono.

Para validar o modelo criado e avaliar a precisão do método, foi utilizada a validação cruzada. Esta validação foi realizada da seguinte forma: a regressão linear simples era gerada utilizando cinco medidas e a sexta medida era utilizada para validar a equação criada pelo modelo. Sendo assim, foram criados seis modelos com seis validações, uma para cada medida. Os valores preditos pelos seis modelos criados foram dispostos frente aos valores medidos pelo TOC e, assim, foi determinado o coeficiente de correlação $(R)$ entre os mesmos.

O modelo de regressão linear múltipla e a validação cruzada foram realizados utilizando o programa computacional estatístico chamado Waikato Environment for Knowledge Analysis (Weka). 


\section{CAPÍTULO 5}

\subsection{Resultados e Discussão}

\subsubsection{Determinação do Carbono Orgânico Total}

Os dados obtidos pela técnica TOC podem ser vistos na Tabela 1. Como pode ser observado, no geral, houve uma diminuição na quantidade de carbono do solo com a profundidade em todos os tratamentos. Porém, não houve grandes modificações na quantidade de carbono quando comparados os tratamentos em profundidades iguais. Os dados apresentados referem-se à média aritmética de experimentos realizados em triplicata.

Observando os dados presentes nesta tabela também pode se constatar que o solo utilizado apresentou valores muito baixos em relação à quantidade de carbono, sendo o maior valor determinado menor que $1 \%$ (exatamente, $0,85 \%$ ). 
Tabela 1: Porcentagens de carbono orgânico no solo obtidas pela técnica TOC.

\begin{tabular}{|c|c|c|c|}
\hline Tratamento & $\begin{array}{c}\text { Profundidade } \\
(\mathbf{c m})\end{array}$ & $\begin{array}{c}\text { Teor de } \\
\text { Carbono (\%) }\end{array}$ & $\begin{array}{c}\text { Erro Padrão } \\
( \pm)\end{array}$ \\
\hline \multirow[t]{6}{*}{ EO } & $0-10$ & 0,82 & 0,01 \\
\hline & $10-20$ & 0,69 & 0,01 \\
\hline & $20-40$ & 0,65 & 0,01 \\
\hline & $40-60$ & 0,58 & 0,01 \\
\hline & $60-80$ & 0,51 & 0,01 \\
\hline & $80-100$ & 0,41 & 0,01 \\
\hline \multirow[t]{6}{*}{ E33 } & $0-10$ & 0,79 & 0,01 \\
\hline & $10-20$ & 0,62 & 0,01 \\
\hline & $20-40$ & 0,62 & 0,01 \\
\hline & $40-60$ & 0,53 & 0,01 \\
\hline & $60-80$ & 0,4 & 0,01 \\
\hline & $80-100$ & 0,32 & 0,01 \\
\hline \multirow[t]{6}{*}{ E66 } & $0-10$ & 0,81 & 0,01 \\
\hline & $10-20$ & 0,68 & 0,01 \\
\hline & $20-40$ & 0,63 & 0,01 \\
\hline & $40-60$ & 0,64 & 0,01 \\
\hline & $60-80$ & 0,48 & 0,01 \\
\hline & $80-100$ & 0,38 & 0,01 \\
\hline \multirow[t]{6}{*}{ E100 } & $0-10$ & 0,83 & 0,01 \\
\hline & $10-20$ & 0,69 & 0,01 \\
\hline & $20-40$ & 0,65 & 0,01 \\
\hline & $40-60$ & 0,63 & 0,02 \\
\hline & $60-80$ & 0,47 & 0,01 \\
\hline & $80-100$ & 0,36 & 0,01 \\
\hline \multirow[t]{6}{*}{ SI } & $0-10$ & 0,84 & 0,02 \\
\hline & $10-20$ & 0,85 & 0,01 \\
\hline & $20-40$ & 0,75 & 0,01 \\
\hline & $40-60$ & 0,65 & 0,01 \\
\hline & $60-80$ & 0,45 & 0,01 \\
\hline & $80-100$ & 0,37 & 0,01 \\
\hline \multirow[t]{6}{*}{ W100 } & $0-10$ & 0,83 & 0,01 \\
\hline & $10-20$ & 0,72 & 0,01 \\
\hline & $20-40$ & 0,65 & 0,01 \\
\hline & $40-60$ & 0,62 & 0,01 \\
\hline & $60-80$ & 0,50 & 0,01 \\
\hline & $80-100$ & 0,40 & 0,01 \\
\hline
\end{tabular}




\subsubsection{Sistema LIBS de bancada}

\subsubsection{Amostras moídas}

\subsection{Energia do laser $50 \mathrm{~mJ}$ e acúmulo de 10 tiros}

Espectros LIBS tendem a ter uma baixa reprodutibilidade e, se o detector não for um ICCD, um grande sinal de fundo contínuo. O sinal de fundo pode variar fortemente de espectro para espectro e de amostra para amostra. A origem dessas grandes flutuações no sinal e no sinal de fundo é uma forte característica não linear da interação laser-material. Mesmo para ablação de uma superfície plana e de composição homogênea, pequenas flutuações na intensidade do laser podem causar mudanças significativas na aparência do espectro LIBS. Esse efeito danoso é multiplicado por rugosidade e superfícies não homogêneas ou por pós e aerossóis. Sendo assim, uma modelagem adequada do sinal de fundo em LIBS é muito importante para análises qualitativas e quantitativas [88].

Na Figura 6 é mostrado o espectro médio obtido para a amostra de solo SI na profundidade de 0-10 $\mathrm{cm}$ obtido utilizando-se a energia máxima do laser $(50 \mathrm{~mJ})$ e acúmulo de 10 tiros. É apresentado apenas o gráfico do tratamento SI obtido nessas condições de energia do laser e número de tiros visto que todos os espectros das amostras de todos os seis tratamentos nos quatro métodos utilizados apresentaram o mesmo perfil diferenciando apenas na intensidade do sinal das linhas de emissão. 


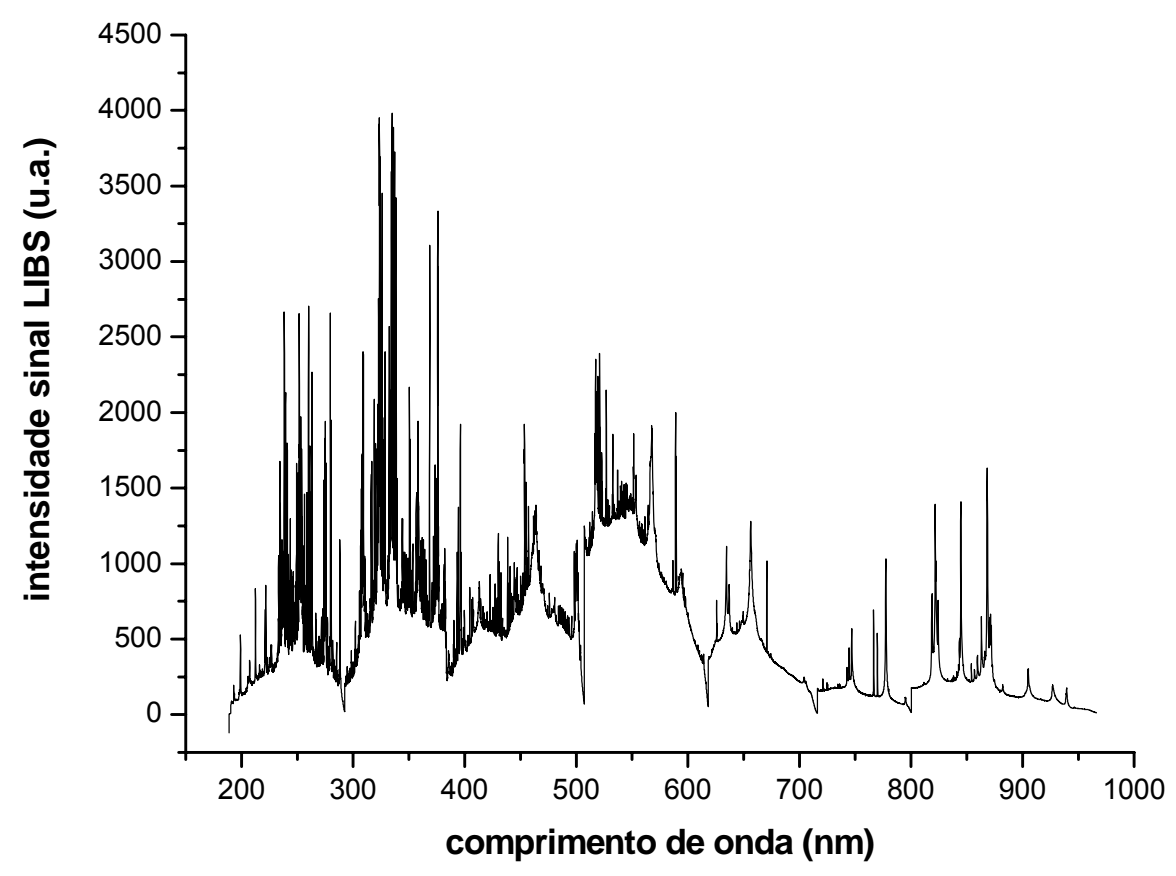

Figura 6: Espectro obtido para o tratamento SI na profundidade $0-10 \mathrm{~cm}$ utilizando energia do laser em $50 \mathrm{~mJ}$ e acúmulo de 10 tiros.

Pela Figura 6 é possível visualizar o grande número de linhas de emissão que são obtidas em um espectro de amostra de solo. Solo é uma amostra bastante heterogênea e esse elevado número de linhas de emissão observado é característico de materiais dessa natureza, pois reflete a grande diversidade elementar de sua composição. Também é possível observar os problemas referentes ao sinal de fundo que foram relatados no capítulo 4 e que precisaram ser corrigidos.

Para facilitar a visualização do pico de carbono em 193,03 nm, foi somente utilizada a faixa espectral de 190 a $230 \mathrm{~nm}$. Na Figura 7 são mostrados alguns espectros referentes à amostra na profundidade $0-10 \mathrm{~cm}$ do tratamento SI na faixa espectral citada e destacando o pico de carbono em 193,03 nm. 

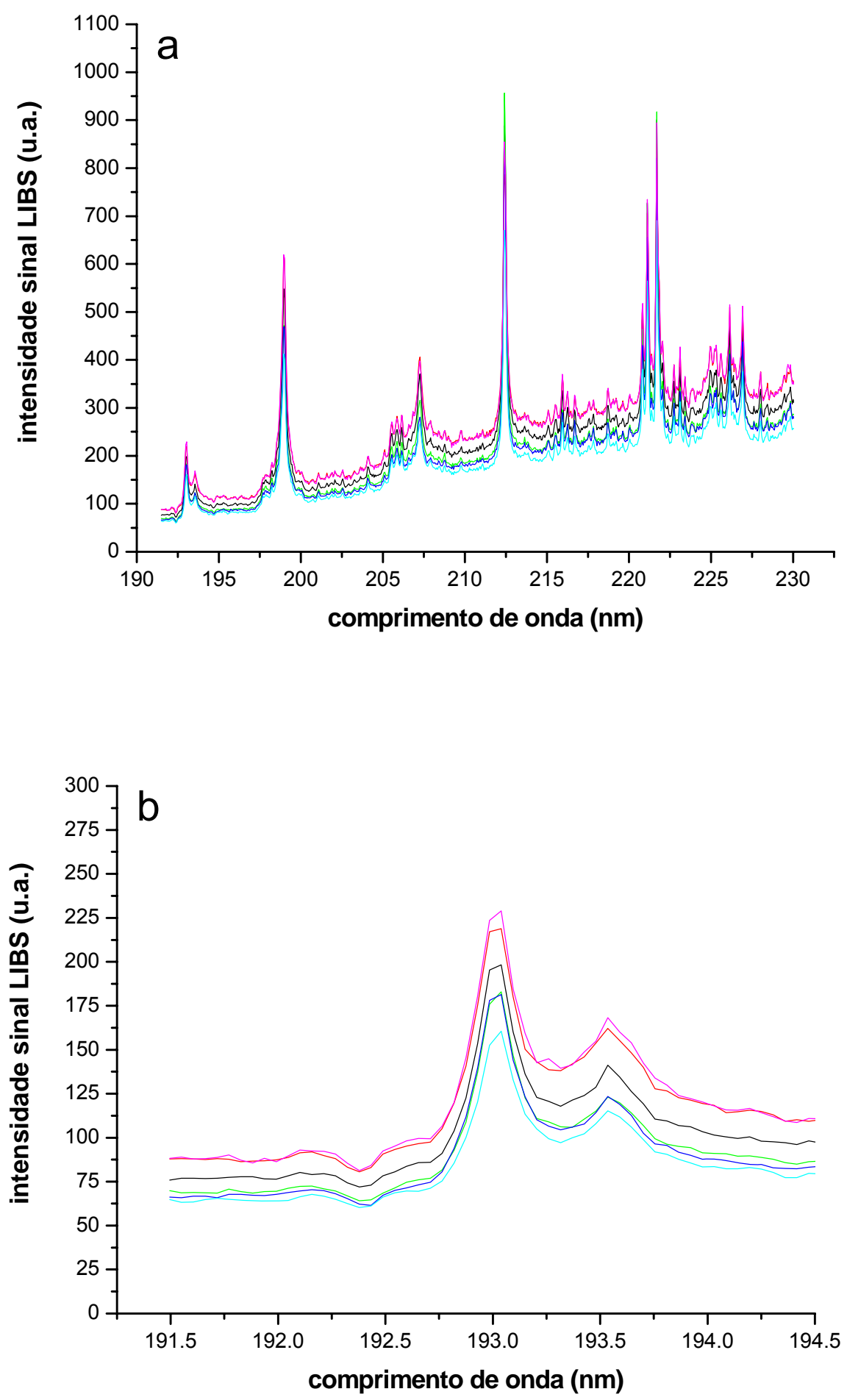

Figura 7: (a) Exemplo da variação na intensidade do sinal de fundo tiro a tiro para amostra na profundidade $0-10 \mathrm{~cm}$ do tratamento SI obtido com energia do laser em $50 \mathrm{~mJ}$ e acúmulo de 10 tiros; (b) Visualização da variação na intensidade do sinal no pico de carbono em $193,03 \mathrm{~nm}$. 
Conforme pode ser observado, ocorre um desvio na intensidade do sinal de fundo, além do perfil ascendente do mesmo. É necessário salientar que essa variação na intensidade e esse perfil ascendente do sinal de fundo ocorreram em todas as amostras de todos os tratamentos nos quatro métodos avaliados.

No intuito de minimizar corretamente esse perfil ascendente e poder avaliar a quantidade de carbono primeiramente foi corrigido o sinal de fundo de todos os espectros para que todos iniciassem próximo a zero e, posteriormente, foi corrigido perfil ascendente que o sinal de fundo dos espectros apresentavam, como dito anteriormente no capítulo 4. A programação foi escrita baseada no espectro, assim uma regressão linear foi ajustada e, determinada sua inclinação, o espectro foi corrigido. Na Figura 8 é apresentada a comparação entre um espectro sem a correção do perfil ascendente do sinal de fundo e o mesmo espectro corrigido.

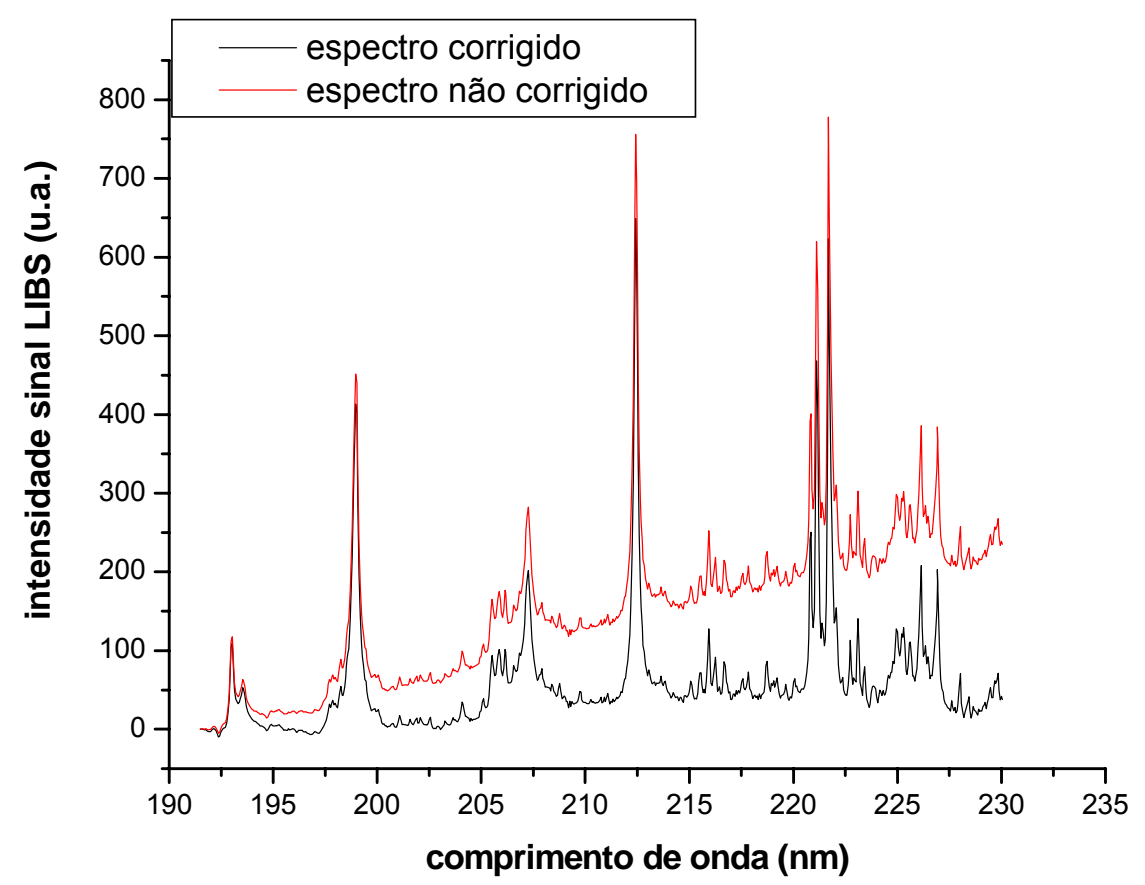

Figura 8: Correção do perfil ascendente do sinal de fundo - comparação entre o espectro sem correção e o mesmo corrigido utilizando o programa SAS. 
Finalizada a correção, normalizou-se o sinal de emissão do carbono dividindo sua intensidade pela intensidade do sinal de emissão do alumínio em 193,53 nm. Na Figura 9 é possível visualizar os picos de carbono e alumínio que foram utilizados para essa normalização.

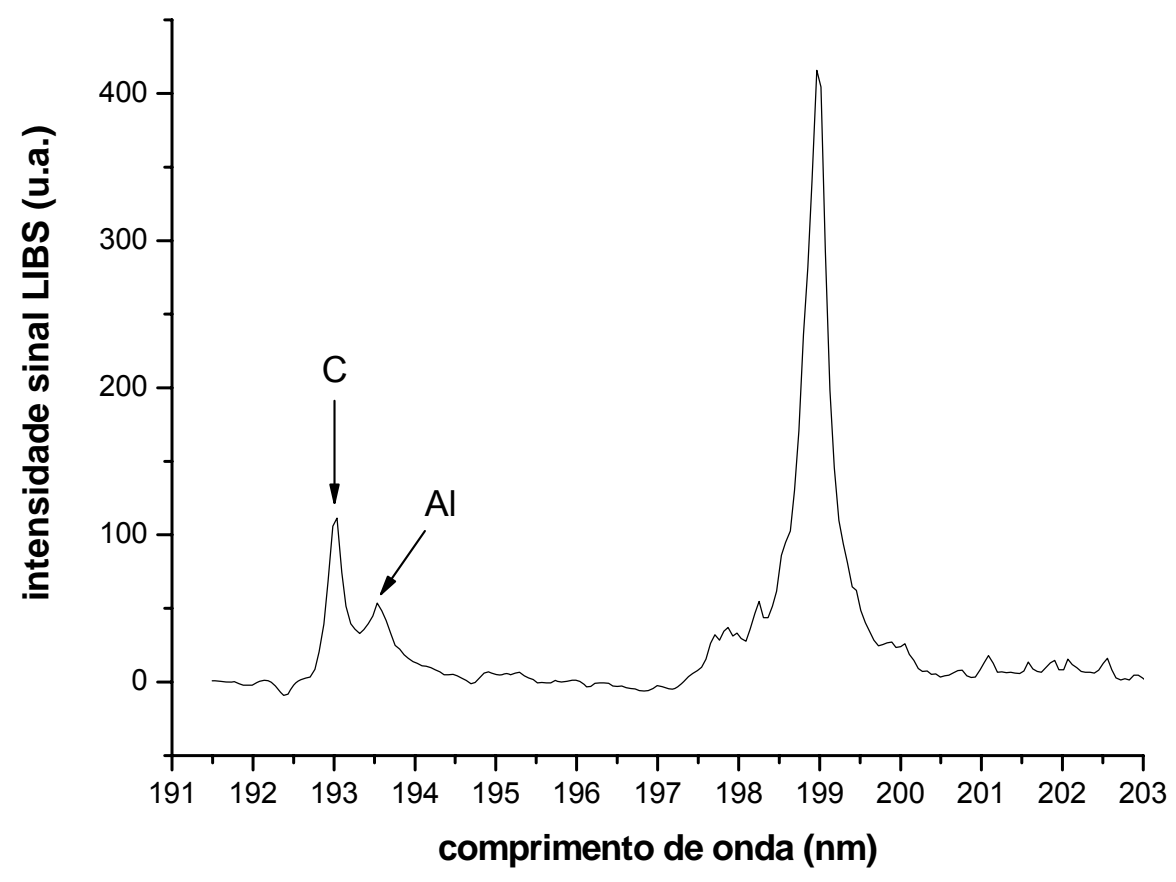

Figura 9: Espectro ilustrando os picos de emissão de carbono e alumínio utilizados para normalização.

Após normalizar cada um dos espectros obtidos, calculou-se a média, que representa uma estimativa da centralidade, e o desvio padrão, que representa uma estimativa da dispersão dos dados. Contudo, como a média e o desvio padrão são afetados por valores extremos ou discrepantes (outliers), um estudo para identificar medidas discrepantes foi realizado. Esse estudo foi realizado construindo-se os gráficos de caixas (box-plot). Com eles foi possível visualizar dentre as 60 medidas feitas para cada amostra quais apresentaram valores discrepantes e, assim, eliminálas. A Figura 10 exemplifica os gráficos de caixas para as amostras do tratamento SI 
onde as medidas foram obtidas utilizando-se energia do laser em $50 \mathrm{~mJ}$ e acúmulo de 10 tiros.

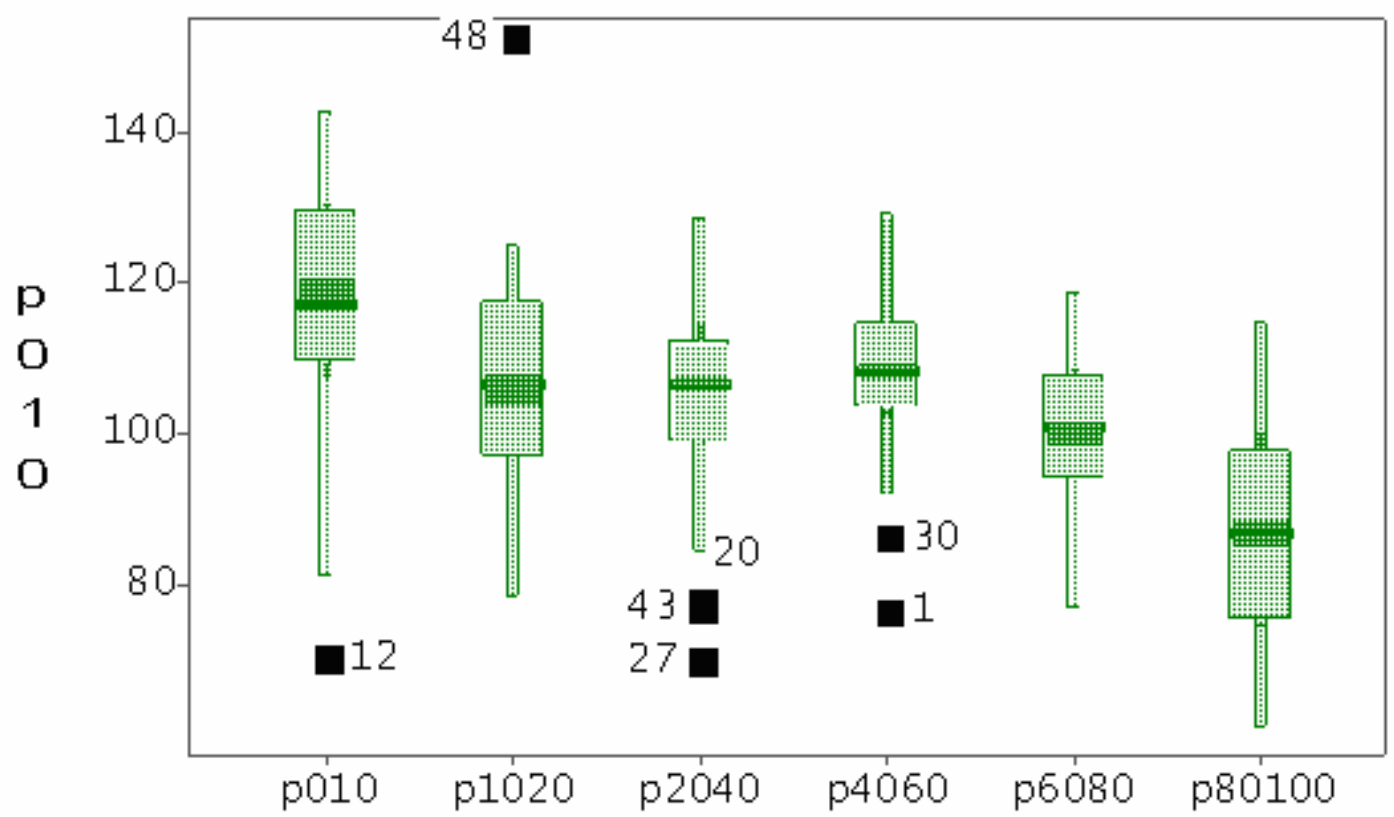

Figura 10: Gráfico de caixas para detecção de medidas discrepantes do tratamento SI realizado com energia do laser em $50 \mathrm{~mJ}$ e acúmulo de 10 tiros.

Como pode ser verificado utilizando os gráficos de caixas da Figura 10 , foi possível visualizar facilmente quais dentre as 60 medidas apresentavam valores discrepantes já que as mesmas ficavam fora dos quartis.

Após eliminar as medidas que apresentaram valores discrepantes e calcular a média, foi possível realizar as análises de regressão linear simples. Conforme descrito anteriormente, foram utilizados os tratamentos E0, E33, E66 e E100 para criar os modelos e os tratamentos SI e W100 para validá-los. As barras de erros apresentadas em todos os gráficos são de erro padrão, que é obtido dividindo-se o valor do desvio padrão pela raiz quadrada do número de replicatas.

Para a regressão linear simples utilizou-se sempre a intensidade normalizada do sinal de carbono em 193,03 nm, para todos os quatro métodos utilizados. Assim, utilizando-se a intensidade do sinal de carbono em 193,03 nm e a concentração de 
carbono obtida pelo TOC como variável dependente foi possível realizar a regressão linear simples. Na Figura 11 é mostrada a curva obtida utilizando o método em que se empregou energia do laser em 50 mJ e acúmulo de 10 tiros.

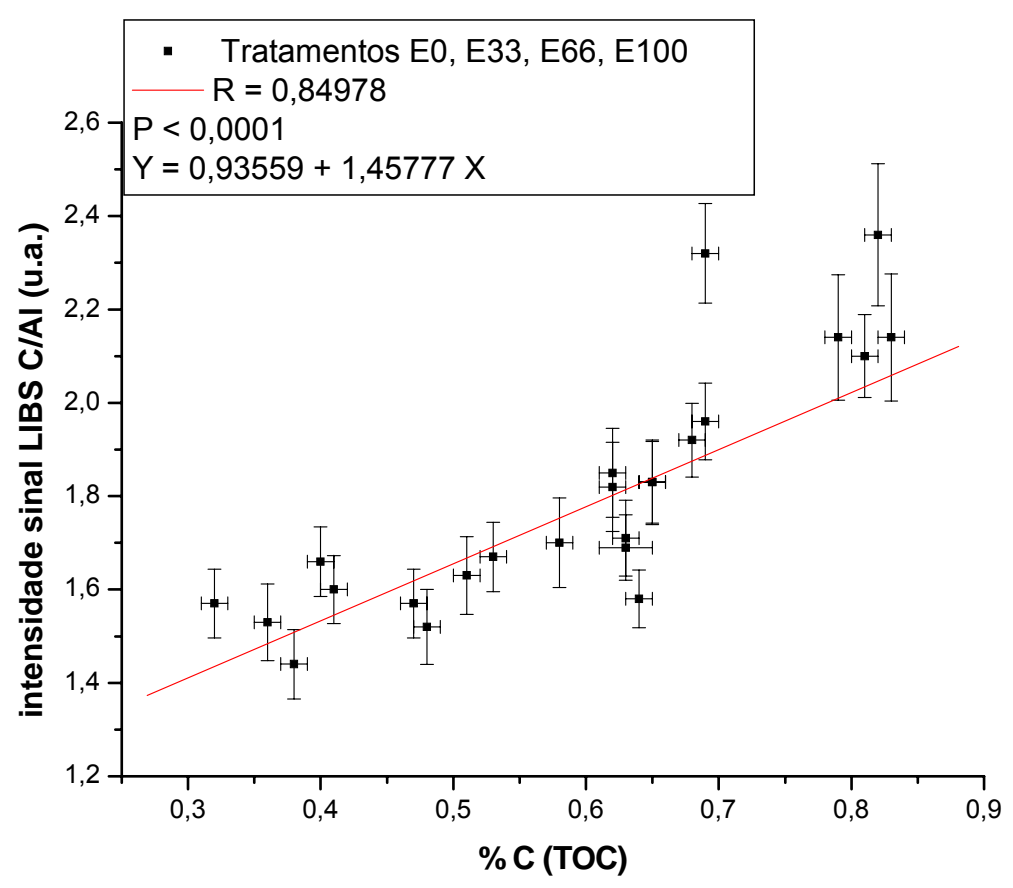

Figura 11: Regressão linear obtida com os tratamentos E0, E33, E66 e E100 utilizando energia do laser em $50 \mathrm{~mJ}$ e acúmulo de 10 tiros.

A equação obtida por essa curva foi $Y=0,93559+1,45777 X$, e o coeficiente de correlação foi 0,84978 . Considerando que a suposição foi aceita, pois a probabilidade do coeficiente de correlação ser zero foi muito baixa (o P-valor, $\mathrm{P}<$ 0,0001), tem-se que o modelo pode ser aplicado para se estimar a quantidade de carbono nas amostras de solo. Utilizou-se as amostras dos tratamentos SI e W100 para validar o método, como pode ser visto na Figura 12. 


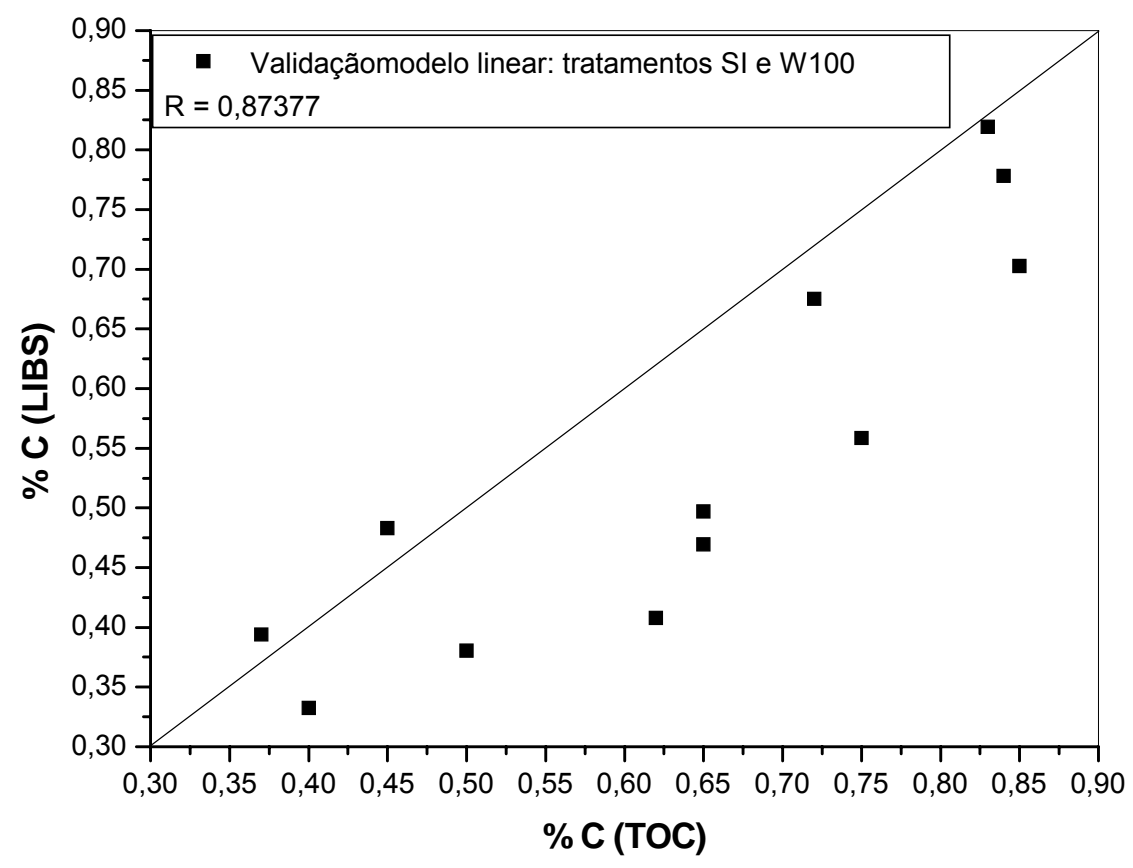

Figura 12: Validação da análise de regressão linear simples dos dados obtidos com LIBS para amostras dos tratamentos SI e W100 utilizando energia do laser em $50 \mathrm{~mJ}$ e acúmulo de 10 tiros.

O gráfico da Figura 12 mostra que foi obtido um coeficiente de correlação igual a 0,87377 para a concentração de carbono estimada pelo LIBS e a concentração de carbono estimada pelo TOC. De forma geral, a estimativa da concentração de carbono feita pelo LIBS, foi menor do que a obtida pelo TOC. Um dos motivos para essa diferença pode ser atribuída às diferenças intrínsecas entre as técnicas LIBS e TOC. Ambas as técnicas dispensam um pré-tratamento (tratamento químico) das amostras de solo, realizando análise direta das mesmas. Porém, a técnica TOC analisa apenas o carbono contido nas amostras através de uma oxidação à $\mathrm{CO}$ e $\mathrm{CO}_{2}$ a uma temperatura de $900{ }^{\circ} \mathrm{C}$, ou seja, não há interferência de outro(s) elemento(s) na medição. Na técnica LIBS, quando o pulso do laser é focalizado na superfície da amostra de solo, o material da mesma é volatilizado e ocorre a formação do plasma. Devido à presença de átomos, íons provenientes de vários 
elementos diferentes presentes na amostra pode ocorrer interferências espectrais que acabam prejudicando a emissão e, conseqüentemente, prejudicam a medição quantitativa. Outro fator que pode prejudicar as medidas em sistemas LIBS é a grande quantidade de material particulado que é lançado quando ocorre a expansão do plasma. As pequenas partículas que compõem este material podem ocasionar o espalhamento de luz proveniente do plasma, prejudicando as medidas.

Outro motivo para essa diferença é a heterogeneidade das amostras de solo, característica já citada anteriormente. Devido às amostras de solo serem muito heterogêneas, a quantidade de carbono não está disposta igualmente nas mesmas. Como a quantidade amostrada pelo laser em LIBS é muito baixa a probabilidade de se amostrar a mesma quantidade de carbono a cada medida é muito baixa, que pode gerar um desvio negativo na estimativa da quantidade de carbono, mesmo realizando as medidas em diferentes pontos da superfície da pastilha.

Um modelo baseado em crescimento exponencial também foi utilizado e pode ser visto na Figura 13. 


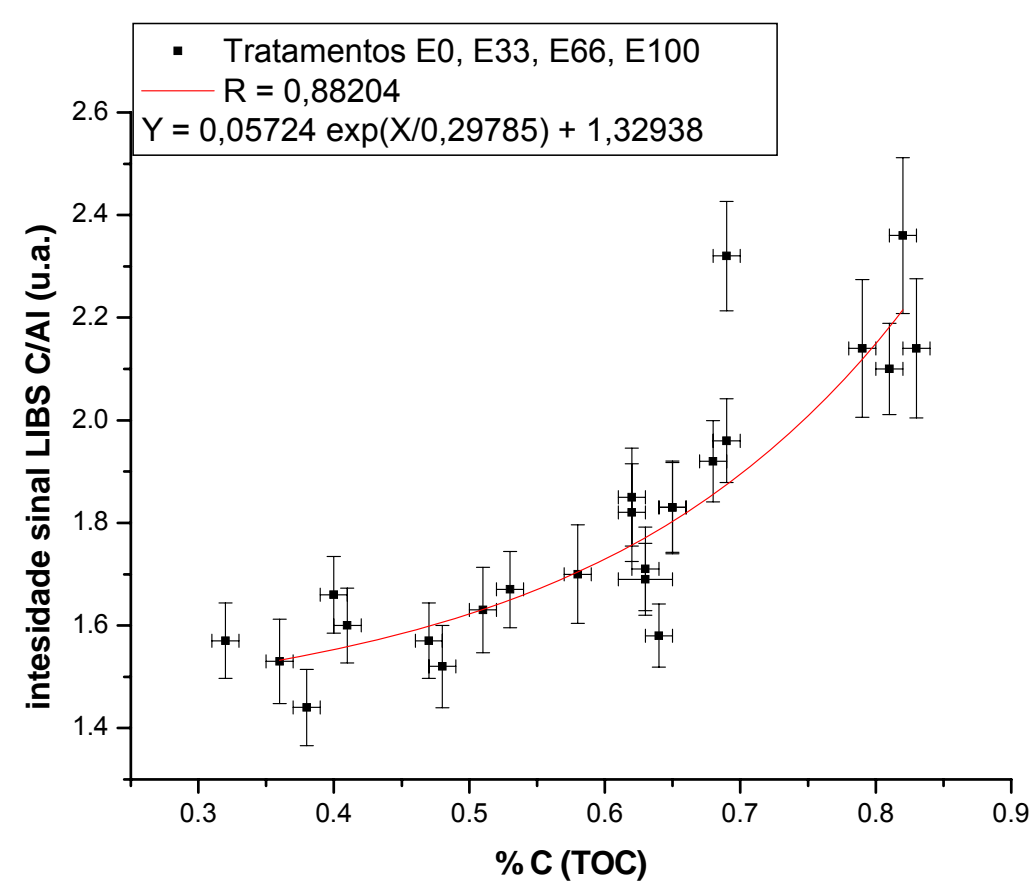

Figura 13: Crescimento exponencial obtido com os tratamentos E0, E33, E66 e E100 utilizando energia do laser em $50 \mathrm{~mJ}$ e acúmulo de 10 tiros.

A equação obtida por esse modelo foi $Y=0,05724 \mathrm{e}^{(\mathrm{X} / 0,29785)}+1,32938$, e o coeficiente de correlação foi igual a 0,88204 , um valor ligeiramente maior ao que foi obtido utilizando o modelo de regressão linear $(R=0,84978)$. Este modelo de crescimento exponencial foi utilizado para se estimar a quantidade de carbono e esta validação pode ser vista na Figura 14. 


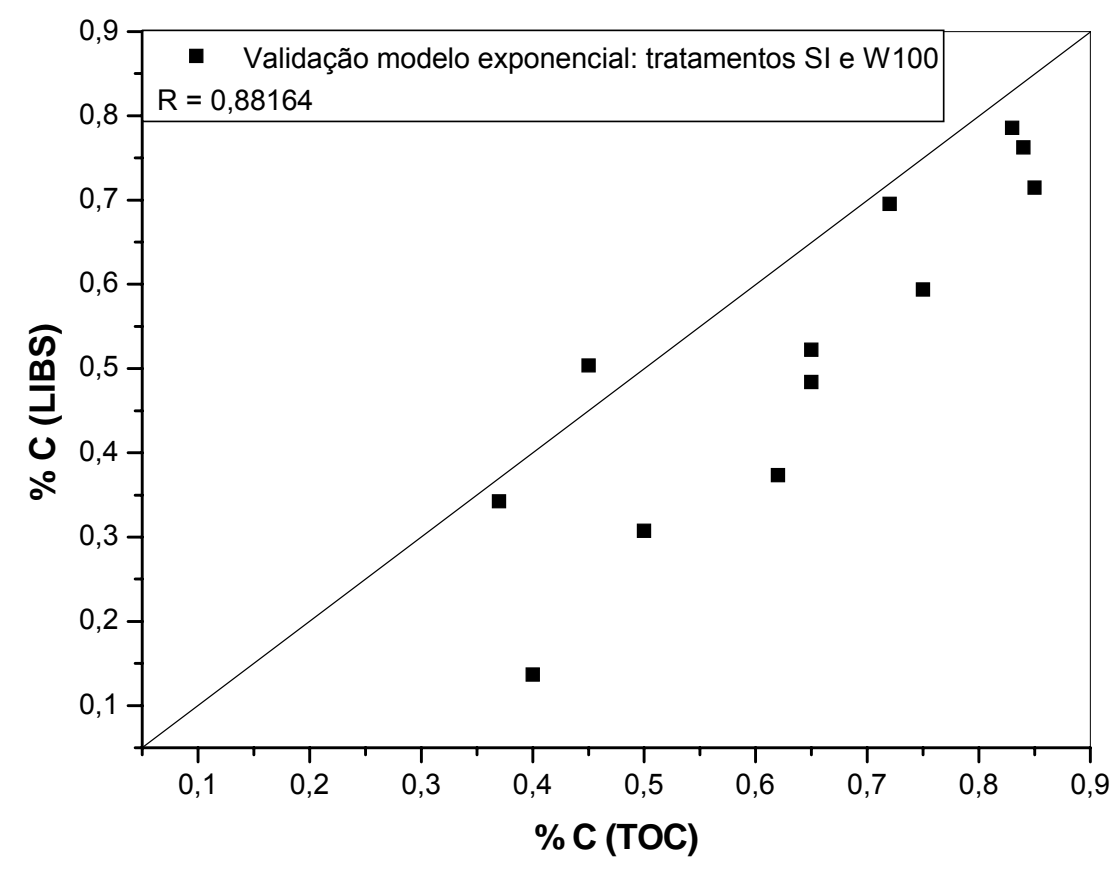

Figura 14: Validação do modelo de crescimento exponencial dos dados obtidos com LIBS para amostras dos tratamentos SI e W100 utilizando energia do laser em $50 \mathrm{~mJ}$ e acúmulo de 10 tiros.

Como pode ser visto na Figura 14, este modelo resultou num coeficiente de correlação ligeiramente maior ao que foi obtido com a regressão linear simples $(0,88164$ em comparação com 0,87377$)$. Assim como ocorreu para a regressão linear simples, aqui também os valores de carbono preditos pelo LIBS foram, em geral, menores que os obtidos pelo TOC. Os valores de concentração de carbono estimados utilizando os 2 modelos podem ser vistos na Tabela 2. 
Tabela 2: Concentrações de carbono estimadas pelo sistema LIBS utilizando o modelo de regressão linear simples e crescimento exponencial, utilizando energia do laser em $50 \mathrm{~mJ}$ e acúmulo de 10 tiros.

\begin{tabular}{ccccc}
\hline Tratamento & $\begin{array}{c}\text { Profundidade } \\
\mathbf{( c m )}\end{array}$ & $\mathbf{C}_{\text {TOC }}(\%)$ & $\begin{array}{c}\mathbf{C}_{\text {LIBS }} \text { modelo } \\
\text { de regressão } \\
\text { linear simples } \\
(\%)\end{array}$ & $\begin{array}{c}\mathbf{C}_{\text {LIBS }} \text { modelo } \\
\text { de crescimento } \\
\text { exponencial } \\
\text { (\%) }\end{array}$ \\
\hline SI & $0-10$ & 0,84 & 0,78 & 0,76 \\
& $10-20$ & 0,85 & 0,70 & 0,71 \\
& $20-40$ & 0,75 & 0,56 & 0,59 \\
& $40-60$ & 0,65 & 0,50 & 0,52 \\
W100 & $60-80$ & 0,45 & 0,48 & 0,50 \\
& $80-100$ & 0,37 & 0,39 & 0,34 \\
& $0-10$ & 0,83 & 0,82 & 0,79 \\
& $10-20$ & 0,72 & 0,67 & 0,69 \\
& $20-40$ & 0,65 & 0,47 & 0,48 \\
& $40-60$ & 0,62 & 0,41 & 0,37 \\
& $60-80$ & 0,50 & 0,38 & 0,31 \\
& $80-100$ & 0,40 & 0,33 & 0,14 \\
\hline
\end{tabular}

Observando os dados presentes na Tabela 2, pode-se constatar que embora o modelo de crescimento exponencial tenha apresentado um coeficiente de correlação ligeiramente maior ao que foi obtido utilizando o modelo de regressão linear simples este, no geral, foi mais eficiente para estimar a quantidade de carbono nas amostras de solo. Foram avaliados os erros nos 2 modelos utilizados na predição. Chamou-se de erro o valor absoluto obtido da diferença entre o valor da concentração de carbono estimada pelo TOC e o valor da concentração de carbono estimada pelo LIBS. O erro médio absoluto é o valor obtido da soma dos erros divido pelo número de amostras utilizadas na validação, ou seja, é a soma dos erros divido por 12. Estes dados podem ser vistos na Tabela 3. 
Tabela 3: Erros de predição utilizando os modelos de regressão linear simples e crescimento exponencial, utilizando energia do laser em $50 \mathrm{~mJ}$ e acúmulo de 10 tiros.

\begin{tabular}{cccc}
\hline Tratamento & Profundidade & $\begin{array}{c}\text { Erro do modelo de } \\
\text { regressão linear } \\
\text { simples }\end{array}$ & $\begin{array}{c}\text { Erro do modelo de } \\
\text { crescimento } \\
\text { exponencial }\end{array}$ \\
\hline SI & $0-10$ & 0,06 & 0,08 \\
& $10-20$ & 0,15 & 0,14 \\
$20-40$ & 0,19 & 0,16 \\
W100 & $40-60$ & 0,15 & 0,13 \\
& $60-80$ & 0,03 & 0,05 \\
& $80-100$ & 0,02 & 0,03 \\
& $0-10$ & 0,01 & 0,04 \\
& $10-20$ & 0,05 & 0,03 \\
& $20-40$ & 0,18 & 0,17 \\
Erro Médio & $40-60$ & 0,21 & 0,25 \\
Absoluto & $60-80$ & 0,12 & 0,19 \\
& $80-100$ & 0,07 & 0,26 \\
& & 0,10 & 0,13 \\
\hline
\end{tabular}

Observando a Tabela 3 podemos constatar novamente que o modelo de regressão linear é mais adequado, pois seu erro médio absoluto foi menor que o erro médio absoluto do modelo de crescimento exponencial.

\subsection{Energia do laser $50 \mathrm{~mJ}$ e acúmulo de 2 tiros}

O número de tiros acumulados foi diminuído para poder estudar este efeito sobre as medidas de carbono. Assim, utilizando a energia do laser em $50 \mathrm{~mJ}$ e acúmulo de 2 tiros os espectros de todas as amostras de todos os tratamentos também precisaram ser corrigidos devido aos mesmos problemas descritos anteriormente. Também foi realizado o estudo para identificar valores discrepantes e assim eliminálos. Estes resultados foram semelhantes aos obtidos anteriormente utilizando a energia do laser em $50 \mathrm{~mJ}$ e acúmulo de 10 tiros.

Realizadas todas as correções foi realizar a regressão linear simples. Esta curva pode ser vista no gráfico da Figura 15. 


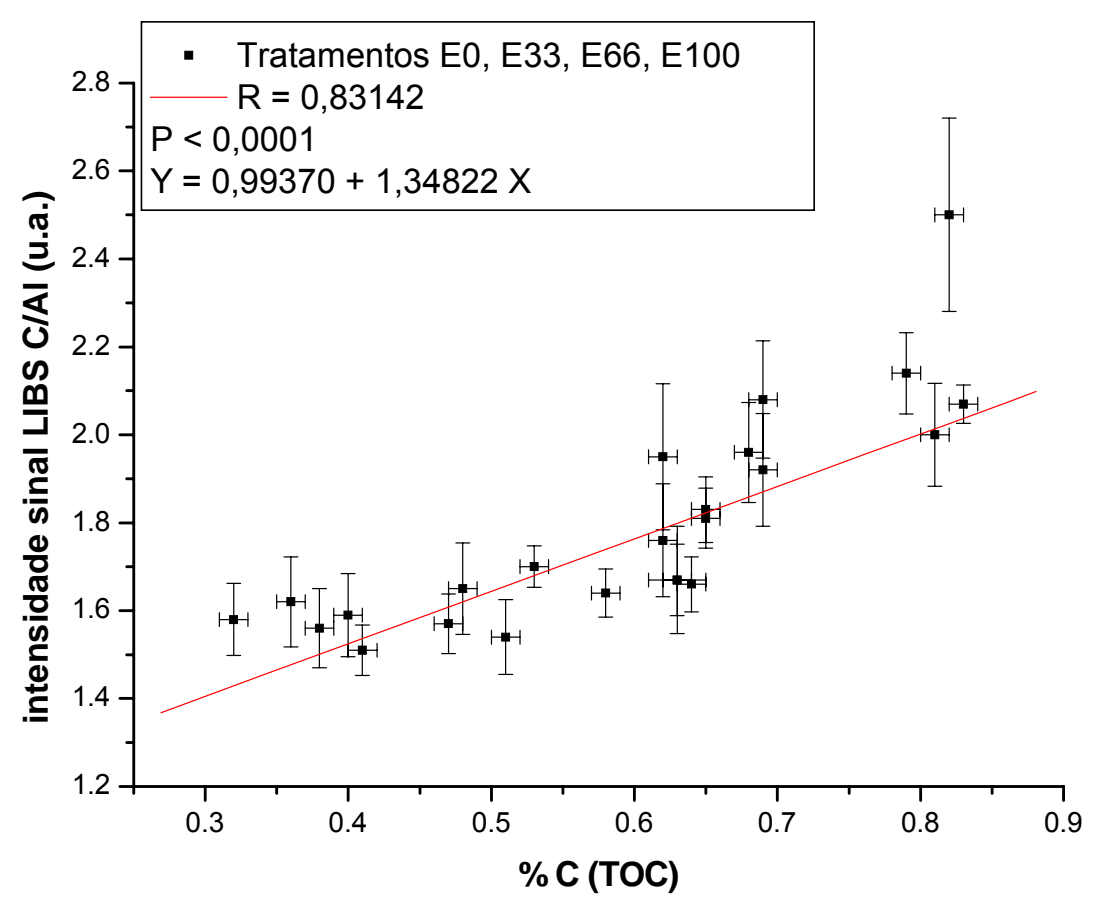

Figura 15: Regressão linear obtida com os tratamentos E0, E33, E66 e E100 utilizando energia do laser em $50 \mathrm{~mJ}$ e acúmulo de 2 tiros.

Para essa curva foi obtida a equação $Y=0,99370+1,34822 X$, e o coeficiente de correlação foi 0,83142 . Como o P-valor aqui também foi muito baixo, o modelo foi aceito e pôde-se validar o método e esta validação pode ser vista na Figura 16. 


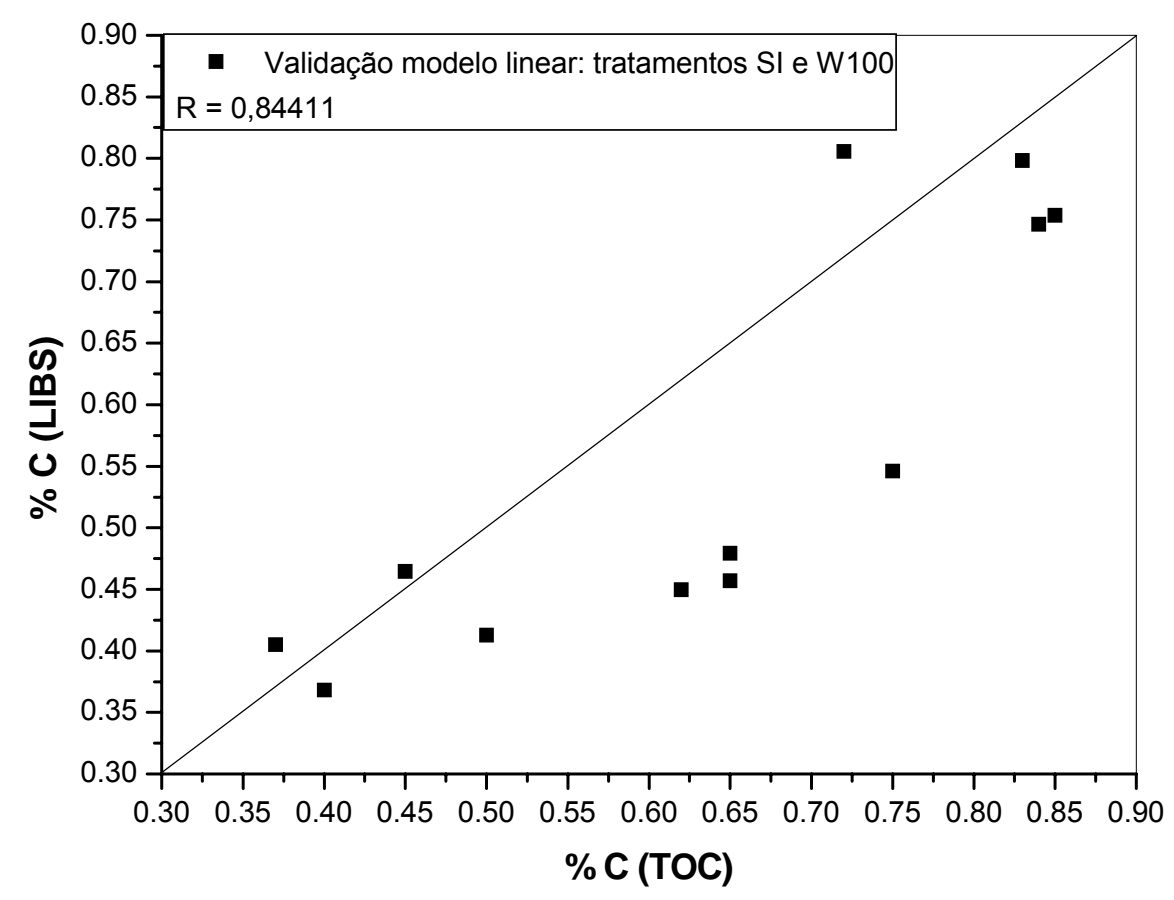

Figura 16: Validação da análise de regressão linear simples dos dados obtidos com LIBS para amostras dos tratamentos SI e W100 utilizando energia do laser em $50 \mathrm{~mJ}$ e acúmulo de 2 tiros.

Assim como para a metodologia utilizando a energia do laser em $50 \mathrm{~mJ}$ e acúmulo de 10 tiros aqui também os valores estimados das porcentagens de carbono, em geral, também foram menores do que as porcentagens estimadas pelo TOC.

Comparando-se a metodologia que utilizou a energia do laser em $50 \mathrm{~mJ}$ e acúmulo de 10 tiros com a metodologia que utilizou a energia do laser em $50 \mathrm{~mJ}$ e acúmulo de 2 tiros pode-se observar que essa última apresentou um coeficiente de correlação ligeiramente menor $(0,84411$ em comparação com 0,87377$)$. Esse fato pode ser atribuído ao maior número de espectros acumulados no primeiro método utilizado para aquisição e, conseqüentemente, maior massa amostrada. Em ambas as metodologias foram feitas 60 medidas utilizando o laser com energia de $50 \mathrm{~mJ}$, porém em uma foram acumulados 10 tiros e em outra foram acumulados 2 tiros a 
cada medida. Ou seja, foram acumulados 600 tiros na primeira metodologia e 120 tiros na segunda. Mesmo após a retirada das medidas que apresentaram valores discrepantes, a diferença ainda manteve-se alta entre o número de tiros acumulados nas duas metodologias.

Assim como para a metodologia utilizando energia do laser em $50 \mathrm{~mJ}$ e acúmulo de 10 tiros, aqui também foi construído um modelo de crescimento exponencial. Este modelo pode ser visto na Figura 17.

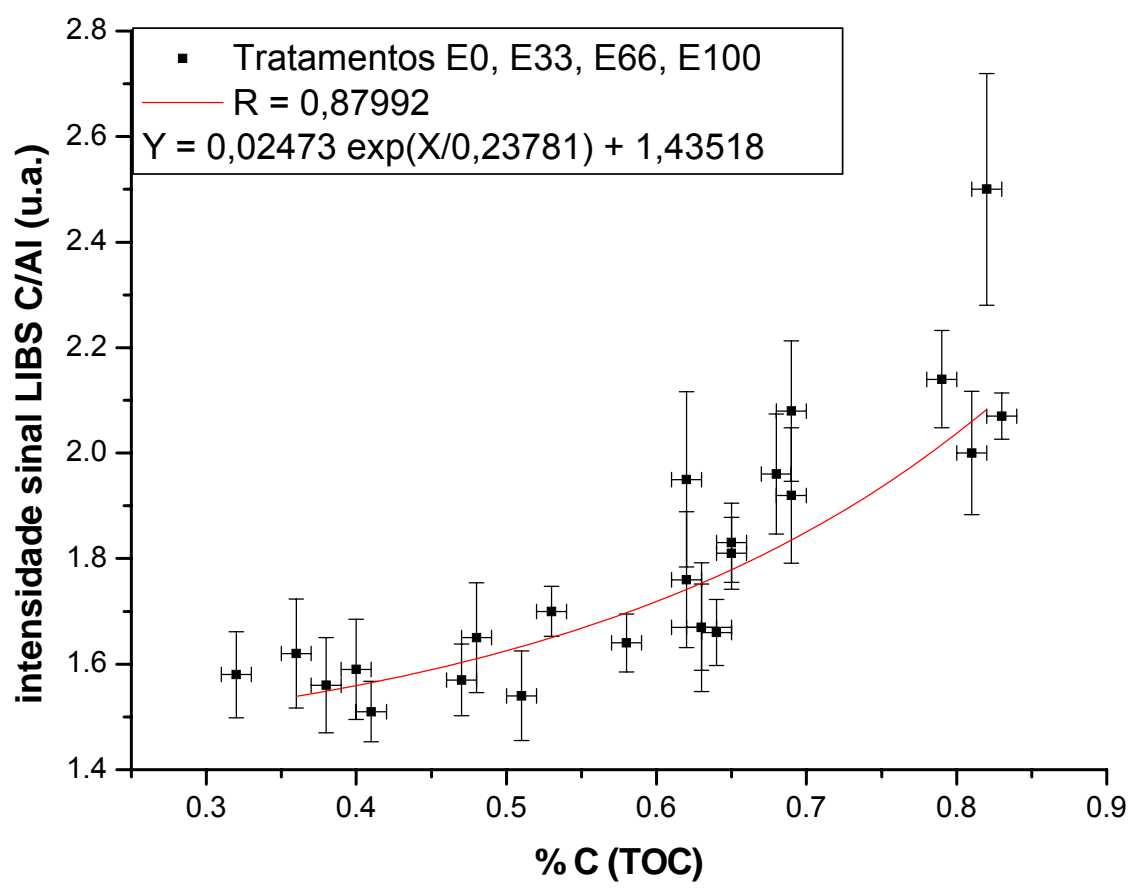

Figura 17: Crescimento exponencial obtido com os tratamentos E0, E33, E66 e E100 utilizando energia do laser em $50 \mathrm{~mJ}$ e acúmulo de 2 tiros.

A equação obtida para este modelo foi $Y=0,02473 \mathrm{e}^{(\mathrm{X} / 0,23781)}+1,433518$, e o coeficiente de correlação foi igual a 0,87992. Este modelo também apresentou um coeficiente de correlação ligeiramente maior que o coeficiente de correlação obtido com o modelo de regressão linear $(0,879921$ frente a 0,83142$)$. Esse modelo de crescimento exponencial também foi utilizado para se estimar a quantidade de carbono nas amostras de solo e essa validação pode ser vista na Figura 18. 


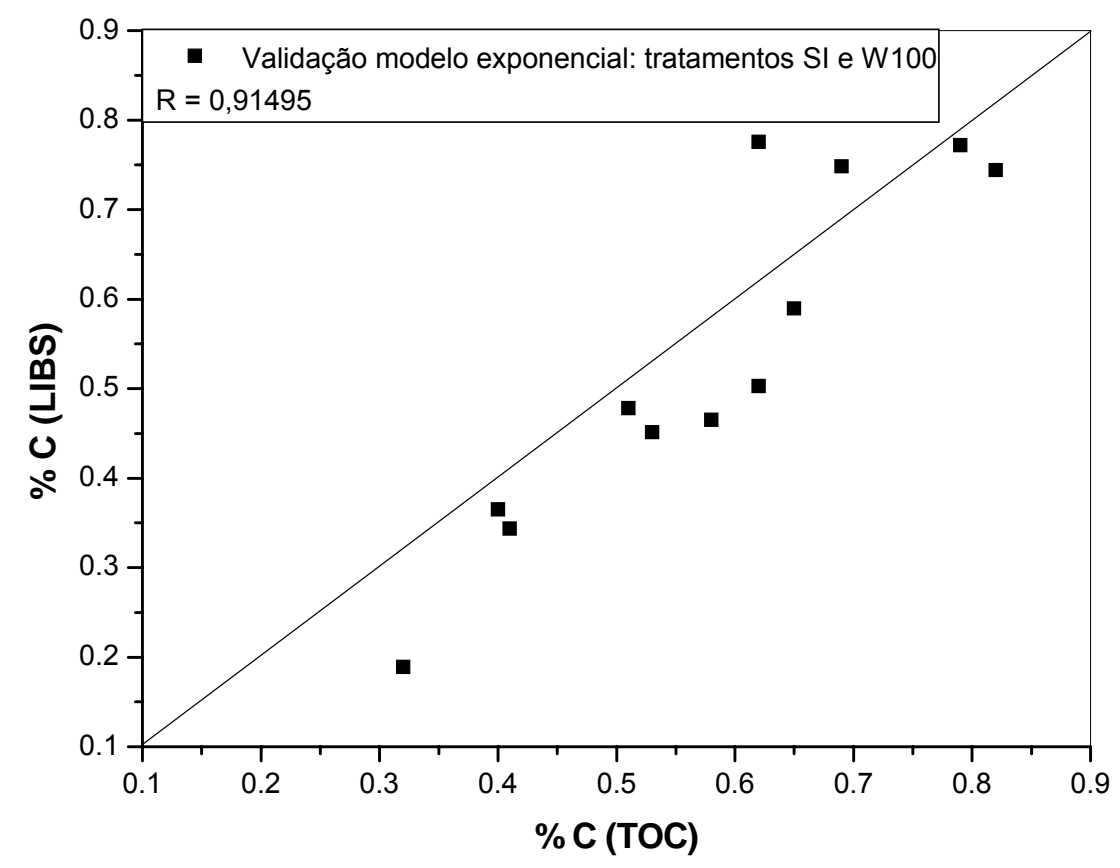

Figura 18: Validação do modelo de crescimento exponencial dos dados obtidos com LIBS para amostras dos tratamentos SI e W100 utilizando energia do laser em $50 \mathrm{~mJ}$ e acúmulo de 2 tiros.

Aqui também pode ser observado que os valores estimados pelo LIBS foram, em geral, menores que os valores estimados pelo TOC. O coeficiente de correlação para esta validação também foi maior que o obtido na validação utilizando o modelo de regressão linear simples $(0,91495$ frente a 0,84411$)$. Mas como pôde ser visto anteriormente, um maior valor de coeficiente de correlação não é suficiente para avaliar qual modelo é mais adequado para estimar a quantidade de carbono em amostras de solo por LIBS. Sendo assim, na Tabela 4 podem ser vistos os valores de concentração de carbono preditos por ambos os modelos. 
Tabela 4: Concentrações de carbono estimadas pelo sistema LIBS utilizando o modelo de regressão linear simples e crescimento exponencial, utilizando energia do laser em $50 \mathrm{~mJ}$ e acúmulo de 2 tiros.

\begin{tabular}{ccccc}
\hline Tratamento & $\begin{array}{c}\text { Profundidade } \\
\mathbf{( c m )}\end{array}$ & $\mathbf{C}_{\text {TOC }}(\%)$ & $\begin{array}{c}\mathbf{C}_{\text {LIBS }} \text { modelo } \\
\text { de regressão } \\
\text { linear simples } \\
\mathbf{( \% )}\end{array}$ & $\begin{array}{c}\mathbf{C}_{\text {LIBS }} \text { modelo } \\
\text { de crescimento } \\
\text { exponencial } \\
\text { (\%) }\end{array}$ \\
\hline SI & $0-10$ & 0,84 & 0,75 & 0,74 \\
& $10-20$ & 0,85 & 0,75 & 0,75 \\
& $20-40$ & 0,75 & 0,55 & 0,59 \\
& $40-60$ & 0,65 & 0,46 & 0,46 \\
W100 & $60-80$ & 0,45 & 0,46 & 0,48 \\
& $80-100$ & 0,37 & 0,41 & 0,34 \\
& $0-10$ & 0,83 & 0,80 & 0,77 \\
& $10-20$ & 0,72 & 0,81 & 0,78 \\
& $20-40$ & 0,65 & 0,48 & 0,50 \\
& $40-60$ & 0,62 & 0,45 & 0,45 \\
& $60-80$ & 0,50 & 0,41 & 0,37 \\
& $80-100$ & 0,40 & 0,37 & 0,19 \\
\hline
\end{tabular}

Com os dados da Tabela 4 é possível observar que apesar do modelo de regressão linear simples ter apresentado um coeficiente de correlação menor, os valores de concentração de carbono preditos por este modelo, em geral, são mais próximos aos valores estimados pelo TOC. Também foi feita a análise dos erros obtidos pelos 2 modelos. Estes podem ser vistos na Tabela 5.

Tabela 5: Erros de predição utilizando os modelos de regressão linear simples e crescimento exponencial, utilizando energia do laser em $50 \mathrm{~mJ}$ e acúmulo de 2 tiros.

\begin{tabular}{cccc}
\hline Tratamento & Profundidade & $\begin{array}{c}\text { Erro do modelo de } \\
\text { regressão linear } \\
\text { simples }\end{array}$ & $\begin{array}{c}\text { Erro do modelo de } \\
\text { crescimento } \\
\text { exponencial }\end{array}$ \\
\hline SI & $0-10$ & 0,09 & 0,10 \\
& $10-20$ & 0,10 & 0,10 \\
$20-40$ & 0,20 & 0,16 \\
& $40-60$ & 0,19 & 0,19 \\
W100 & $60-80$ & 0,01 & 0,03 \\
& $80-100$ & 0,04 & 0,03 \\
& $0-10$ & 0,03 & 0,06 \\
& $10-20$ & 0,09 & 0,06 \\
& $20-40$ & 0,17 & 0,15 \\
& $40-60$ & 0,17 & 0,17 \\
Erro Médio & $60-80$ & 0,09 & 0,13 \\
Absoluto & $80-100$ & 0,03 & 0,21 \\
& & 0,10 & 0,12 \\
\hline
\end{tabular}


Podemos constatar novamente, observando a Tabela 5, que o modelo de regressão linear é mais adequado, pois seu erro médio absoluto foi menor que o erro médio absoluto do modelo de crescimento exponencial.

\subsection{Energia do laser $25 \mathrm{~mJ}$ e acúmulo de 10 tiros}

Para fins comparativos, diminui-se a energia do laser para poder se analisar o efeito sobre as medições. A partir desse ponto serão discutidos os dados obtidos utilizando-se a energia do laser em $25 \mathrm{~mJ}$ e um acúmulo de 10 tiros. Após terem sido realizadas todas as correções descritas anteriormente, a regressão linear simples foi realizada e pode ser vista na Figura 19.

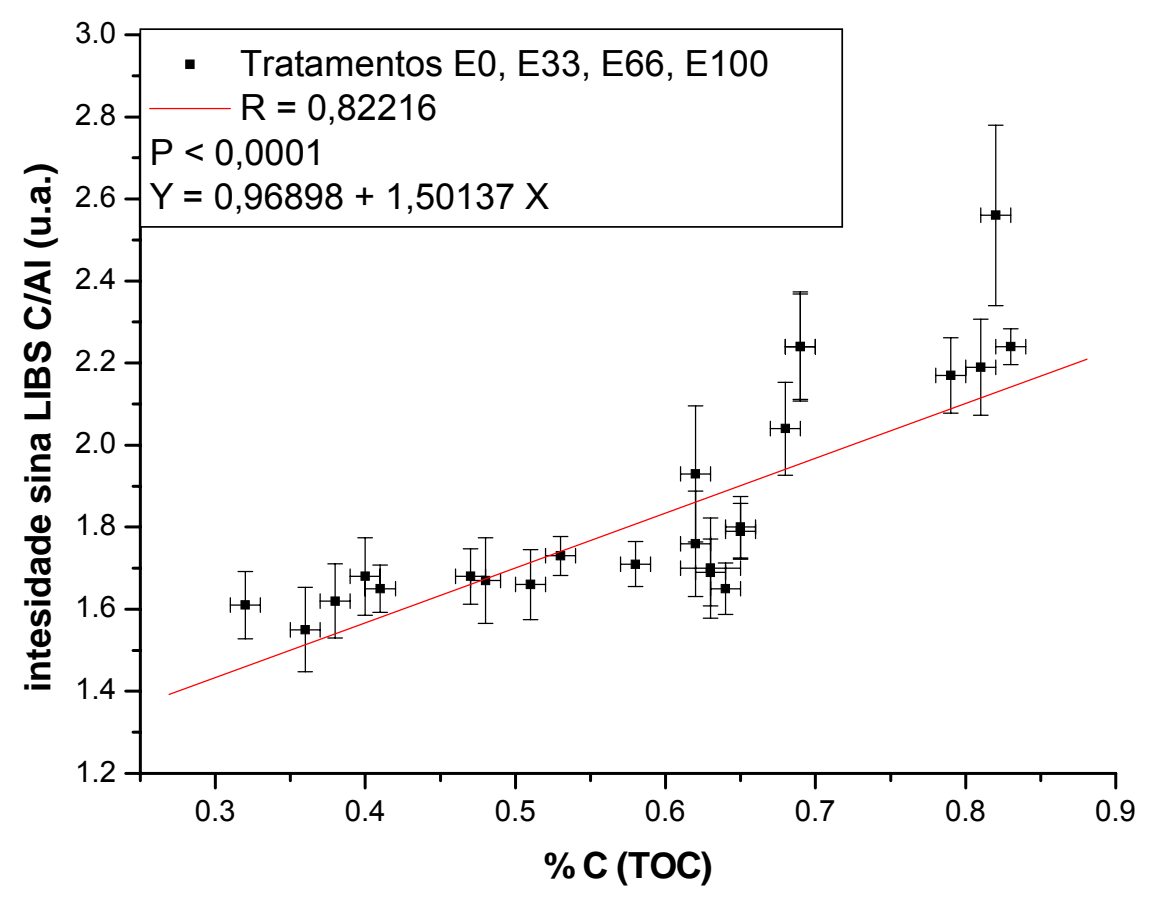

Figura 19: Regressão linear obtida com os tratamentos E0, E33, E66 e E100 utilizando energia do laser em $25 \mathrm{~mJ}$ e acúmulo de 10 tiros.

A equação obtida por essa curva foi $Y=0,96898+1,50137 X$, e o coeficiente de correlação foi 0,82216. Este modelo de regressão linear também foi aceito, pois o P- 
valor também foi muito baixo. Com isso, a validação para esse modelo pode ser vista na Figura 20.

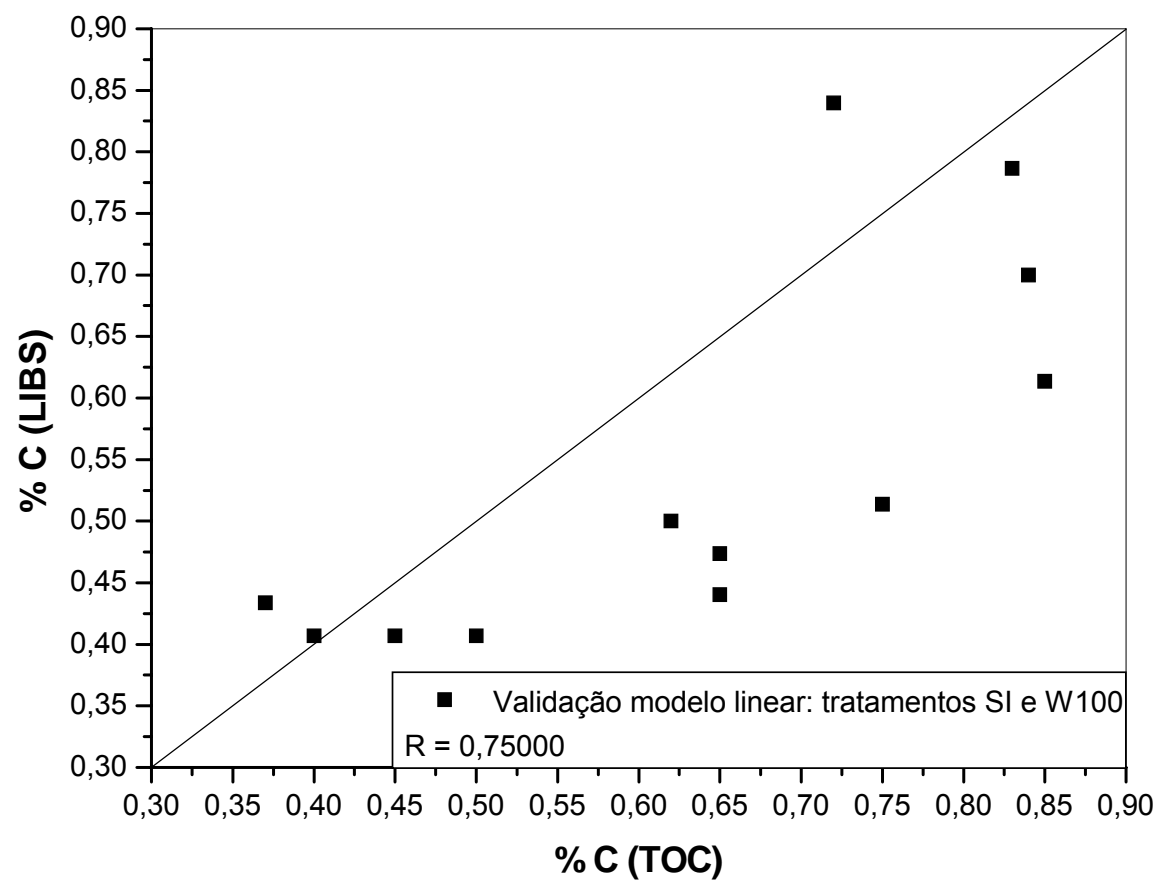

Figura 20: Validação da análise de regressão linear simples dos dados obtidos com LIBS para amostras dos tratamentos SI e W100 utilizando energia do laser em $25 \mathrm{~mJ}$ e acúmulo de 10 tiros.

Comparando-se com as outras 2 metodologias que utilizaram a energia do laser em 50 mJ e acúmulo de 10 e 2 tiros, a utilização do laser com energia em 25 mJ e acúmulo de 10 tiros apresentou um coeficiente de correlação menor do que as outras duas $(0,75$ em comparação com 0,87 e 0,84).

Maiores energias do laser levam a formação de plasmas com concentrações maiores do material ablado, devido à quantidade em massa que é amostrada ser maior. Sendo assim, ao se diminuir a energia do laser nesta metodologia, a quantidade de carbono no plasma foi menor, em comparação com as metodologias que utilizaram a energia do laser em $50 \mathrm{~mJ}$. Como este solo que foi analisado apresenta valores muito baixos de quantidade de carbono esta diminuição pode ter 
contribuído para esta diferença entre os resultados encontrados nas três metodologias.

Um modelo de crescimento exponencial também foi utilizado e pode ser visto na Figura 21.

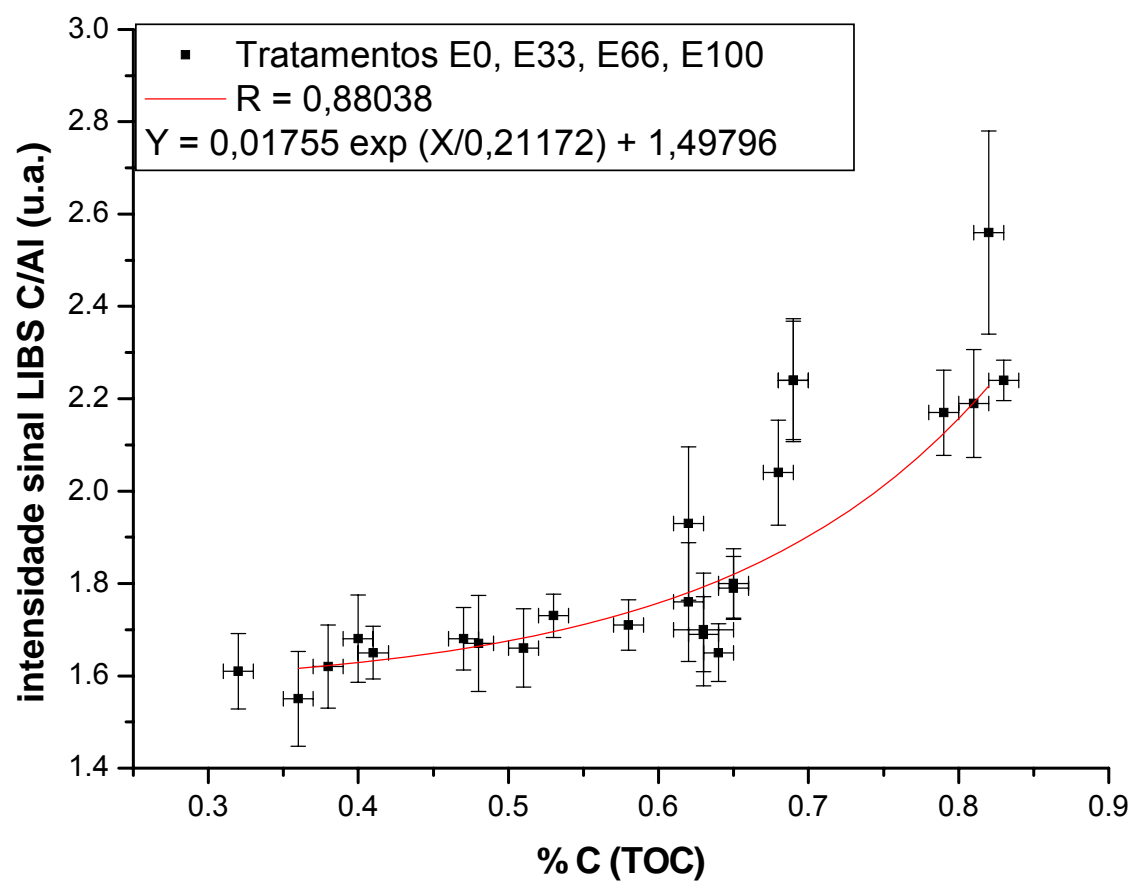

Figura 21: Crescimento exponencial obtido com os tratamentos E0, E33, E66 e E100 utilizando energia do laser em $25 \mathrm{~mJ}$ e acúmulo de 10 tiros.

A equação obtida para este modelo foi $Y=0,01755 \mathrm{e}^{(\mathrm{X} / 0,21172)}+1,49796$, e o coeficiente de correlação obtido foi igual a 0,88038 que, assim como ocorrido anteriormente, é ligeiramente superior ao coeficiente de correlação obtido no modelo de regressão linear simples. Assim, o modelo de crescimento foi validado e esta validação pode ser vista na Figura 22. 


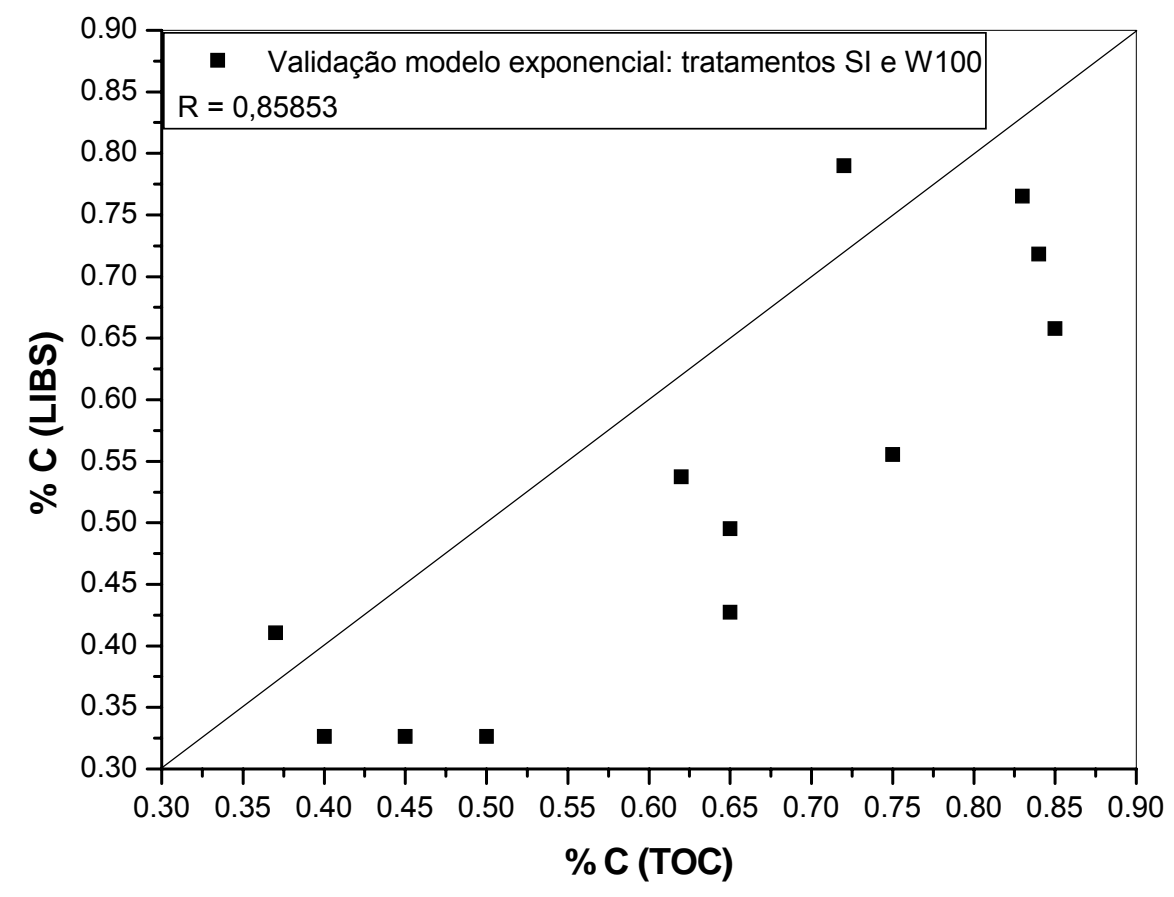

Figura 22: Validação do modelo de crescimento exponencial dos dados obtidos com LIBS para amostras dos tratamentos SI e W100 utilizando energia do laser em $25 \mathrm{~mJ}$ e acúmulo de 10 tiros.

Pode ser observado pela Figura 22 que os valores estimados pelo LIBS foram, em geral, menores que os valores estimados pelo TOC e o coeficiente de correlação para esta validação também foi maior que o obtido na validação utilizando o modelo de regressão linear simples $(0,85853$ frente a 0,75000$)$. Para avaliar melhor qual modelo foi mais adequado para estimar a quantidade de carbono em amostras de solo por LIBS, foram avaliados os valores de concentração de carbono estimados por ambos os modelos. Assim sendo, na Tabela 6 podem ser vistos os valores de concentração de carbono preditos pelos modelos. 
Tabela 6: Concentrações de carbono estimadas pelo sistema LIBS utilizando o modelo de regressão linear simples e crescimento exponencial, utilizando energia do laser em $25 \mathrm{~mJ}$ e acúmulo de 10 tiros.

\begin{tabular}{ccccc}
\hline Tratamento & $\begin{array}{c}\text { Profundidade } \\
\text { (cm) }\end{array}$ & $\mathbf{C}_{\text {TOC }}$ (\%) & $\begin{array}{c}\mathbf{C}_{\text {LIBS }} \text { modelo } \\
\text { de regressão } \\
\text { linear simples } \\
(\%)\end{array}$ & $\begin{array}{c}\mathbf{C}_{\text {LIBS }} \text { modelo } \\
\text { de crescimento } \\
\text { exponencial } \\
\text { (\%) }\end{array}$ \\
\hline SI & $0-10$ & 0,84 & 0,70 & 0,72 \\
& $10-20$ & 0,85 & 0,61 & 0,66 \\
& $20-40$ & 0,75 & 0,51 & 0,56 \\
& $40-60$ & 0,65 & 0,44 & 0,43 \\
W100 & $60-80$ & 0,45 & 0,41 & 0,33 \\
& $80-100$ & 0,37 & 0,43 & 0,41 \\
& $0-10$ & 0,83 & 0,79 & 0,77 \\
& $10-20$ & 0,72 & 0,84 & 0,79 \\
& $20-40$ & 0,65 & 0,47 & 0,50 \\
& $40-60$ & 0,62 & 0,50 & 0,54 \\
& $60-80$ & 0,50 & 0,41 & 0,33 \\
& $80-100$ & 0,40 & 0,41 & 0,33 \\
\hline
\end{tabular}

Contrariamente ao que ocorreu nas metodologias apresentadas anteriormente, aqui o modelo de crescimento exponencial foi, em geral, mais eficiente para estimar a quantidade de carbono nas amostras de solo. Para avaliar melhor este resultado, foi feita a análise dos erros obtidos pelos 2 modelos. Estes podem ser vistos na Tabela 7.

Tabela 7: Erros de predição utilizando os modelos de regressão linear simples e crescimento exponencial utilizando energia do laser em $25 \mathrm{~mJ}$ e acúmulo de 10 tiros.

\begin{tabular}{cccc}
\hline Tratamento & Profundidade & $\begin{array}{c}\text { Erro do modelo de } \\
\text { regressão linear } \\
\text { simples }\end{array}$ & $\begin{array}{c}\text { Erro do modelo de } \\
\text { crescimento } \\
\text { exponencial }\end{array}$ \\
\hline SI & $0-10$ & 0,14 & 0,12 \\
& $10-20$ & 0,24 & 0,19 \\
& $20-40$ & 0,24 & 0,19 \\
W100 & $40-60$ & 0,21 & 0,22 \\
& $60-80$ & 0,04 & 0,12 \\
& $80-100$ & 0,06 & 0,04 \\
& $0-10$ & 0,04 & 0,06 \\
& $10-20$ & 0,12 & 0,07 \\
& $20-40$ & 0,18 & 0,15 \\
Erro Médio & $40-60$ & 0,12 & 0,08 \\
Absoluto & $60-80$ & 0,09 & 0,17 \\
& $80-100$ & 0,01 & 0,07 \\
& & 0,12 & 0,12 \\
\hline
\end{tabular}


Apesar dos valores estimados pelo modelo de crescimento exponencial, no geral, terem sido mais próximos aos valores estimados pelo TOC, seu erro médio absoluto é igual ao erro médio absoluto apresentado pelo modelo de regressão linear simples. Assim sendo, houve uma tendência de que, neste caso, o modelo de crescimento exponencial foi mais adequado para se estimar a quantidade de carbono.

\subsection{Energia do laser $25 \mathrm{~mJ}$ e acúmulo de 2 tiros}

Finalizando o estudo para uma melhor maneira de se realizar as medidas LIBS, manteve-se a energia do laser em $25 \mathrm{~mJ}$ e diminui-se o número de tiros acumulados para poder analisar este efeito sobre as medições. Serão discutidos, a partir desse ponto, os dados obtidos utilizando-se a energia do laser em $25 \mathrm{~mJ}$ e um acúmulo de 2 tiros. Com esta metodologia foi realizada a regressão linear simples que pode ser vista na Figura 23.

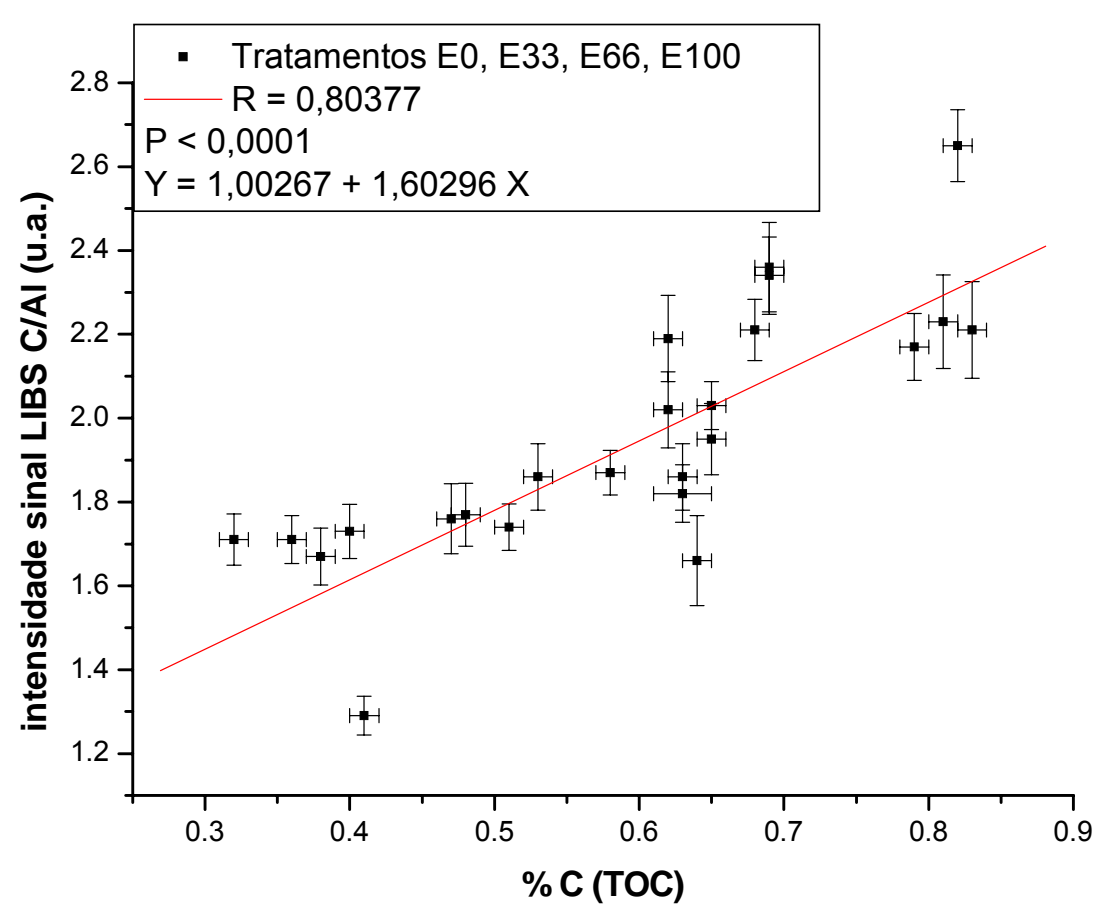


Figura 23: Regressão linear obtida com os tratamentos E0, E33, E66 e E100 utilizando energia do laser em $25 \mathrm{~mJ}$ e acúmulo de 2 tiros.

Com esta curva obteve-se a equação $Y=1,00267+1,60296 \mathrm{X}$, e o coeficiente de correlação foi 0,80377 . Devido ao baixo valor apresentado pelo P-valor, este modelo foi aceito e sua validação pode ser vista na Figura 24.

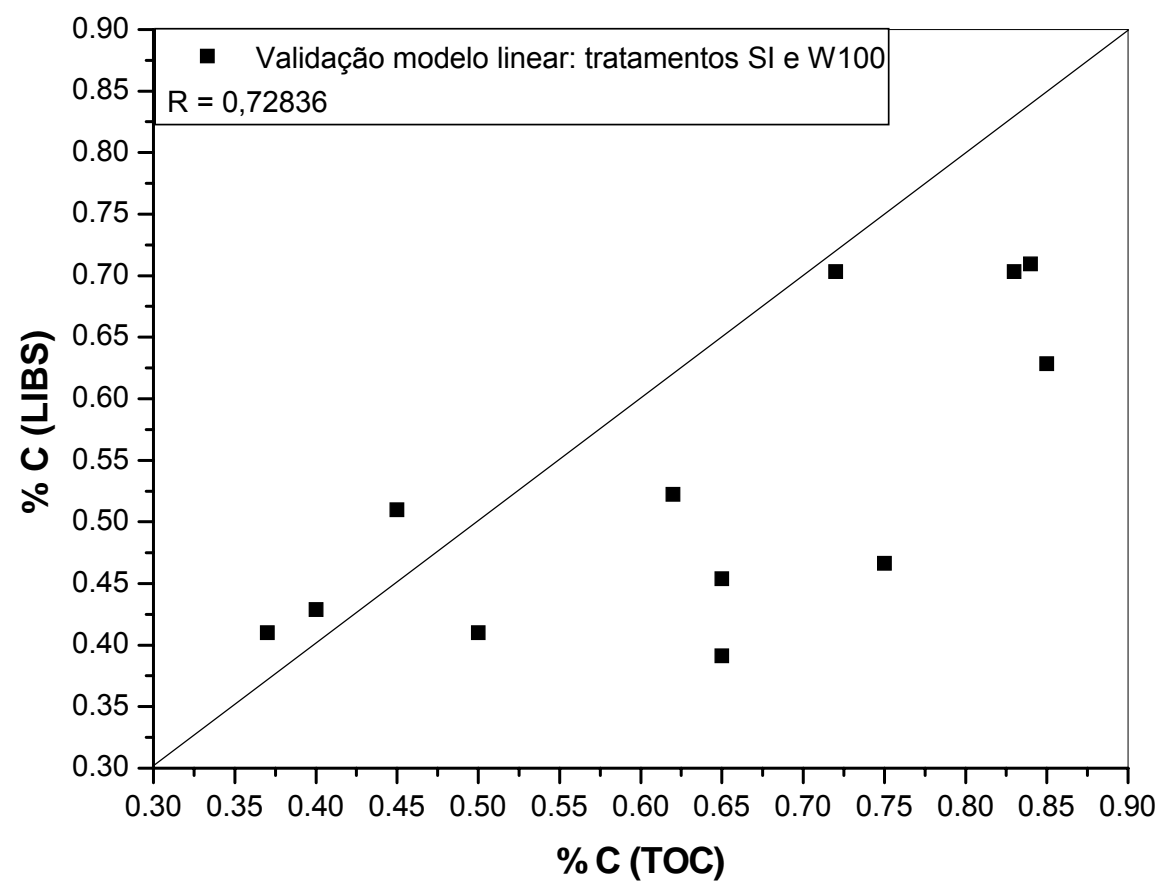

Figura 24: Validação da análise de regressão linear simples dos dados obtidos com LIBS para amostras dos tratamentos SI e W100, utilizando energia do laser em 25 mJ e acúmulo de 2 tiros.

Como pode ser observado na Figura 24, esta metodologia foi a que apresentou o menor coeficiente de correlação $(R=0,72836)$ dentre todas as metodologias utilizadas. Esse fato pode ser devido a menor quantidade de massa amostrada nessa última metodologia em comparação com as outras 3 descritas anteriormente.

Assim como foi feito para as outras metodologias, na Figura 25 pode ser visto o modelo de crescimento exponencial que foi utilizado. 


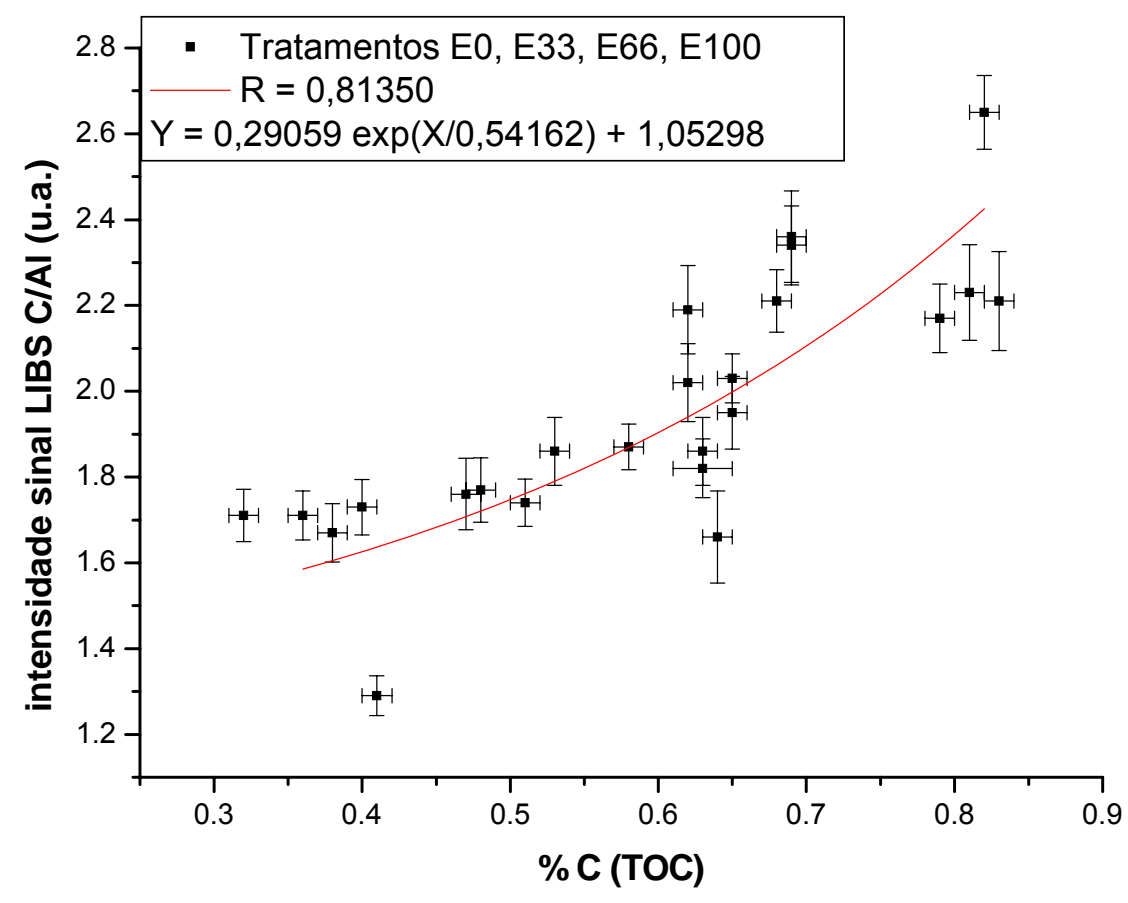

Figura 25: Crescimento exponencial obtido com os tratamentos E0, E33, E66 e E100 utilizando energia do laser em $25 \mathrm{~mJ}$ e acúmulo de 2 tiros.

A equação obtida para este modelo foi $Y=0,29059 \mathrm{e}^{(\mathrm{X} / 0,54162)}+1,05298$, e o coeficiente de correlação obtido foi igual a 0,81350, que é ligeiramente superior ao coeficiente de correlação obtido no modelo de regressão linear simples. Assim, o modelo de crescimento foi validado e esta validação pode ser vista na Figura 26. 


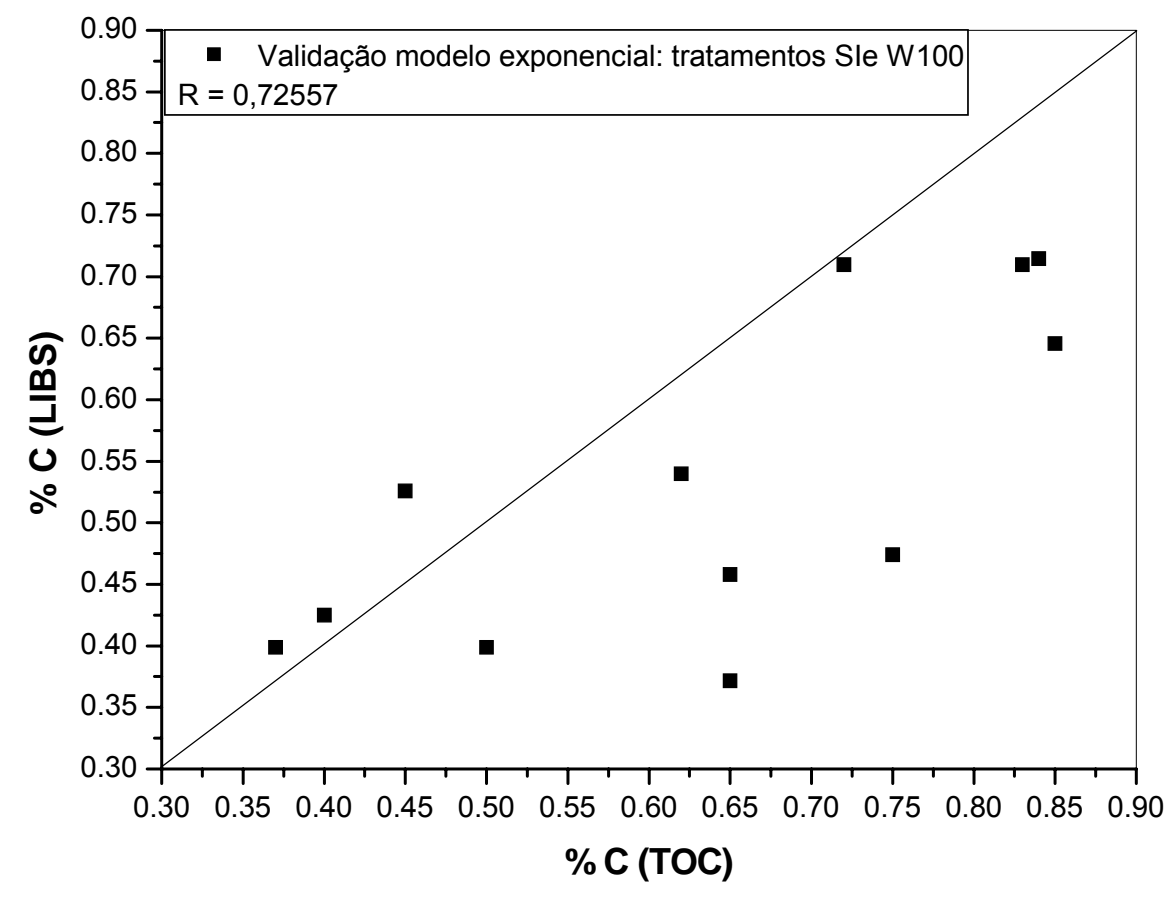

Figura 26: Validação do modelo de crescimento exponencial dos dados obtidos com LIBS para amostras dos tratamentos SI e W100 utilizando energia do laser em $25 \mathrm{~mJ}$ e acúmulo de 2 tiros.

Contrariamente ao que ocorreu nas outras metodologias utilizadas, aqui o coeficiente de correlação obtido para a validação utilizando o modelo de crescimento exponencial não foi superior ao coeficiente de correlação que foi obtido utilizando o modelo de regressão linear simples. Para avaliar melhor qual modelo foi mais adequado para estimar a quantidade de carbono em amostras de solo por LIBS, foram avaliados os valores de concentração de carbono estimados por ambos os modelos. Assim sendo, na Tabela 8 podem ser vistos os valores de concentração de carbono preditos pelos modelos. 
Tabela 8: Concentrações de carbono estimadas pelo sistema LIBS utilizando o modelo de regressão linear simples e crescimento exponencial utilizando energia do laser em $25 \mathrm{~mJ}$ e acúmulo de 2 tiros.

\begin{tabular}{ccccc}
\hline Tratamento & $\begin{array}{c}\text { Profundidade } \\
\text { (cm) }\end{array}$ & $\mathbf{C}_{\text {TOC }}$ (\%) & $\begin{array}{c}\mathbf{C}_{\text {LIBS }} \text { modelo } \\
\text { de regressão } \\
\text { linear simples } \\
(\%)\end{array}$ & $\begin{array}{c}\mathbf{C}_{\text {LIBS }} \text { modelo } \\
\text { de crescimento } \\
\text { exponencial } \\
\text { (\%) }\end{array}$ \\
\hline SI & $0-10$ & 0,84 & 0,71 & 0,72 \\
& $10-20$ & 0,85 & 0,63 & 0,65 \\
& $20-40$ & 0,75 & 0,47 & 0,47 \\
& $40-60$ & 0,65 & 0,39 & 0,37 \\
W100 & $60-80$ & 0,45 & 0,51 & 0,53 \\
& $80-100$ & 0,37 & 0,41 & 0,40 \\
& $0-10$ & 0,83 & 0,70 & 0,71 \\
& $10-20$ & 0,72 & 0,70 & 0,71 \\
& $20-40$ & 0,65 & 0,45 & 0,46 \\
& $40-60$ & 0,62 & 0,52 & 0,54 \\
& $60-80$ & 0,50 & 0,41 & 0,40 \\
& $80-100$ & 0,40 & 0,43 & 0,43 \\
\hline
\end{tabular}

Assim como ocorreu na metodologia apresentada anteriormente, o modelo de crescimento exponencial foi, em geral, mais eficiente para estimar a quantidade de carbono nas amostras de solo. Para avaliar melhor este resultado, foi feita a análise dos erros obtidos pelos 2 modelos. Estes podem ser vistos na Tabela 9.

Tabela 9: Erros de predição utilizando os modelos de regressão linear simples e crescimento exponencial utilizando energia do laser em $25 \mathrm{~mJ}$ e acúmulo de 2 tiros.

\begin{tabular}{cccc}
\hline Tratamento & Profundidade & $\begin{array}{c}\text { Erro do modelo de } \\
\text { regressão linear } \\
\text { simples }\end{array}$ & $\begin{array}{c}\text { Erro do modelo de } \\
\text { crescimento } \\
\text { exponencial }\end{array}$ \\
\hline SI & $0-10$ & 0,13 & 0,12 \\
& $10-20$ & 0,22 & 0,20 \\
$20-40$ & 0,28 & 0,28 \\
& $40-60$ & 0,26 & 0,28 \\
W100 & $60-80$ & 0,06 & 0,08 \\
& $80-100$ & 0,04 & 0,03 \\
& $0-10$ & 0,13 & 0,12 \\
& $10-20$ & 0,02 & 0,01 \\
& $20-40$ & 0,20 & 0,19 \\
& $40-60$ & 0,10 & 0,08 \\
Erro Médio & $60-80$ & 0,09 & 0,10 \\
Absoluto & $80-100$ & 0,03 & 0,03 \\
& & 0,13 & 0,13 \\
\hline
\end{tabular}


Como pode ser visto na Tabela 9, o modelo de crescimento exponencial apresentou um erro absoluto igual ao erro médio absoluto do modelo de regressão linear simples e, como ocorrido anteriormente, pode-se apenas dizer que houve uma tendência de que o modelo de crescimento exponencial foi mais adequado para estimar a quantidade de carbono nas amostras de solo.

\subsection{Comparação entre as metodologias}

Finalizando a discussão paras as amostras moídas criogenicamente, as 4 metodologias empregadas foram comparadas para avaliar qual delas foi a mais eficiente para estimar a quantidade de carbono nas amostras de solo. Na Tabela 10 podem ser vistos todos os valores de concentração estimados pelo TOC e pelo LIBS, nas 4 metodologias, utilizando o modelo de regressão linear simples.

Tabela 10: Comparação entre os valores de concentração estimados pelo LIBS utilizando o modelo de regressão linear simples.

\begin{tabular}{lcccccc}
\hline Tratamento & $\begin{array}{c}\text { Profundidade } \\
\mathbf{( c m )}\end{array}$ & $\mathbf{C}_{\text {TOC }} \mathbf{( \% )}$ & $\begin{array}{c}\mathbf{C}_{\text {LIBS }} \\
\text { energia } \\
\mathbf{5 0} \mathbf{~ m j ~ 1 0 ~} \\
\text { tiros (\%) }\end{array}$ & $\begin{array}{c}\mathbf{C}_{\text {LIBS }} \\
\text { energia } \\
\mathbf{5 0} \mathbf{~ m J ~ 2 ~} \\
\text { tiros (\%) }\end{array}$ & $\begin{array}{c}\mathbf{C}_{\text {LIBS }} \\
\text { energia } \\
\mathbf{2 5} \mathbf{~ m j ~ 1 0 ~} \\
\text { tiros (\%) }\end{array}$ & $\begin{array}{c}\mathbf{C}_{\text {LIBS }} \\
\text { energia } \\
\mathbf{2 5} \mathbf{~ m J ~ 2 ~} \\
\text { tiros (\%) }\end{array}$ \\
\hline SI & $0-10$ & 0,84 & 0,78 & 0,75 & 0,70 & 0,71 \\
& $10-20$ & 0,85 & 0,70 & 0,75 & 0,61 & 0,63 \\
& $20-40$ & 0,75 & 0,56 & 0,55 & 0,51 & 0,47 \\
& $40-60$ & 0,65 & 0,50 & 0,46 & 0,44 & 0,39 \\
W100 & $60-80$ & 0,45 & 0,48 & 0,46 & 0,41 & 0,51 \\
& $80-100$ & 0,37 & 0,39 & 0,41 & 0,43 & 0,41 \\
& $0-10$ & 0,83 & 0,82 & 0,80 & 0,79 & 0,70 \\
& $10-20$ & 0,72 & 0,67 & 0,81 & 0,84 & 0,70 \\
& $20-40$ & 0,65 & 0,47 & 0,48 & 0,47 & 0,45 \\
& $40-60$ & 0,62 & 0,41 & 0,45 & 0,50 & 0,52 \\
& $60-80$ & 0,50 & 0,38 & 0,41 & 0,41 & 0,41 \\
& $80-100$ & 0,40 & 0,33 & 0,37 & 0,41 & 0,43 \\
\hline
\end{tabular}

Como pode ser visto na Tabela 10, a metodologia que utilizou a energia do laser em $50 \mathrm{~mJ}$ e acúmulo de 10 tiros foi a que apresentou valores mais próximos, no geral, aos valores de concentração estimados pelo TOC. Na Tabela 11 podem ser vistos os valores dos erros médios absolutos obtidos para as 4 metodologias utilizando o modelo de regressão linear simples. 
Tabela 11: Erros médios absolutos obtidos pelas 4 metodologias utilizando o modelo de regressão linear simples.

\begin{tabular}{lc}
\hline Metodologia & Erro Médio Absoluto \\
\hline Energia $50 \mathrm{~mJ} 10$ tiros & 0,10 \\
Energia $50 \mathrm{~mJ} 2$ tiros & 0,10 \\
Energia $25 \mathrm{~mJ} 10$ tiros & 0,12 \\
Energia $25 \mathrm{~mJ} 2$ tiros & 0,11 \\
\hline
\end{tabular}

Observando os dados da Tabela 11, pode-se dizer que as melhores metodologias foram as que utilizaram a energia máxima do laser $(50 \mathrm{~mJ})$ pois foram as que apresentaram o menor erro médio absoluto. Avaliando os dados das Tabelas 10 e 11, pode-se apenas dizer que há uma tendência de que a metodologia que utilizou energia do laser em $50 \mathrm{~mJ}$ e acúmulo de 10 tiros seja a mais adequada para se estimar a quantidade de carbono nas amostras de solo.

Os modelos de regressão linear, para as metodologias que utilizaram a energia máxima do laser, foram mais adequados para se estimar a concentração de carbono nas amostras de solo do que os modelos de crescimento exponencial. Fato que comprova isto é que os valores dos erros médios absolutos obtidos nos modelos de regressão linear foram menores do que os obtidos utilizando o modelo de crescimento exponencial. Já para as metodologias que utilizaram a energia do laser em $25 \mathrm{~mJ}$ nada pode ser dito claramente, pois os valores do erros médios absolutos foram iguais. Pode-se apenas dizer que os modelos de crescimento exponencial apresentam uma tendência de se ajustar melhor nessa condição de energia do laser. Esses valores de erros médios absolutos, para ambos os modelos, podem ser visto na Tabela 12. 
Tabela 12: Erros médios absolutos obtidos com os modelos de regressão linear simples e crescimento exponencial.

\begin{tabular}{lcc}
\hline Metodologia & $\begin{array}{c}\text { Erro médio absoluto } \\
\text { modelo de regressão } \\
\text { linear simples }\end{array}$ & $\begin{array}{c}\text { Erro médio absoluto } \\
\text { modelo de crescimento } \\
\text { exponencial }\end{array}$ \\
\hline Energia $50 \mathrm{~mJ} 10$ tiros & 0,10 & 0,13 \\
Energia $50 \mathrm{~mJ} 2$ tiros & 0,10 & 0,12 \\
Energia 25 mJ 10 tiros & 0,12 & 0,12 \\
Energia 25 mJ 2 tiros & 0,13 & 0,13 \\
\hline
\end{tabular}

Com isso, constatou-se que a melhor metodologia para se estimar a concentração de carbono nas amostras de solo utilizadas foi utilizando energia do laser em 50 mJ e acúmulo de 10 tiros. Há uma tendência de que o modelo de regressão linear simples possa fazer estimativas mais precisas, como pode ser observado na Tabela 2.

\subsubsection{Amostras não moídas}

Para se avaliar a influência do tamanho das partículas e, conseqüentemente, maior heterogeneidade das amostras de solo sobre as determinações utilizando LIBS, utilizou-se as amostras de solo dos mesmos 6 tratamentos que apenas foram peneiradas, não foram moídas em moinho criogênico.

Devido aos resultados previamente obtidos com as amostras moídas criogenicamente, as medidas LIBS foram realizadas apenas utilizando a energia do laser em 50 mJ e acúmulo de 10 tiros, já que essa metodologia apresentou melhor resultado. Sob essas condições, foram realizadas 60 medidas de cada amostra procedente de cada tratamento. Assim como para as amostras moídas, os espectros obtidos para as amostras não moídas também sofreram os mesmos processos de correção do sinal de fundo antes que fossem realizadas as análises estatísticas. 
Também foi realizada a análise para se identificar medidas discrepantes e, assim, eliminá-las.

Realizadas todas as correções, pode-se efetuar análise de regressão linear simples e crescimento exponencial. Aqui também foram utilizadas as amostras dos tratamentos E0, E33, E66 e E100 para criar o modelo e os tratamentos SI e W100 para validá-lo.

Com a intensidade do sinal de carbono em 193,03 nm e a concentração de carbono obtida pelo TOC foi possível realizar a regressão linear simples utilizando energia do laser em 50 mJ e acúmulo de 10 tiros para as amostras não moídas, que pode ser observada na Figura 27.

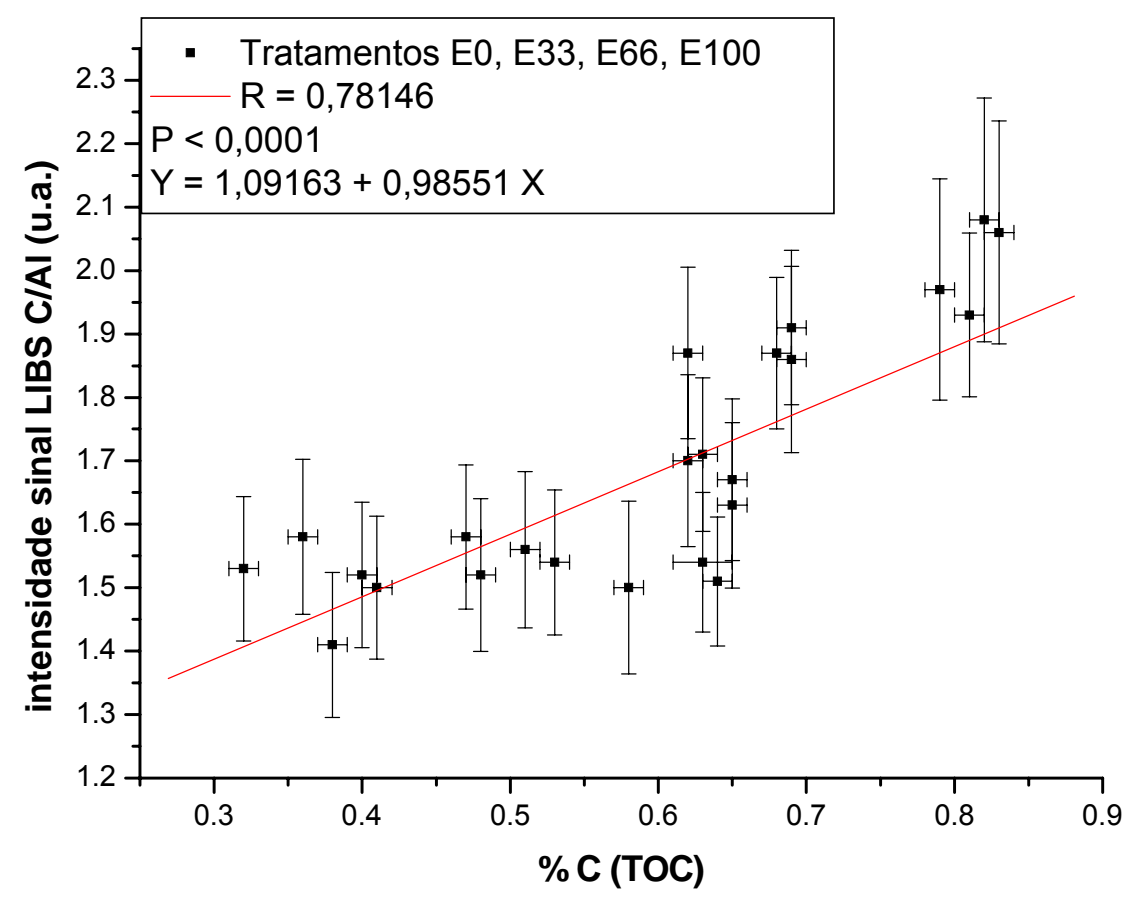

Figura 27: Regressão linear obtida com os tratamentos E0, E33, E66 e E100 não moídos utilizando energia do laser em $50 \mathrm{~mJ}$ e acúmulo de 10 tiros.

A equação obtida por essa curva foi $Y=1,09163+0,98551 X$, e o coeficiente de correlação foi 0,78146 e este modelo foi aceito. Na Figura 28 pode visualizar a validação deste modelo proposto. 


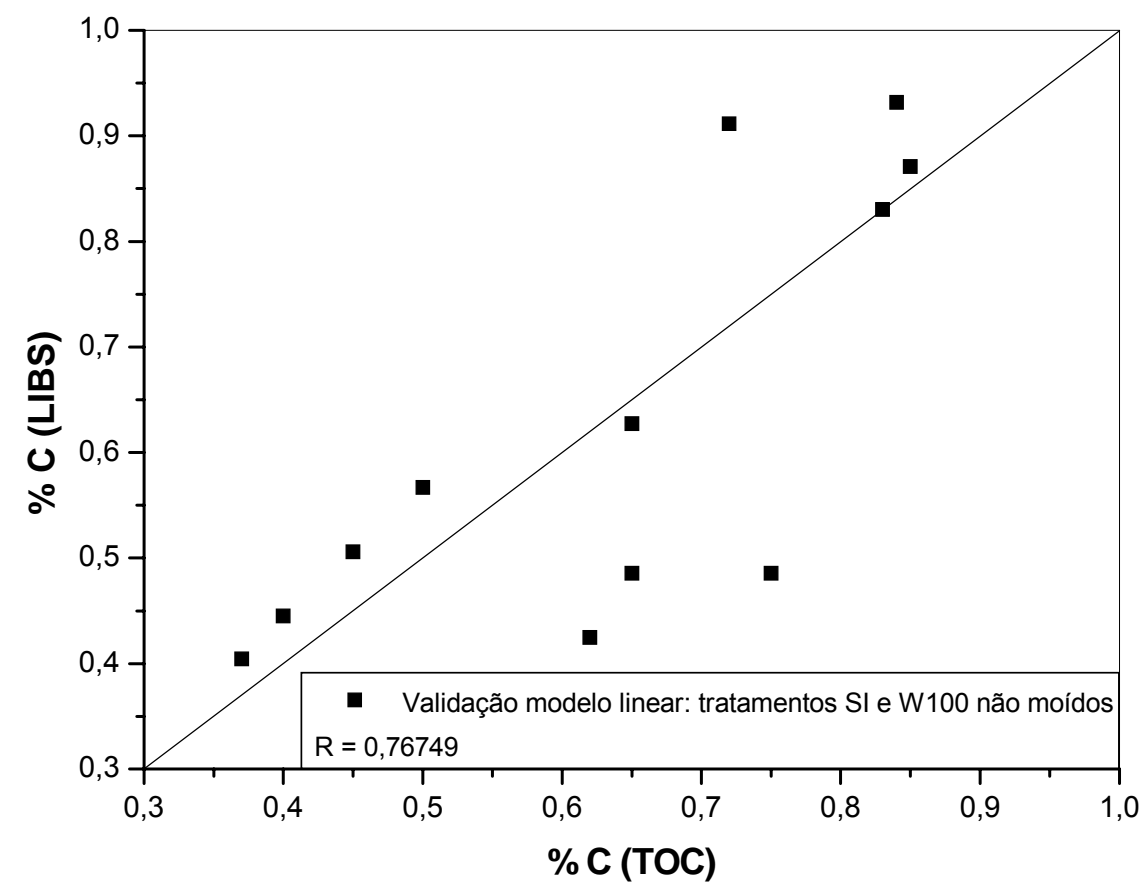

Figura 28: Validação da análise de regressão linear simples dos dados obtidos com LIBS para amostras dos tratamentos SI e W100 não moídos utilizando energia do laser em $50 \mathrm{~mJ}$ e acúmulo de 10 tiros.

Ao contrário do que aconteceu com as amostras moídas, aqui a concentração de carbono estimada pelo LIBS, em geral, foi maior do que a estimada pelo TOC. As amostras de solo não moídas podem apresentar aglomerados de matéria orgânica que ao serem amostrados pelo LIBS resultam numa concentração de carbono acima da que é realmente encontrada nas amostras. Trabalhos têm demonstrado que essa microheterogeneidade em pequenas massas de amostras ocasiona distorções nos resultados [82]. A moagem criogênica minimiza esse efeito. Essa maior heterogeneidade das amostras não moídas também pode ser observada pelas barras de erro da curva de calibração, que apresentaram valores maiores em comparação com as amostras moídas, como pode ser visto comparando as Figuras 11 e 27. O coeficiente de correlação obtido aqui, para a validação, foi menor que o obtido para as amostras moídas (0,76749 em comparação com 0,87377$)$. 
Assim como foi feito para as amostras moídas, também foi testado um ajuste baseado no mesmo modelo de crescimento exponencial utilizado anteriormente. Este modelo ajustado pode ser observado na Figura 29.

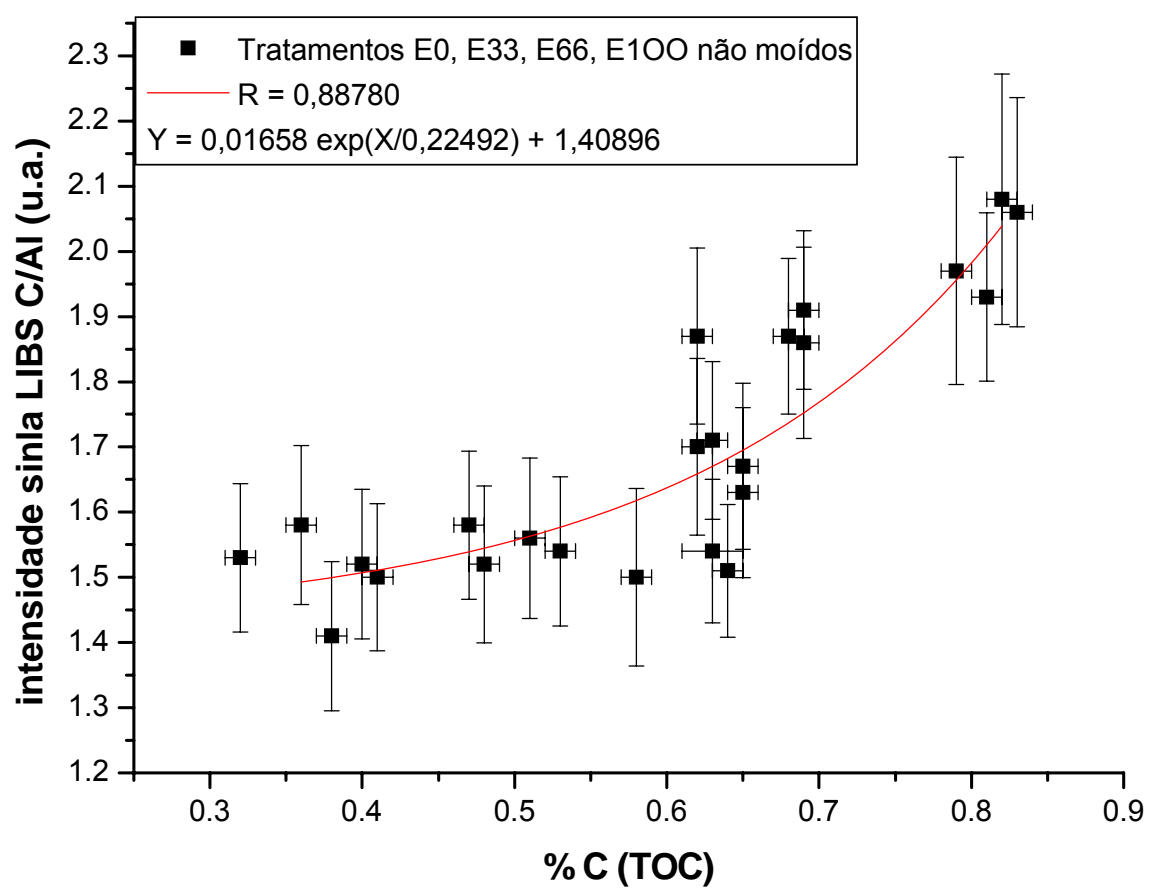

Figura 29: Crescimento exponencial obtido com os tratamentos E0, E33, E66 e E100 não moídos, utilizando energia do laser em $50 \mathrm{~mJ}$ e acúmulo de 10 tiros.

A equação obtida para este modelo foi $Y=0,01658 e^{(X / 0,22492)}+1,40896$, e o coeficiente de correlação foi igual a 0,88780. Assim como ocorreu para as amostras moídas, aqui também o coeficiente de correlação obtido com o modelo de crescimento exponencial foi superior ao obtido com o modelo de regressão linear. Este modelo foi utilizado para se estimar a concentração de carbono nas amostras de solo e esta validação pode ser vista na Figura 30. 


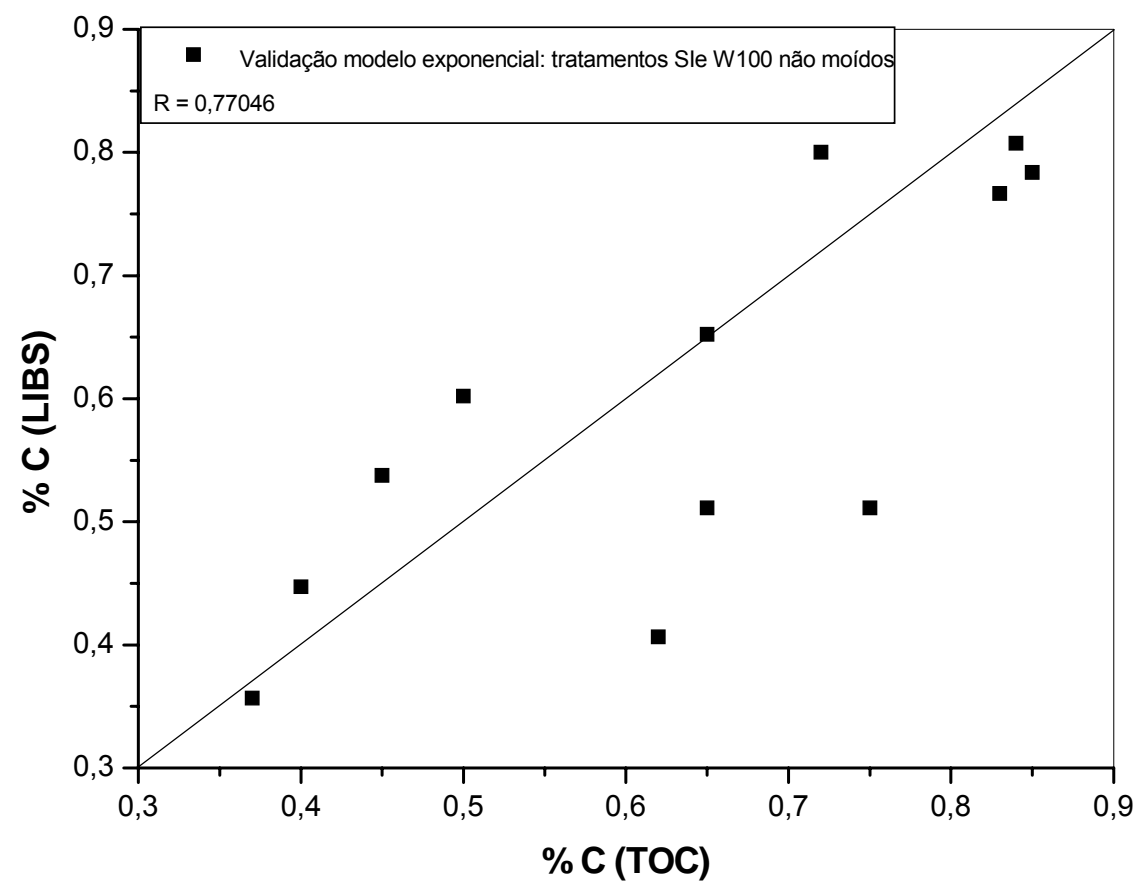

Figura 30: Validação do modelo de crescimento exponencial dos dados obtidos com LIBS para amostras não moídas dos tratamentos SI e W100, utilizando energia do laser em $50 \mathrm{~mJ}$ e acúmulo de 10 tiros.

O coeficiente de correlação obtido nesta validação foi ligeiramente superior ao valor obtido na validação do modelo de regressão linear simples. Os valores de concentração obtidos por ambos os modelos podem ser vistos na Tabela 13. 
Tabela 13: Concentrações de carbono estimadas pelo sistema LIBS utilizando o modelo de regressão linear simples e crescimento exponencial, utilizando energia do laser em $50 \mathrm{~mJ}$ e acúmulo de 10 tiros.

\begin{tabular}{ccccc}
\hline Tratamento & $\begin{array}{c}\text { Profundidade } \\
\mathbf{( c m )}\end{array}$ & $\mathbf{C}_{\text {TOC }}(\%)$ & $\begin{array}{c}\mathbf{C}_{\text {LIBS }} \text { modelo } \\
\text { de regressão } \\
\text { linear simples } \\
(\%)\end{array}$ & $\begin{array}{c}\mathbf{C}_{\text {LIBS }} \text { modelo } \\
\text { de crescimento } \\
\text { exponencial } \\
\text { (\%) }\end{array}$ \\
\hline SI & $0-10$ & 0,84 & 0,93 & 0,81 \\
& $10-20$ & 0,85 & 0,87 & 0,78 \\
& $20-40$ & 0,75 & 0,49 & 0,51 \\
& $40-60$ & 0,65 & 0,49 & 0,51 \\
W100 & $60-80$ & 0,45 & 0,51 & 0,54 \\
& $80-100$ & 0,37 & 0,40 & 0,36 \\
& $0-10$ & 0,83 & 0,83 & 0,77 \\
& $10-20$ & 0,72 & 0,91 & 0,80 \\
& $20-40$ & 0,65 & 0,63 & 0,65 \\
& $40-60$ & 0,62 & 0,43 & 0,41 \\
& $60-80$ & 0,50 & 0,57 & 0,60 \\
& $80-100$ & 0,40 & 0,43 & 0,43 \\
\hline
\end{tabular}

Analisando os dados da Tabela 13, pode-se constatar que o modelo de crescimento exponencial, no geral, foi mais eficaz para estimar a concentração de carbono nas amostras. Para podermos constatar isto, os erros obtidos por ambos os modelos foram analisados e podem ser vistos na Tabela 14.

Tabela 14: Erros de predição utilizando os modelos de regressão linear simples e crescimento exponencial utilizando as amostras não moídas e energia do laser em $50 \mathrm{~mJ}$ e acúmulo de 10 tiros.

\begin{tabular}{cccc}
\hline Tratamento & Profundidade & $\begin{array}{c}\text { Erro do modelo de } \\
\text { regressão linear } \\
\text { simples }\end{array}$ & $\begin{array}{c}\text { Erro do modelo de } \\
\text { crescimento } \\
\text { exponencial }\end{array}$ \\
\hline SI & $0-10$ & 0,09 & 0,03 \\
& $10-20$ & 0,02 & 0,07 \\
$20-40$ & 0,26 & 0,24 \\
W100 & $40-60$ & 0,16 & 0,14 \\
& $60-80$ & 0,06 & 0,09 \\
& $80-100$ & 0,03 & 0,01 \\
& $0-10$ & 0,00 & 0,06 \\
& $10-20$ & 0,19 & 0,08 \\
& $20-40$ & 0,02 & 0,00 \\
& $40-60$ & 0,19 & 0,21 \\
Erro Médio & $60-80$ & 0,07 & 0,10 \\
Absoluto & $80-100$ & 0,03 & 0,03 \\
& & 0,09 & 0,09 \\
\hline
\end{tabular}


Observando os dados presentes nesta tabela pôde-se constatar que o erro médio absoluto obtido em ambos os modelos foi igual. Sendo assim, há apenas uma tendência de que o modelo de crescimento exponencial seja mais adequado, neste caso.

Foram comparados os resultados obtidos com as amostras moídas e não moídas em ambos os modelos para poder avaliar a influência do processo de moagem. $\mathrm{Na}$ Tabela 15 podem ser vistos os resultados obtidos com os modelos de regressão linear simples e na Tabela 16 os resultados obtidos com o modelo de crescimento exponencial.

Tabela 15: Comparação entre os valores preditos utilizando o modelo de regressão linear simples para as amostras moídas e não moídas.

\begin{tabular}{|c|c|c|c|c|}
\hline Tratamento & $\begin{array}{l}\text { Profundidade } \\
\text { (cm) }\end{array}$ & $\mathrm{C}_{\mathrm{TOC}}(\%)$ & $\begin{array}{c}\mathrm{C}_{\text {LIBS }} \text { amostra } \\
\text { moída (\%) }\end{array}$ & $\begin{array}{c}\mathrm{C}_{\text {LIBS }} \text { amostra } \\
\text { não moída (\%) }\end{array}$ \\
\hline \multirow[t]{6}{*}{$\mathrm{SI}$} & $0-10$ & 0,84 & 0,78 & 0,93 \\
\hline & $10-20$ & 0,85 & 0,70 & 0,87 \\
\hline & $20-40$ & 0,75 & 0,56 & 0,49 \\
\hline & $40-60$ & 0,65 & 0,50 & 0,49 \\
\hline & $60-80$ & 0,45 & 0,48 & 0,51 \\
\hline & 80-100 & 0,37 & 0,39 & 0,40 \\
\hline \multirow[t]{6}{*}{ W100 } & $0-10$ & 0,83 & 0,82 & 0,83 \\
\hline & $10-20$ & 0,72 & 0,67 & 0,91 \\
\hline & $20-40$ & 0,65 & 0,47 & 0,63 \\
\hline & $40-60$ & 0,62 & 0,41 & 0,43 \\
\hline & $60-80$ & 0,50 & 0,38 & 0,57 \\
\hline & $80-100$ & 0,40 & 0,33 & 0,43 \\
\hline $\begin{array}{l}\text { Erro Médio } \\
\text { Absoluto }\end{array}$ & & & 0,10 & 0,09 \\
\hline $\begin{array}{l}\text { Coeficiente de } \\
\text { correlação (R) }\end{array}$ & & & 0,87377 & 0,76749 \\
\hline
\end{tabular}


Tabela 16: Comparação entre os valores preditos utilizando o modelo crescimento exponencial para as amostras moídas e não moídas.

\begin{tabular}{|c|c|c|c|c|}
\hline Tratamento & $\begin{array}{l}\text { Profundidade } \\
\text { (cm) }\end{array}$ & $\mathrm{C}_{\text {Tос }}(\%)$ & $\begin{array}{c}\mathrm{C}_{\text {LIBS }} \text { amostra } \\
\text { moída (\%) }\end{array}$ & $\begin{array}{l}\mathrm{C}_{\text {LIBS }} \text { amostra } \\
\text { não moída (\%) }\end{array}$ \\
\hline \multirow[t]{6}{*}{ SI } & $0-10$ & 0,84 & 0,76 & 0,81 \\
\hline & $10-20$ & 0,85 & 0,71 & 0,78 \\
\hline & $20-40$ & 0,75 & 0,59 & 0,51 \\
\hline & $40-60$ & 0,65 & 0,52 & 0,51 \\
\hline & $60-80$ & 0,45 & 0,50 & 0,54 \\
\hline & $80-100$ & 0,37 & 0,34 & 0,36 \\
\hline \multirow[t]{6}{*}{ W100 } & $0-10$ & 0,83 & 0,79 & 0,77 \\
\hline & $10-20$ & 0,72 & 0,69 & 0,80 \\
\hline & $20-40$ & 0,65 & 0,48 & 0,65 \\
\hline & $40-60$ & 0,62 & 0,37 & 0,41 \\
\hline & $60-80$ & 0,50 & 0,31 & 0,60 \\
\hline & $80-100$ & 0,40 & 0,14 & 0,43 \\
\hline $\begin{array}{l}\text { Erro Médio } \\
\text { Absoluto }\end{array}$ & & & 0,13 & 0,09 \\
\hline $\begin{array}{l}\text { Coeficiente de } \\
\text { correlação (R) }\end{array}$ & & & 0,88164 & 0,77046 \\
\hline
\end{tabular}

Analisando os dados presentes nas Tabelas 15 e 16, foi possível constatar que o processo de moagem criogênica das amostras de solo não resultou em melhores resultados de predição de concentração de carbono utilizando o sistema LIBS. Sendo assim, esse processo de moagem pode ser descartado acarretando em ganho de tempo e custo.

\subsubsection{Sistema LIBS portátil}

Como dito anteriormente, para as análises efetuadas com o aparelho LIBS portátil foram utilizadas apenas as amostras do tratamento SI moídas criogenicamente.

Assim como ocorreu com o LIBS de bancada, os espectros obtidos para as amostras do tratamento SI apresentaram o mesmo perfil diferenciando apenas na intensidade das linhas de emissão. Na Figura 31 pode ser observado o espectro médio dos 60 tiros da amostra na profundidade $0-10 \mathrm{~cm}$ do tratamento SI. A faixa 
espectral utilizada foi de 190 a $400 \mathrm{~nm}$, pois é onde se encontra a região de interesse.

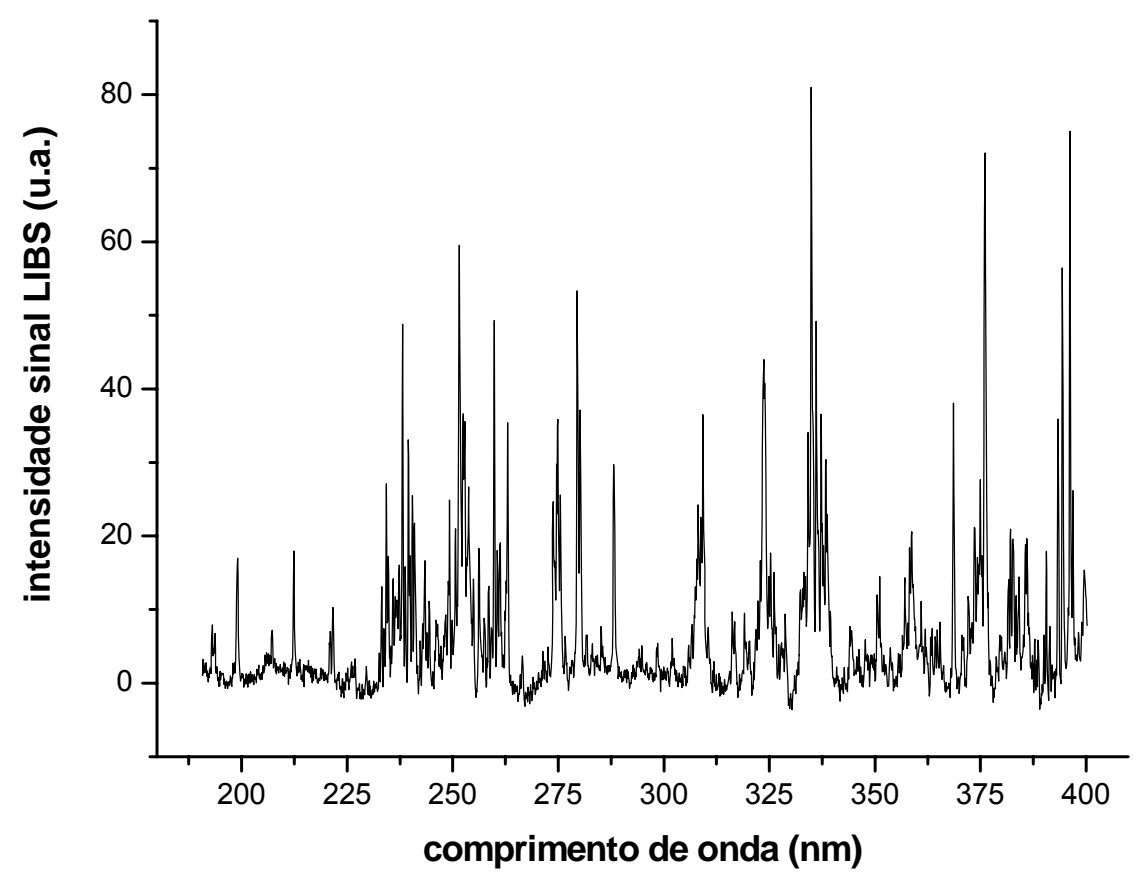

Figura 31: Espectro de emissão médio da amostra na profundidade $0-10 \mathrm{~cm}$ do tratamento SI obtido utilizando o sistema LIBS portátil.

Assim como para os espectros obtidos utilizando o LIBS de bancada, os espectros obtidos utilizando o LIBS portátil apresentaram um grande número de linhas de emissão. Devido à menor resolução do aparelho portátil, algumas linhas não são tão bem definidas e o nível de ruído é maior em comparação com o que foi obtido no aparelho de bancada.

Mesmo com a baixa resolução do equipamento foi possível visualizar facilmente o sinal de emissão do carbono em torno de $193 \mathrm{~nm}$. Na Figura 32 é ilustrado o sinal de emissão do carbono. 


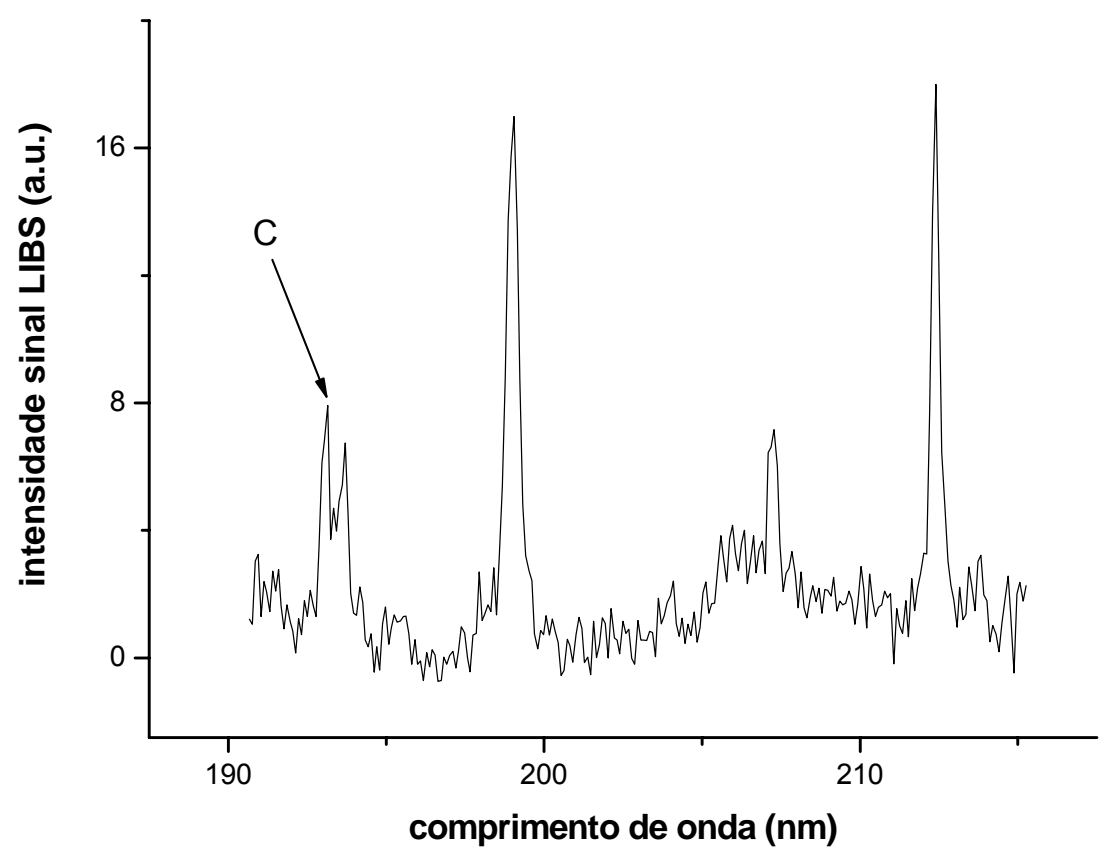

Figura 32: Espectro de emissão da amostra $0-10 \mathrm{~cm}$ do tratamento SI ilustrando o sinal de emissão do carbono.

Obtidos todos os espectros, os mesmos tiveram quer ser corrigidos, pois apresentavam o mesmo problema de variação de intensidade do sinal de fundo tiro a tiro que foi discutido para os dados do aparelho LIBS de bancada.

Como dito anteriormente, adotou-se um método de correção diferente: foi utilizado um programa computacional desenvolvido por Gornushkin e colaboradores para correção do sinal de fundo de espectros LIBS [88]. Este programa mostrou-se um método rápido e eficaz de corrigir o problema de variação de intensidade do sinal de fundo (offset) apresentado pelos espectros. Além disso, os espectros obtidos no sistema portátil não apresentavam o perfil ascendente, como ocorreu com os obtidos no sistema LIBS de bancada. Na Figura 33 é possível observar a janela do programa para a correção do espectro. 


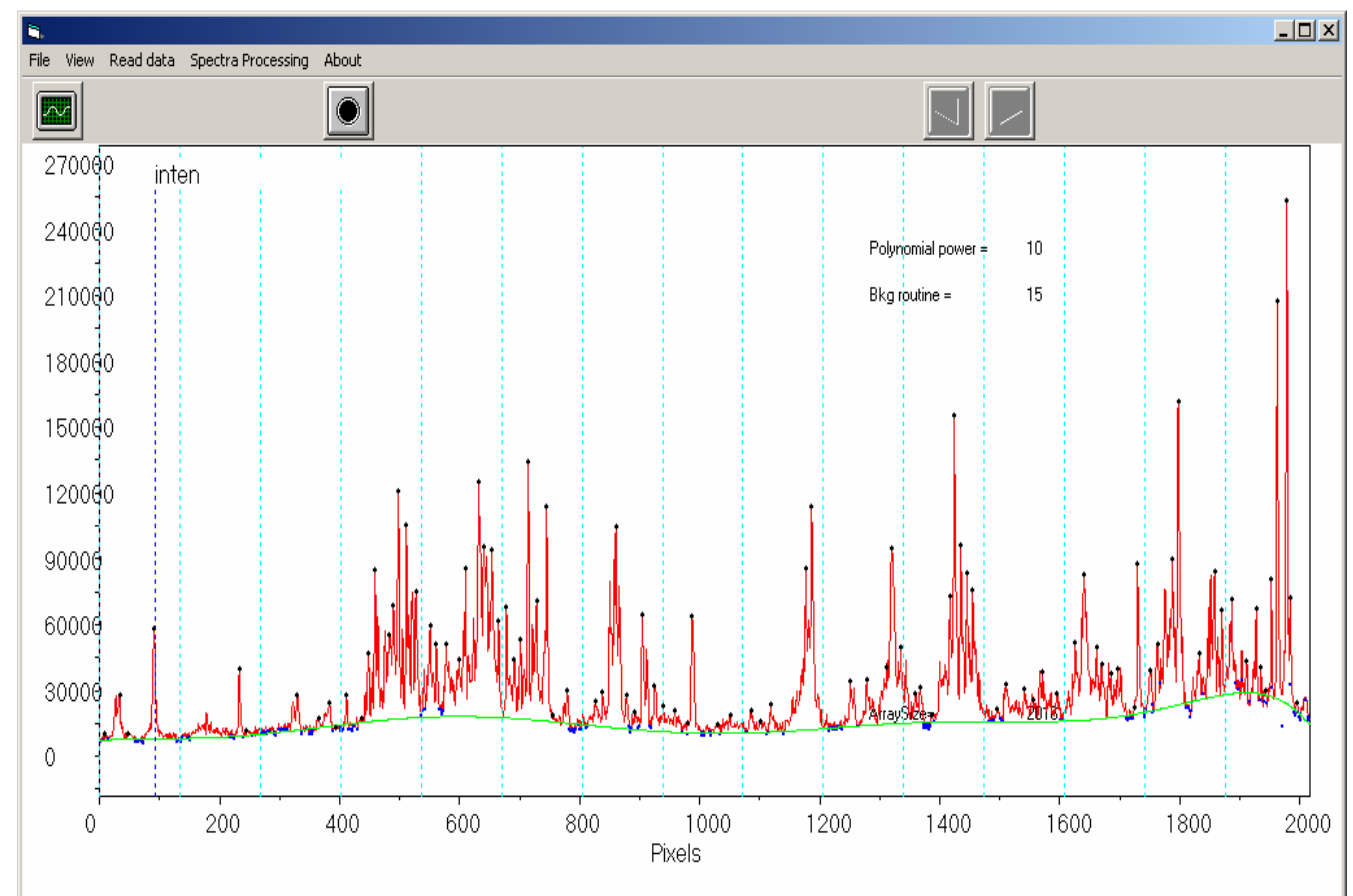

Figura 33: Programa computacional desenvolvido por Gornushkin para correção do sinal de fundo de espectros LIBS.

Na Figura 33 é possível observar a divisão do espectro em 15 partes e o ajuste polinomial que foi feito para corrigir-se o sinal de fundo do espectro. Na Figura 34 é possível visualizar um espectro sem correção em comparação com o mesmo corrigido pelo programa. 


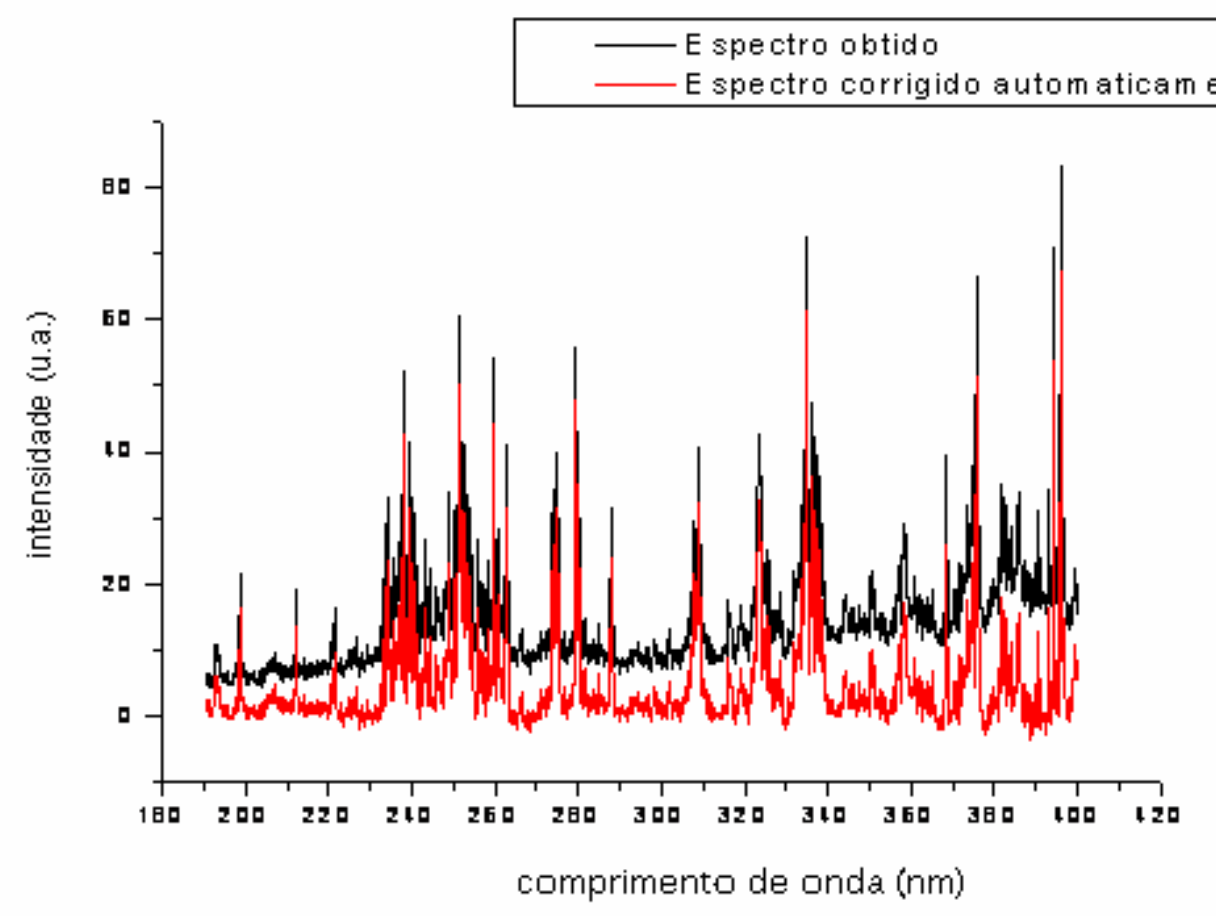

Figura 34: Comparação entre espectro sem correção do sinal de fundo e o mesmo corrigido pelo programa desenvolvido por Gornushkin.

Corrigidos todos os espectros de todas as profundidades do tratamento SI, foi possível realizar a regressão linear simples. Esta curva pode ser observada na Figura 35. 


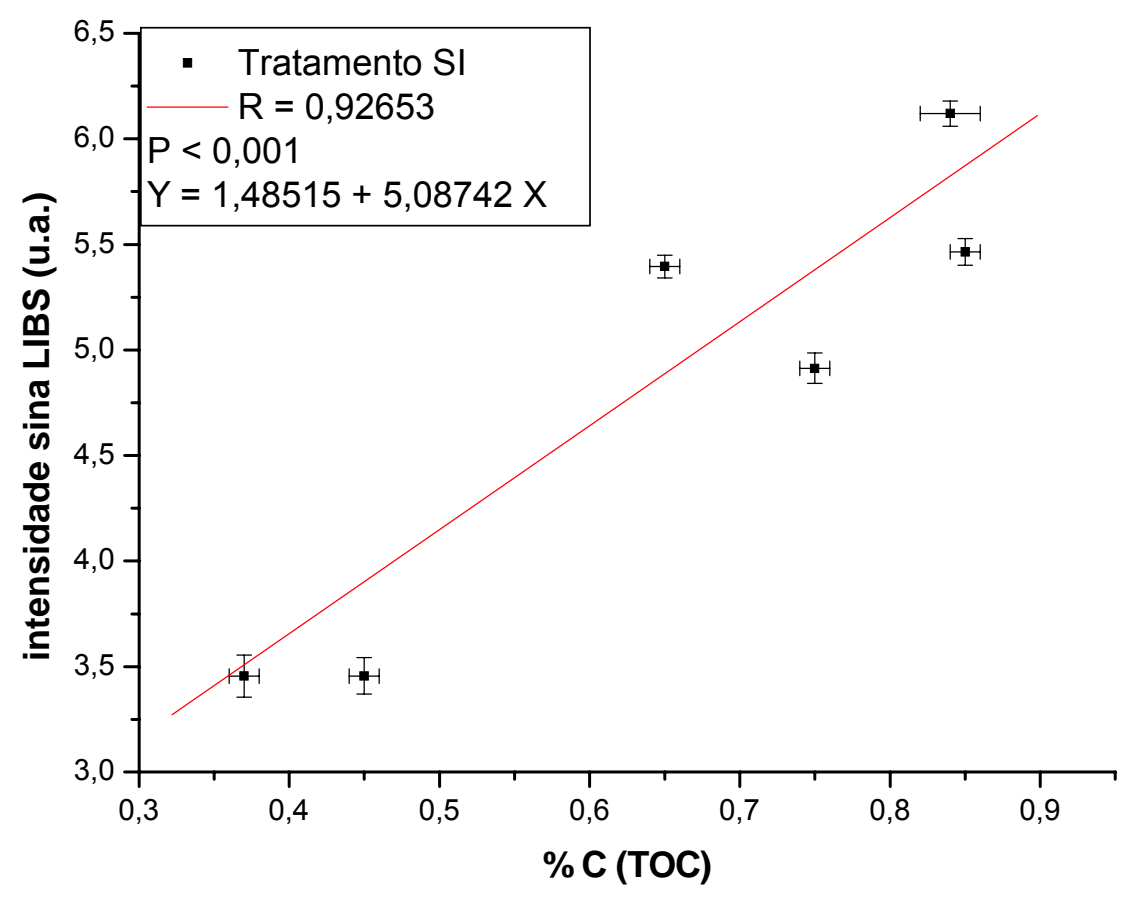

Figura 35: Regressão linear para amostras do tratamento SI obtida utilizando o sistema LIBS portátil.

A equação obtida para essa regressão linear simples foi $Y=1,48515+5,08742$ X, e o coeficiente de correlação obtido foi igual a 0,92653.

Utilizando o programa computacional Weka foi realizada a regressão linear múltipla como descrita anteriormente. O programa computacional Weka selecionou como a melhor intensidade para contruir o modelo com base em uma regressão linear simples a intensidade no comprimento de onda em 192,92 nm, que apresentou um coeficiente de correlação igual a 0,96427.

Esta intensidade no comprimento de onda de 192,92 selecionada pelo programa Weka é diretamente anterior a intensidade no pico de carbono em 193,03 nm. A escolha dessa intensidade nesse comprimento diretamente anterior ao pico de carbono pode ser atribuída ao fato que, ao contrario do que foi feito para os espectros obtidos utilizando o sistema de bancada, os espectros aqui não foram normalizados pelo sinal de emissão do alumínio. Sendo assim, a intensidade do 
sinal do carbono em 192,92 nm é menos influenciada negativamente pelo sinal de emissão do alumínio do que a intensidade do sinal no pico, em 193,03 nm.

Por problemas técnicos apresentados no sistema LIBS portátil, não foi possível realizar as medidas em todos os 6 tratamentos, como foi realizado para o aparelho de bancada. Assim, para validarmos esses dados obtidos foi realizado o teste de validação cruzada, como descrito anteriormente.

O teste de validação cruzada apresentou um coeficiente de correlação entre os valore preditos e a concentração de carbono medida pelo TOC igual a 0,92172.

Os resultados obtidos comprovam a eficiência do método para se estimar carbono em amostras de solo utilizando o sistema LIBS portátil e a capacidade deste sistema portátil, visto que utilizando este sistema foram realizados trabalhos que aceitos para publicação em periódico internacional [89, 90]. 


\section{CAPÍTULO 6}

\subsection{Conclusões}

Nas amostras de solo de clima tropical analisadas, tanto no LIBS de bancada como no portátil, uma linha de emissão em torno de 193 nm foi observada próxima a linha de emissão de carbono, fato não observado em trabalhos que utilizaram amostras de solo de clima temperado. Essa linha foi atribuída ao alumínio.

A presença dessa linha interferia negativamente no sinal de emissão do carbono nas medidas utilizando os sistemas LIBS. Este fato pôde ser minimizado efetuando a normalização do sinal de emissão do carbono obtido, no sistema LIBS de bancada, e realizando a análise de regressão linear múltipla utilizando todo o pico de carbono, para sistema LIBS portátil.

As correções do sinal de fundo realizadas se mostraram eficientes e imprescindíveis para se obter as curvas de calibração utilizando os modelos de regressão linear e crescimento exponencial, no sistema LIBS de bancada. Sem essas correções não seria possível realizar estimativas quantitativas nas amostras de solo utilizadas.

Pode-se concluir também que, para o tipo de solo utilizado, a melhor maneira de se realizar medidas para se estimar a quantidade de carbono utilizando o sistema LIBS de bancada foi utilizando a energia máxima do laser $(50 \mathrm{~mJ})$ acúmulo de 10 tiros.

Observou-se também que a moagem criogênica é uma etapa do tratamento das amostras de solo que pode ser descartada, visto que os resultados obtidos com as amostras moídas não foram melhores aos obtidos com as amostras não moídas. 
Este é um fato benéfico, pois não havendo necessidade de moer criogenicamente as amostras há uma economia de tempo e custo.

Os resultados obtidos com o aparelho LIBS portátil também se mostraram muito promissores já que esse aparelho apresenta limitações em comparação com o sistema de bancada: menor energia do laser, baixa taxa de repetição, baixa resolução. Mas pode-se concluir que com a utilização do programa para correção do sinal de fundo e com a utilização de ferramentas estatísticas foi possível obter resultados comparáveis aos do aparelho LIBS de bancada.

Com isso conclui-se que sistemas LIBS são ferramentas úteis para se realizar estimativas quantitativas, podendo ser usados para a construção de inventários de carbono no solo, que são importantes para áreas ambientais com o foco em seqüestro de carbono, mudanças climáticas globais, avaliação do manejo de solos e o efeito da aplicação de águas residuárias. 


\section{CAPÍTULO 7}

\subsection{Referências bibliográficas}

1. CLIMATE Change 2001: the scientific basis (intergovermental panel climate change). Disponível em: <http://www.grida.no/climate/ipcc_tar/wg1/index.htm>. Acesso em: 01 abr. 2007.

2. FELLER, C.; BEARE, M. Physical control of soil organic matter dynamics in the tropics. Geoderma, v. 79, p. 69-116, 1997.

3. REE, R.M.; BALL, B.C.; CAMPBELL, C.D.; WATSON, C.A. Sustainable management of soil organic matter. New York: CABI Publishing, 2001. 439p.

4. SULCEK, Z.; POVONDRA, P. Methods of decomposition in inorganic analysis. Boca Raton: CRC, 1989. 425p.

5. KURFÜRST, U. Solid sample analysis: direct and slurry sampling using GFAAS and ETV-ICP. Berlin: Springer Verlag, 1998. 456p.

6. BELARRA, M.A.; RESANO, M.; VENHAECKE, F.; MOENS, L. Direct solid sampling with electrothermal vaporization/atomization: what for and how? Trends in Analytical Chemistry, v. 21, p. 828-839, 2002.

7. MARKET Profile: Laser-based analytical technologies. Spectroscopy, v. 18. p. 12, 2003.

8. SANTOS JUNIOR, D.; TARELHO, L.V.G.; KRUG, F.J.; MILORI, D.M.B.P.; MARTIN-NETO, L.; VIEIRA JUNIOR, N.D. Espectrometria de emissão óptica com plasma induzido por laser (LIBS) - fundamentos, aplicações e perspectivas.

Revista Analytica, v. 24, p. 72-81, 2006.

9. BULAJIC, D.; CRISTOFORETTI, G.; CORSI, M.; HIDALGO, M.; LEGNAIOLI, S.; PALLESCHI, V.; SALVETTI, A.; TOGNONI, E.; GREEN, S.; BATES, D.;

STEIGER, A.; FONSECA, J.; MARTINS, J.; MCKAY, J.; TOZER, B.; WELLS, D.; WELLS, R.; HARITH, M.A. Diagnostics of high-temperature steel pipes in industrial environment by laser-induced breakdown spectroscopy technique: the LIBSGRAIN project. Spectrochimica Acta Part B: Atomic Spectroscopy, v. 57, p. 1181-1192, 2002.

10.SALLÉ, B.; CREMERS, D.A.; MAURICE, S.; WIENS, R.C. Laser-induced breakdown spectroscopy for space exploration applications: Influence of the ambient pressure on the calibration curves prepared from soil and clay samples. Spectrochimica Acta Part B: Atomic Spectroscopy, v. 60, p. 479-490, 2005. 
11.DELUCIA, F.C.; SAMUELS, A.C.; HARMON, R.S.; WALTERS, R.A.; MCNESBY, K.L.; LAPOINTE, A.; WINKEL JR., R.J.; MIZIOLEK, A.W. Laserinduced breakdown spectroscopy (LIBS): a promising versatile chemical sensor technology for hazardous material detection. IEEE Sensors Journal, v. 5, p. 681689, 2005.

12.POTTS, P.J.; ELLIS, A.T.; KREGSAMER, P.; MARSHALL, J.; STRELI, C.; WEST, M.; WOBRAUSCHEK, P. Atomic spectrometry update. X-ray fluorescence spectrometry. Journal of Analytical Atomic Spectrometry, v. 18, p. 1297-1316, 2003.

13.BOHLING, C.; HOHMANN. K.; SCHEEL, D.; BAUER, C.; SCHIPPERS, W.; BURGMEIER, J.; WILLER, U.; HOLL, G.; SCHADE, W. All-fiber-coupled laserinduced breakdown spectroscopy sensor for hazardous materials analysis.

Spectrochimica Acta Part B: Atomic Spectroscopy, v. 62, p. 1519-1527, 2007.

14.DE LUCIA JUNIOR, F.C.; GOTTFRIED, J.L.; MUNSON, C.A.; MIZIOLEK, A.W. Double pulse laser-induced breakdown spectroscopy of explosives: Initial study towards improved discrimination. Spectrochimica Acta Part B: Atomic Spectroscopy, v. 62, p. 1399-1404, 2007

15.SALLÉ, B.; MAUCHIEN, P.; MAURICE, S. Laser-Induced Breakdown Spectroscopy in open-path configuration for the analysis of distant objects.

Spectrochimica Acta Part B: Atomic Spectroscopy, v. 62, p. 736-768, 2007.

16.NODA, M.; DEGUCHI, Y.; IWASAKI, S.; YOSHIKAWA, N. Detection of carbon content in a high-temperature and high pressure environment using laser-induced breakdown spectroscopy. Spectrochimica Acta Part B: Atomic Spectroscopy, v. 57, p. 701-709, 2002.

17.GOTTFRIED, J.L.; DE LUCIA JR F.C.; MUNSON, C.A.; MIZIOLEK, A.W. Standoff detection of chemical and biological threats using laser-induced breakdown spectroscopy. Applied Spectroscopy, v. 62, p. 353-363, 2008.

18.LASER induced breakdown spectroscopy: a new chemical sensor technology. Disponível em: <http://www.arl.army.mil/wmrd/LIBS>. Acesso em: 07 jun. 2007.

19.REHSE, S.J.; DIEDRICH, J.; PALCHAUDHURI. S. Identification and discrimination of Pseudomonas aeruginosa bacteria grown in blood and bile by laser-induced breakdown spectroscopy. Spectrochimica Acta Part B: Atomic Spectroscopy, v. 62, p. 1269-1276, 2007.

20.MUNSON, C.A.; DE LUCIA JUNIOR, F.C.; PIEHLER, T.; MCNESBY, K.L; MIZIOLEK, A.W. Investigation of statistics strategies for improving the discriminating power of laser-induced breakdown spectroscopy for chemical and biological warfare agent simulants. Spectrochimica Acta Part B: Atomic Spectroscopy, v. 60, p. 1217-1224, 2005. 
21.WAINER, R.T.; HARMON, R.S.; MIZIOLEK, A.W.; MCNESBY, K.L.; FRENCH, P.D. Analysis of environmental lead contamination: comparison of LIBS field and laboratory instruments. Spectrochimica Acta Part B: Atomic Spectroscopy, v. 56, p. 777-793, 2001.

22.WINEFORDNER, J.D.; GORNUSHKIN, I.B.; CORREL, T.; GIBB, E.; SMITH, B.W.; OMENETTO, N. Comparing several atomic spectrometric methods to the super stars: special emphasis on laser induced breakdown spectrometry, LIBS, a future super star. Journal of Analytical Atomic Spectrometry, v. 19, p. 10611083, 2004.

23.BURAKOV, V.S.; RAIKOV, S.N. Quantitative analysis of alloys and glasses by a calibration-free method using laser-induced breakdown spectroscopy.

Spectrochimica Acta Part B: Atomic Spectroscopy, v. 62, p. 217-223, 2007.

24.MOHAMED, W.T.Y. Improved LIBS limit of detection of Be, Mg, Si, Mn, Fe and $\mathrm{Cu}$ in aluminum alloy samples using a portable Echelle spectrometer with ICCD camera. Optics \& Laser Technology, v. 40, p. 30-38, 2008.

25.PICHAHCHY, A.E.; CREMERS, D.A.; FERRIS, M.J. Elemental analysis of metals under water using laser-induced breakdown spectroscopy.

Spectrochimica Acta Part B: Atomic Spectroscopy, v. 52, p. 25-39, 1997.

26.VIEITEZ, M.O.; HEDBERG, J.; LAUNILA, O.; BERG, L.E. Elemental analysis of steel scrap metals and minerals by laser-induced breakdown spectroscopy. Spectrochimica Acta Part B: Atomic Spectroscopy, v. 60, p. 920-925, 2005.

27.NOLL, R.; BETTE, H.; BRYSCH, A.; KRAUSHAAR, M.; MÖNCH, I.; PETER, L.; STURM, V. Laser-induced breakdown spectrometry - applications for production control and quality assurance in the steel industry. Spectrochimica Acta Part B: Atomic Spectroscopy, v. 56, p. 637-649, 2001.

28.GALBÁCS, G.; GORNUSHKIN, I.B.; SMITH, B.W.; WINEFORDNER, J.D. Semi-quantitative analysis of binary alloys using laser-induced breakdown spectroscopy and a new calibration approach based on linear correlation.

Spectrochimica Acta Part B: Atomic Spectroscopy, v. 56, p. 1159-1173, 2001.

29.HARMON, R.S.; DE LUCIA JR, F.C.; MCMANUS, C.E.; MCMILLAN, N.J.; JENKINS, T.F.; WALSH, M.E.; MIZIOLEK, A. Laser-induced breakdown spectroscopy - An emerging chemical sensor technology for real-time fieldportable, geochemical, mineralogical, and environmental applications. Applied Geochemistry, v. 21, p. 730-747, 2006.

30.GAFT, M.; SAPIR-SOFER, I.; MODIANO, H.; STANA, R. Laser induced breakdown spectroscopy for bulk minerals online analyses. Spectrochimica Acta Part B: Atomic Spectroscopy, v. 62, p. 1496-1503, 2007. 
31.MACMILLAN, N.J.; HARMON, R.S.; DE LUCIA JR, F.C.; MIZIOLEK, A.M. Laser induced breakdown spectroscopy analysis of minerals: cabonates and silicates. Spectrochimica Acta Part B: Atomic Spectroscopy, v. 62, p. 15281536, 2007.

32.ANZANO, J.M.; VILLORIA, M.A.; RUÍZ-MEDINA, A.; LASHERAS, R.J. Laserinduced breakdown spectroscopy for quantitative spectrochemical analysis of geological materials: Effects of the matrix and simultaneous determination.

Analytica Chimica Acta, v. 575, p. 230-235, 2006.

33. CASTILLEJO, M.; MARTÍN, M.; SILVA, D.; STRATOUDAKI, T.; ANGLOS, D.; BURGIO, L.; CLARK, R.J.H. Analysis of pigments in polychromes by use of laser induced breakdown spectroscopy and Raman microscopy. Journal of Molecular Structure, v. 550-551, p. 191-198, 2000.

34.MELESSANAKI, K.; MATEO, M.; FERRENCE, S.C.; BETANCOURT, P.P.; ANGLOS, D. The application of LIBS for the analysis of archaeological ceramic and metals artifacts. Applied Surface Science, v. 197-198, p. 156-163, 2002.

35.GARCÍA-AYUSO, L.E.; AMADOR-HERNÁNDEZ, J.; FERNÁNDEZ-ROMERO, J.M.;LUQUE DE CASTRO,M.D. Characterization of jewellery products by laserinduced breakdown spectroscopy. Analytica Chimica Acta, v. 457, p. 247-256, 2002.

36.FORTES, F.J.; CORTÉS, M.; SIMÓN, M.D.; CABALÍN, L.M.; LASERNA, J.J. Chronocultural sorting of archaeological bronze objects using laser-induced breakdown spectrometry. Analytica Chimica Acta, v. 554, p. 136-143, 2005.

37.KUZUYA, M.; MURAKAMI, M.; MARUYAMA, N. Quantitative analysis of ceramics by laser-induced breakdown spectroscopy. Spectrochimica Acta Part B: Atomic Spectroscopy, v. 58, p. 957-965, 2003.

38.LE MEUR, J.; MENUT, D.; WODLING, P.; SALMON, L.;THRO, P.Y.; CHEVILLARD, S.; UGOLIN, N. First improvements in the detection and quantification of label-free nucleic acids by laser-induced breakdown spectroscopy: Application to the deoxyribonucleic acid micro-array technology. Spectrochimica Acta Part B: Atomic Spectroscopy, v. 63, p. 465-473, 2008.

39.TRAN, M.; SUN, Q.; SMITH, B.; WINEFORDNER, J.D. Direct determination of trace elements in terephthalic acid by laser induced breakdown spectroscopy.

Analytica Chimica Acta, v. 419, p. 153-158, 2000.

40.FERIOLI, F.; BUCKLEY, S.G. Measurements of hydrocarbons using laserinduced breakdown spectroscopy. Combustion and Flame, v. 144, p. 435-447, 2006.

41.GONDAL, M.A.; SIDDIQU, M.N. Identification of different kinds of plastics using laser-induced breakdown spectroscopy for waste management. Journal of Environmental Science And Health Part A - Toxic/Hazardous Substances \& Environmental Engineering, v. 42, p. 1989-1997, 2007. 
42. GONDAL, M.A.; HUSSAIN, T.; YAMANI, Z.H.; BAIG, M.A. Detection of heavy metals in Arabian crude oil residue using laser induced breakdown spectroscopy. Talanta, v. 69, p. 1072-1078, 2006.

43.ST-ONGE, L.; KWONG, E.; SABSABI, M.; VADAS, E.B. Quantitative analysis of pharmaceutical products by laser-induced breakdown spectroscopy.

Spectrochimica Acta Part B: Atomic Spectroscopy, v. 57, p. 1131-1140, 2002.

44.GALIOVÁ,M.; KAISER, J.; NOVOTNÝ, K.; SAMEK, O.; REALE, L.; MALINA, R.; PÁLENÍKOVÁ, K.; LIŠKA, M.; ČUDEK, V.; KANICKÝ, V.; OTRUBA, V.; POMA, A.; TUCCI, A. Utilization of laser induced breakdown spectroscopy for investigation of the metal accumulation in vegetal tissues. Spectrochimica Acta Part B: Atomic Spectroscopy, v. 62, p. 1597-1605, 2007.

45.SUN, Q.; TRAN, M.; SMITH, B.W.; WINEFORDNER, J.D. Zinc analysis in human skin by laser induced-breakdown spectroscopy. Talanta, v. 52, p. 293$300,2000$.

46. COURRĖGES-LACOSTE, G.B.; AHLERS, B.;PÉREZ, F.R. Combined Raman spectrometer/laser-induced breakdown spectrometer for the next ESA mission to Mars. Spectrochimica Acta Part B: Atomic Spectroscopy, v. 68, p. 1023-1028, 2007.

47.SALLÉ, B.; LACOUR, J.L.; MAUCHIEN, P.; FICHET, P.; MAURICE, S.; MANHĖS, G. Comparative study of different methodologies for quantitative rock analysis by Laser-Induced Breakdown Spectroscopy in a simulated Martian atmosphere. Spectrochimica Acta Part B: Atomic Spectroscopy, v. 61, p. 301313, 2006.

48.ARP, Z.A.; CREMERS, D.A.; HARRIS, R.D.; OSCHWALD, D.M.; PARKER JR, G.R.; WAYNE, D.M. Feasibility of generating a useful laser-induced breakdown spectroscopy plasma on rocks at high pressure: preliminary study for a Venus mission. Spectrochimica Acta Part B: Atomic Spectroscopy. v. 59, p. 987-999, 2004.

49.LAZIC, V.; RAUSCHENBACH, I.; JOVICEVIC, S.; JESSBERGER, E.K.; FANTONI, R.; DI FINO, M. Laser induced breakdown spectroscopy of soils, rocks and ice at subzero temperatures in simulated martian conditions.

Spectrochimica Acta Part B: Atomic Spectroscopy, v. 62, p. 1546-1556, 2007.

50.SHU, R.; QI, H.X.; LUE, G.; MA, D.M.; HE, Z.P.; XUE, Y.Q. Laser-induced breakdown spectroscopy based detection of lunar soil simulants for moon exploration. Chinese Optics Letters, v. 5, p. 58-59, 2007.

51.CREMERS, D.A.; EBINGER, M.H.; BRESHEARS, D.D.; UNKEFER, P.J.; KAMMERDIENER, S.A.; FERRIS, M.J.; CATLETT, K.M.; BROWN, J.R. Measuring Total Soil Carbon with Laser-Induced Breakdown Spectroscopy (LIBS). Journal Of Environmental Quality, v. 30, p. 2202-2206, 2001. 
52.EBINGER,M.H.; NORFLEET, M.L.; BRESHEARS, D.D.; CREMERS, D.A.; FERRIS, M.J.; UNKEFER, P.J.; LAMB, M.S.; GODDARD, K.L.; MEYER, C.W. Extending the Applicability of Laser-Induced Breakdown Spectroscopy for Total Soil Carbon Measurement. Soil Science Society of America, v. 67, p. 16161619, 2003.

53.MARTIN, M.Z.; WULLSCHLEGER, S.D.;GARTEN JR., C.T.; PALUMBO, A.V. Laser-induced breakdown spectroscopy for the environmental determination of total carbon and nitrogen in soils. Applied Optics, v. 42, p. 2072-2077, 2003.

54.JENSEN, L.C.; LANGFORD, S.C.; DICKINSON, J.T.; ADDLEMAN, R.S. Mechanistic studies of laser-induced breakdown spectroscopy of model environmental samples. Spectrochimica Acta Part B: Atomic Spectroscopy, v. 50, p. 1501-1519, 1995.

55.CAPITELLI, F.; COLAO, F.; PROVENZANO, M.R.; FANTONI, R.; BRUNETTI, G.; SENESI, N. Determination of heavy metals in soils by Laser Induced Breakdown Spectroscopy. Geoderma, v. 1006, p. 45-62, 2002.

56.CORSI, M.; CRISTOFORETTI, G.; HIDALGO, M.; LEGNAIOLI, S.; PALLESCHI, V.; SALVETTI, A.; TOGNONI, E.; VALLEBONA, C. Double pulse, calibration-free laser-induced breakdown spectroscopy: A new technique for in situ standard-less analysis of polluted soils. Applied Geochemistry, v. 21, p. 748-755, 2006.

57.GEHL, R.J.; RICE, C.W. Emerging technologies for in situ measurement of soil carbon. Climatic Change, v. 80, p. 43-54, 2007.

58.BUSTAMANTE, M.F.; RINALDI, C.A.; FERRERO, J.C. Laser induced breakdown spectroscopy characterization of $\mathrm{Ca}$ in a soil depth profile.

Spectrochimica Acta Part B: Atomic Spectroscopy, v. 57, p. 303-309, 2002.

59.HUSSAIN, T.; GONDAL, M.A.; YAMANI, Z.H.; BAIG, M.A. Measurement of nutrients in green house soil with laser induced breakdown spectroscopy. Environmental Monitoring and Assessment. v. 124, p. 131-139, 2007

60.HUSSAIN, T.; GONDAL, M.A. Monitoring and assessment of toxic metals in Gulf War oil spill contaminated soil using laser-induced breakdown spectroscopy. Environmental Monitoring and Assessment, v. 136, p. 391-399, 2008.

61.LAZIC, V.;BARBINI, R.; COLAO, F.; FANTONI, R.; PALUCCI, A. Selfabsorption model in quantitative laser induced breakdown spectroscopy measurements on soils and sediments. Spectrochimica Acta Part B: Atomic Spectroscopy, v. 56, p. 807-820, 2001.

62.GALIOVA, M,; MOZNA, V.; STANKOVA, A.; NOVOTNY, K.; KANICKY, V. Study of laser-sample interactions of glasses and soils using laser-induced breakdown spectroscopy and optical emission spectroscopy with inductively coupled plasma. Chemicke Listy, v. 100, p. 204-209, 2006. 
63.BOUSQUET, B.; SIRVEN, J.B.; CANIONI, L. Towards quantitative laserinduced breakdown spectroscopy analysis of soil samples. Spectrochimica Acta Part B: Atomic Spectroscopy, v. 62, p. 1582-1589, 2007.

64.KORTENBRUCK, F.H.; NOLL, R.; WINTJENS, P.; FALK, H.; BECKER, C. Analysis of heavy metals in soils using laser-induced breakdown spectrometry combined with laser-induced fluorescence. Spectrochimica Acta Part B: Atomic Spectroscopy, v. 56, p. 933-945, 2001.

65.WINDOM, B.C.; DIWAKAR, P.K.; HAHN, D.W. Dual-pulse Laser Induced Breakdown Spectroscopy for analysis of gaseous and aerosol systems: Plasmaanalyte interactions. Spectrochimica Acta Part B: Atomic Spectroscopy, v. 61, p. 788-796, 2006.

66.MOLINA, A.; SHADDIX, C.R.; SICKAFOOSE, S.M.; WALSH, P.M.; BLEVINS, L.G. Effect of temperature and $\mathrm{CO} 2$ concentration on laser-induced breakdown spectroscopy measurements of alkali fume. Spectrochimica Acta Part B: Atomic Spectroscopy, v. 60, p. 1103-1114, 2005.

67.KIDO, A.; HOSHI, K.; KUSAKA, H.; OGAWA, H.; MIYAMOTO, N. Instantaneous Measurement of Local Concentration and Vapor Fraction in Liquid gas mistures by Laser Induced Breakdown Spectroscopy. Japan Society of Mechanical Engineers International Journal, v. 49, p. 520-525, 2006.

68.HANA, M.; OMAR, M.M.; GAMAL, Y.E.E.D. Study of laser-induced breakdown spectroscopy of gases. Radiation Physics and Chemistry, v. 57, p. 11-20, 2000.

69.KENNEDY, P.K.; HAMMER, D.X.; ROCKWELL, B.A. Laser-Induced Breakdown In Aqueous Media. Progress in Quantum Electronics, v. 21, p. 155248, 1997.

70.DE GIACOMO, A.; DELL'AGLIO, M.; DE PASCALE, O.; CAPITELLI, M. From single pulse to double pulse ns-Laser Induced Breakdown Spectroscopy under water: Elemental analysis of aqueous solutions and submerged solid samples. Spectrochimica Acta Part B: Atomic Spectroscopy, v. 62, p. 721-738, 2007.

71.ALAMELU, D.; SARKAR, A.; AGGARWAL, S.K. Laser Induced Breakdown Spectroscopy for Simultaneous Determination of Sm, Eu and Gd in Aqueous Solution. Talanta, v. 77, p. 256-261, 2008.

72.FICHET, P.; MAUCHIEN, P.; WAGNER, J.F.; MOULIN, C. Quantitative elemental determination in water and oil by laser induced breakdown spectroscopy. Analytica Chimica Acta, v. 429, p. 269-278, 2001.

73.RADZIEMSKI, L.J. From LASER to LIBS, the path of technology development. Spectrochimica Acta Part B: Atomic Spectroscopy, v. 57, p. 1109-1113, 2002. 
74.SONG, K.; LEE, Y.; SNEDDON, J. Recent developments in instrumentation for laser induced breakdown spectroscopy. Applied Spectroscopy Reviews, v. 37, p. $89-117,2002$.

75.TOGNONI, E.; PALLESCHI, V.; CORSI, M.; CRISTOFORETTI, G.

Quantitative micro-analysis by laser-induced breakdown spectroscopy: a review of the experimental approaches. Spectrochimica Acta Part B: Atomic Spectroscopy, v. 57, p. 1115-1130, 2002.

76. CAPITELLI, M.; CASAVOLA, A.; COLONIA, G.; GIACOMO, A. Laser-induced plasma expansion: theoretical and experimental aspects. Spectrochimica Acta Part B: Atomic Spectroscopy, v. 59, p. 271-289, 2004.

77.BRECH, F.; CROSS, L. Optical microemission stimulated by a ruby maser. Applied Spectrocopy, v. 16, p. 59, 1962.

78.RUNGE, E.F.; MINCK, R.W.; BRYAN, F.R. Spectrochemical analysis using a pulsed laser source. Spectrochimica Acta Part B: Atomic Spectroscopy, v. 20, p.733-735, 1964.

79.MARTIN, M.Z.; WULLSHLEGER, S.D.; GARTEN, C.T.; PALUMBO, A.V.; SMITH, J.G. Elemental analysis of environmental and biological samples using laser-induced breakdown spectroscopy and pulsed Raman spectroscopy. Journal of Dispersion Science and Technology. v. 25, p.687-694, 2004.

80.SACCHI, C.A. Laser-induced electric breakdown in water. Journal of the Optical Society of America B, v. 8, p. 337-345, 1991.

81. FICHET, P.; TABARANT, M.; SALLÉ, B.; GAUTIER, C. Comparisons between LIBS and ICP/OES. Analytical and Bioanalytica Chemistry, v. 385, p. 338-344, 2006.

82.PAUWELS, J.; HOFMANN, C.; VANDECASTEELE, C. On the usefulness of SS-ZAAS for the microhomogeneity control of CRMS. Fresenius Journal of Analytical Chemistry, v. 348, p. 418-421, 1994.

83.ZEISLER, R. Reference materials for small-sample analysis. Fresenius Journal Of Analytical Chemistry, v. 360, p. 376-379, 1998.

84.KURFÜRST, U. Statistical treatment of ETA-AAS (electrothermal atomisation atomic absorption spectrometry) solid sampling data of heterogeneous samples. Pure and Applied Chemistry, v. 63, p. 1205-1211, 1991.

85.NATIONAL INSTITUTE OF STANDARDS AND TECHNOLOGY. Atomic spectra database lines form. Disponível em: <http://physics.nist.gov/PhysRefData/ASD/lines_form.html>. Acesso em: 10 jan. 2008.

86.MORRETTIN, P.A.; BUSSAB, W.O. Estatítica básica. 3. ed. São Paulo: Atual, 1986. 320p. 
87.DE ANDRÉ, C.D.S; PAULA, G.A. Noções de estatística: correlação e regressão. Disponível em: <http://www.ime.usp.br/ mae116/aula/2007/d-2007aula-02-descritivall.pdf>. Acesso em: 27 set. 2008.

88.GORNUSHKIN, I.B.; EAGAN, P.E.; NOVIKOV, A.B.; SMITH, B.W.;

WINEFORDNER, J.D. Automatic Correction of Continuum Background in LaserInduced Breakdown and Raman Spectrometry. Applied Spectroscopy, v. 57, p. 197-207, 2003.

89.SILVA, R.M.; MILORI, D.M.B.P.; FERREIRA, E.C.; FERREIRA, E.J.; KRUG, F.J.; MARTIN-NETO, L. Total Carbon Measurement in Whole Tropical Soil Sample. Spectrochimica Acta Part B: Atomic Spectroscopy, v. 63, p. 12211224, 2008.

90.FERREIRA, E.C.; MILORI, D.MB.P.; FERREIRA, E.J.; SILVA, R.M.; MARTINNETO, L. Artificial Neural Network as strategy calibration for Laser Induced Breakdown Spectroscopy soil analysis. Spectrochimica Acta Part B: Atomic Spectroscopy, v. 63, p. 1216-1220, 2008. 